University of Louisville

ThinkIR: The University of Louisville's Institutional Repository

Electronic Theses and Dissertations

$5-2020$

\title{
The norms are more guidelines than actual rules: applying Isomorphism to disability accommodations in the catholic church.
}

Jonathon Holland

University of Louisville

Follow this and additional works at: https://ir.library.louisville.edu/etd

Part of the Other Sociology Commons

\section{Recommended Citation}

Holland, Jonathon, "The norms are more guidelines than actual rules: applying Isomorphism to disability accommodations in the catholic church." (2020). Electronic Theses and Dissertations. Paper 3494.

https://doi.org/10.18297/etd/3494

This Doctoral Dissertation is brought to you for free and open access by ThinkIR: The University of Louisville's Institutional Repository. It has been accepted for inclusion in Electronic Theses and Dissertations by an authorized administrator of ThinkIR: The University of Louisville's Institutional Repository. This title appears here courtesy of the author, who has retained all other copyrights. For more information, please contact thinkir@louisville.edu. 
THE NORMS ARE MORE GUIDELINES THAN ACTUAL RULES: APPLYING ISOMORPHISM TO DISABILITY ACCOMMODATIONS IN THE CATHOLIC CHURCH

\author{
By \\ Jonathon Holland \\ B.S., Bradley University, 2011 \\ M.A., University of Kentucky, 2014
}

A Dissertation

Submitted to the Faculty of the

College of Arts and Sciences of the University of Louisville

In Partial Fulfillment of the Requirements for the Degree of

Doctor of Philosophy

in Applied Sociology

Department of Sociology
University of Louisville
Louisville, Kentucky

August 2020 

THE NORMS ARE MORE GUIDELINES THAN ACTUAL RULES: APPLYING ISOMORPHISM TO DISABILITY ACCOMMODATIONS IN THE CATHOLIC CHURCH

\author{
By \\ Jonathon Holland \\ B.S., Bradley University, 2011 \\ M.A., University of Kentucky, 2014 \\ A Dissertation Approved on
}

June 17,2020

by the following Dissertation Committee:

Dissertation Chair

David Roelfs

Latrica Best

Michal Kofman

Lauren Heberle

Jon Wiggins 


\section{DEDICATION}

This dissertation is dedicated to my father who passed away while I was completing graduate school. He was always my cheerleader in my educational endeavors and life decisions. 


\section{ACKNOWLEDGMENTS}

I would like to thank my advisor, Dr. David Roelfs, for his continual guidance throughout graduate school and especially during the dissertation process. I would also like to thank my other committee members, Dr. Latrica Best, Dr. Michal Kofman, Dr. Lauren Heberle, and Dr. Jon Wiggins for their continued support from the inception of this project. I also want to thank Dr. Melanie Gast for her efforts and support in helping me get this project started. Thank you to my wife, Elina, for her support throughout graduate school and even applying to graduate school and all the steps in between. She made me feel like I could do it. I also want to thank my parents, Jean and Tim, who have always been my cheerleaders. I want to thank my sister, Suzanne, who always supported my educational endeavors. Finally, I want to thank in-laws, Elena Matveeva, Sergey Matveev, Faina Fite, Jordan Fite, Dina Palmer, and Andrew Palmer who always gave me lots of support and celebrated all my accomplishments. 


\begin{abstract}
THE NORMS ARE MORE GUIDELINES THAN ACTUAL RULES: APPLYING ISOMORPHISM TO DISABILITY ACCOMMODATIONS IN THE CATHOLIC CHURCH Jonathon Holland
\end{abstract}

June 17,2020

This dissertation addresses the role of isomorphism as it pertains to disability accommodations in the Catholic Church. Isomorphism is the concept articulated by DiMaggio and Powell (1983) that organizations are becoming more similar. They do this in three ways: mimetic (when one organization copies another organization), coercive (when one organization or cultural practices pressure another organization to perform an action or adopt a policy), and normative (when organizations adopt similar actions because their leaders are following a common set of norms established through professional or educational processes). Sacraments that address disability issues in the Catholic Church are unique because they are exempt from federal and state laws. Therefore, the only entity that can coerce a parish (individual Catholic Church headed by a priest) is the diocese (the umbrella organization the governs parishes headed by a bishop). This dissertation uses that dynamic to isolate the coercive factors and quantify the three types of isomorphism. To do this I mainly use two surveys sent to parishes and dioceses in the United States by the Center for Applied Research in the Apostolate (CARA). The findings show that normative isomorphism is the most influential type of 
isomorphism, around three times as influential as mimetic isomorphism. Coercive isomorphism is not influential in any models in the dissertation. I conclude that the reason coercive isomorphism is not influential is because the tools bishops use to influence disability accommodations lack a strong enforcement mechanism. Most bishops do not regard disability accommodations as a high priority and without a strong enforcement mechanism, disability accommodations are not regularly implemented. Normative isomorphism is influential because a priest and bishop's position is inherently social, therefore people and organizations have the opportunity to affect how the priest/bishop thinks about disability accommodations. Once they start thinking about them, other organizations have an opportunity to influence the decision and mimetic isomorphism can also influence their decision because the priest or bishop is searching for solutions and looks to similar organizations for those solutions. 
TABLE OF CONTENTS

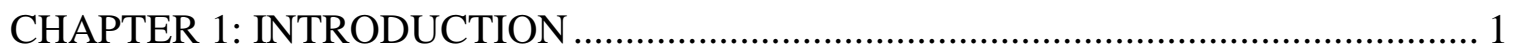

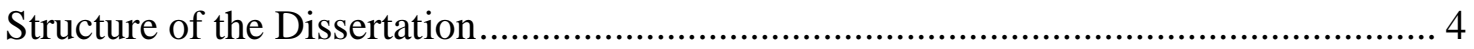

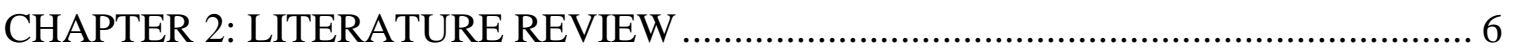

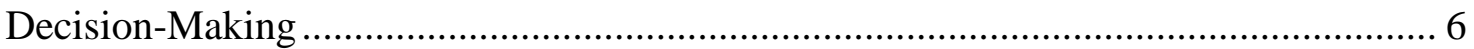

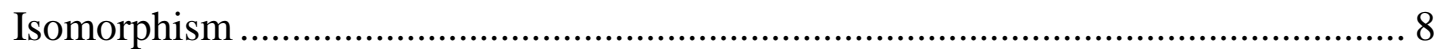

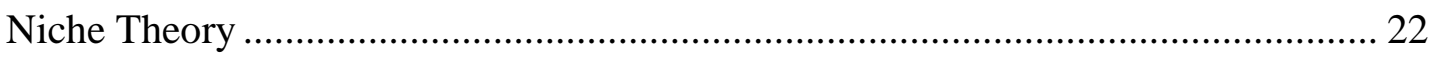

Applying Organizational Theory to the Catholic Church Context................................ 26

Religious Organizational Literature ................................................................... 30

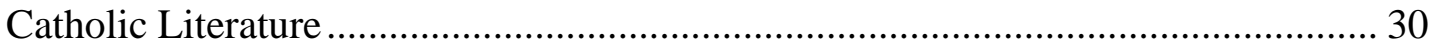

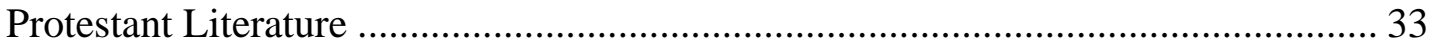

Accommodations for People with Disabilities and the ADA ………………………... 35

Laws About Accommodations for People with Disabilities ………………………... 35

Religious Accommodations for People with Disabilities Outside of the Law .......... 39

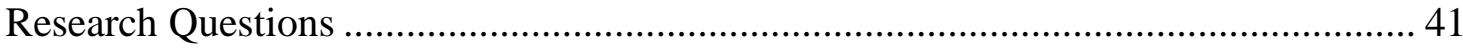

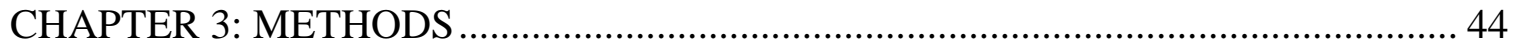

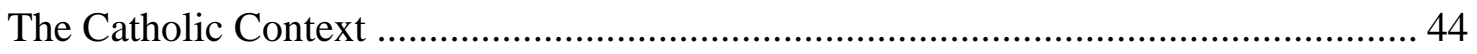

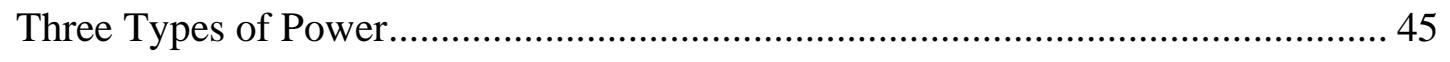

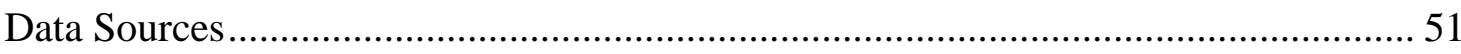

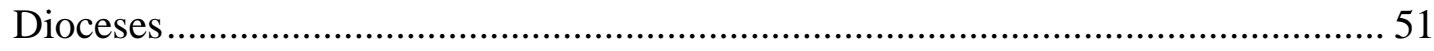

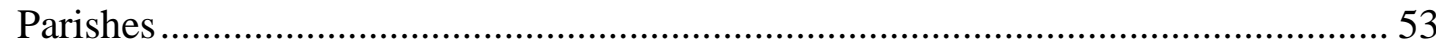

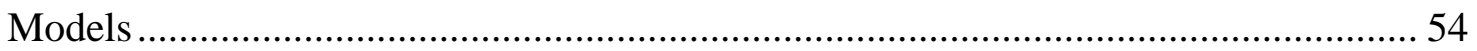

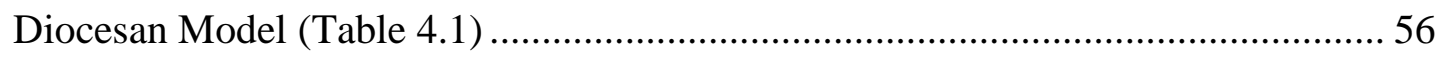

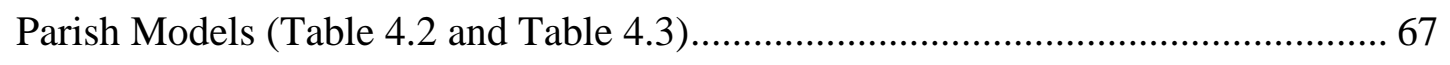

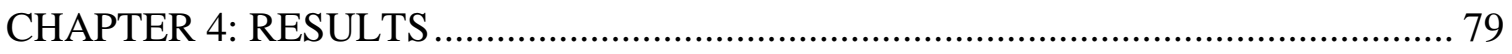

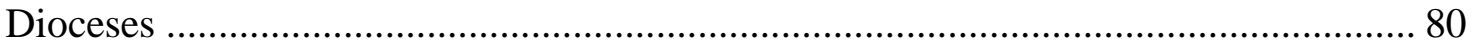

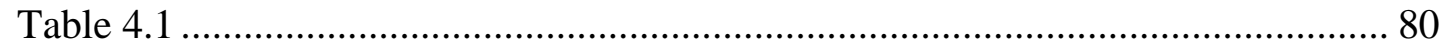

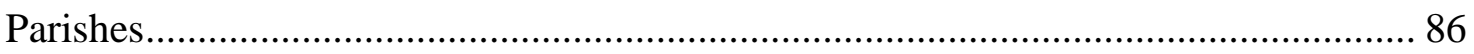




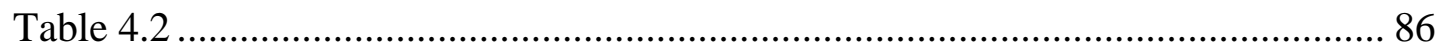

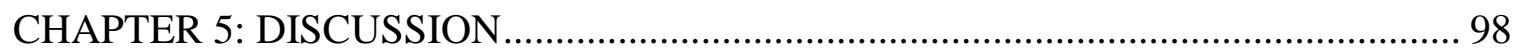

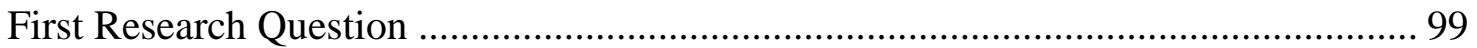

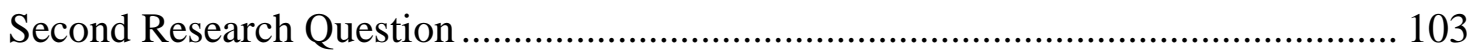

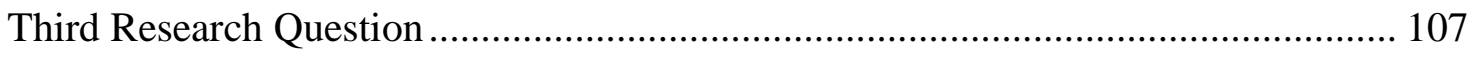

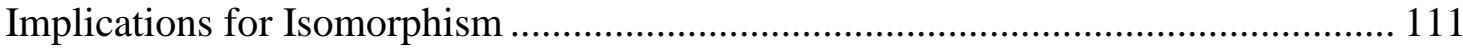

Implications for Organizations in a Religious Context ....................................... 115

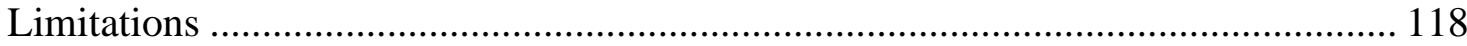

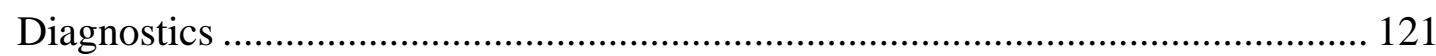

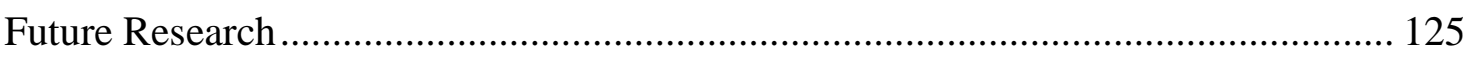

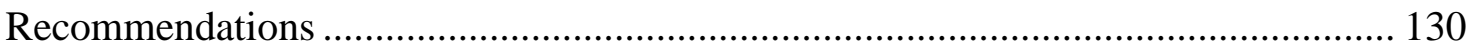

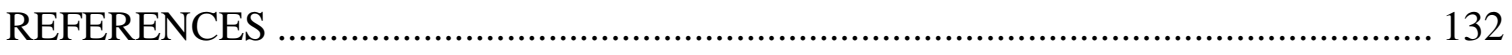

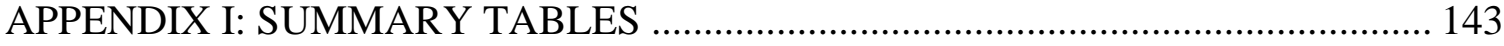

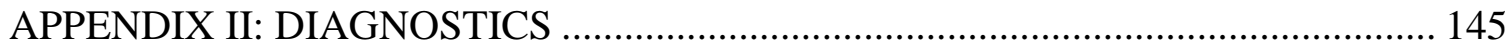

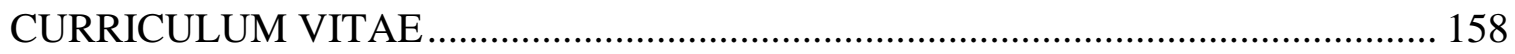




\section{LIST OF TABLES}

Table 3.1: Corresponding Variables for Parishes and Dioceses ........................................56

Table 3.2: Descriptive Statistics of Diocesan Variables Measuring Isomorphism.............58

Table 3.3: Descriptive Statistics of Diocesan Control Variables..........................................62

Table 3.4: Descriptive Statistics of Parish Variables Measuring Isomorphism.................69

Table 3.5: Descriptive Statistics of Parish Control Variables.............................................74

Table 4.1: Binary Logistic Regressions Predicting the Presence of Sacramental Norms for Persons with Disabilities within a Catholic Diocese..........................................83

Table 4.2: Ordered Logistic Regression Predicting Initiation Sacramental Policies with

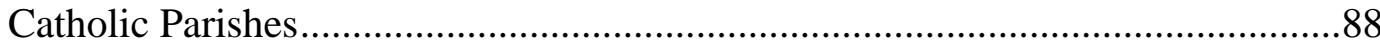

Table 4.3: Ordered Logistic Regression Predicting Marriage Preparation Policies with Catholic Parishes

Table 6.1: Methods Summary Table: Isomorphism ......................................................143

Table 6.2: Methods Summary Table: Isomorphism and Ecology ………........................144

Table 7.1: Variance Intolerance Factors for Models 1.1 and 1.2 ....................................145

Table 7.2: Box-Tidwell Test for Models 1.1 and 1.2..................................................145

Table 7.3: Variance Intolerance Factors for Models 1.3 and 1.4.....................................146

Table 7.4: Box-Tidwell Test for Models 1.3 and 1.4 ....................................................146

Table 7.5: Variance Intolerance Factors for Models 2.1 and 2.2 .....................................147

Table 7.6: Box-Tidwell Test for Models 2.1 and 2.2....................................................147

Table 7.7: Studentized Pearson Residuals for Models 2.1 and 2.2 .................................147

Table 7.8: Brant Test for Models 2.1 and 2.2 ...........................................................148

Table 7.9: Variance Intolerance Factors for Models 2.3 and 2.4 .....................................148

Table 7.10: Box-Tidwell Test for Models 2.3 and 2.4 .................................................149

Table 7.11: Studentized Pearson Residuals for Models 2.3 and 2.4 …...........................149 
Table 7.12: Brant Test for Models 2.3 and 2.4

Table 7.13: Generalized Estimation Equation Predicting the Initiation Sacramental Policies Cut between "Not at All"/"Only a Little" and "Somewhat"/"Very Much" with a Catholic Parish .150

Table 7.14: Generalized Estimation Equation Predicting the Initiation Sacramental Policies Cut between "Not at All"/"Only a Little"/"Somewhat" and "Very Much" with a Catholic Parish 151

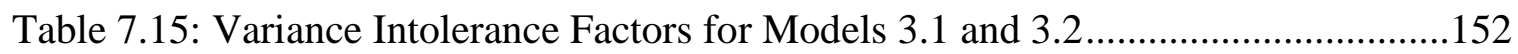

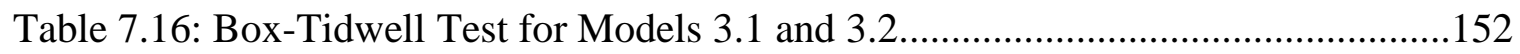

Table 7.17: Studentized Pearson Residuals for Models 3.1 and 3.2 .............................152

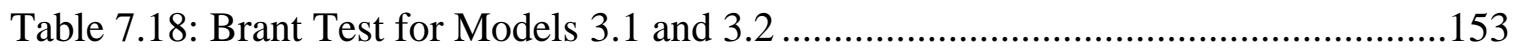

Table 7.19: Variance Intolerance Factors for Models 3.3 and 3.4 ...............................153

Table 7.20: Box-Tidwell Test for Models 3.3 and 3.4 ..............................................154

Table 7.21: Studentized Pearson Residuals for Models 3.3 and 3.4..............................154

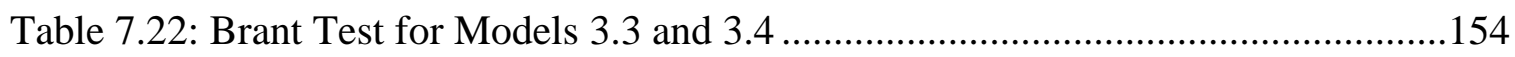

Table 7.23: Generalized Estimation Equation Predicting Marriage Preparation Policies between "Not at All" and "Only a Little"/"Somewhat"/"Very Much" with a Catholic Parish .155

Table 7.24: Generalized Estimation Equation Predicting the Initiation Sacramental Policies Cut between "Not at All"/"Only a Little" and "Somewhat"/"Very Much" with a Catholic Parish .156

Table 7.25: Generalized Estimation Equation Predicting the Initiation Sacramental Policies Cut between "Not at All"/"Only a Little"/"Somewhat" and "Very Much" with a Catholic Parish 157 


\section{CHAPTER 1: INTRODUCTION}

Undoubtedly, people know that wheelchair ramps are a common site in most places around the United States; so common that people may not notice except when they are absent. The reason that the ramps are there is simple: the national government created legislation mandating them and businesses complied. The same type of phenomenon can be observed in entirely different settings that have nothing to do with wheelchair ramps. People who have visited multiple colleges might notice that the architecture of college campuses are largely the same. There is usually a quad and at least one building designed with Greco-Roman style architecture. The reasons for the similarities in this instance are more complicated - there is no legislation passed about how college campuses should look - yet they all look strikingly similar. The ubiquity of wheelchair ramps and the similarity of college architecture are both examples of the same phenomenon: organizational isomorphism.

DiMaggio and Powell (1983) articulated their theory of isomorphism, that organizations adopt similar structures and behaviors, in response to Weber's (1978) assertion that organizations are in an "iron cage" of competition and efficiency. DiMaggio and Powell described three types of isomorphism: coercive, normative, and mimetic (which I define later in this dissertation). Each type has been used to analyze phenomena, but recent work has noted that "evidence is scant as to which (type of isomorphism) is most effective.” (Díez-Martín, Díez-de-Castro and Vázquez-Sánchez 2018:35). In fact, no study has numerically ranked (i.e., quantified) each type to discover 
which is most important for organizational decision-making in a given context. This dissertation quantifies the importance of each type of isomorphism. Additional influences on organizational decision making are also examined, including factors from the organizational ecology perspective, which focuses on decision-making in response to competition in the environment.

In this dissertation I investigate the relative impacts of coercive, normative, and mimetic isomorphism on organizational decision-making. To accomplish this, I study accommodations for people with disabilities within the U.S. Catholic Church. Disabilities is defined broadly, as anyone with "sensory: when one of the senses is no longer functioning as normal", "physical: a disability that may interfere with the development or function of bones, muscles, joints, or central nervous system", "intellectual: significant limitations in both intellectual functioning and adaptive behavior", autism, "mental illness: range of conditions affecting thinking, behavior and mood", "chronic illness: a disease or illness lasting 3 months or more", "veterans with a war-related injury/illness", and "aging-related: a condition that is associated with the degeneration of the body" conditions (Holland and Gaunt 2016a:89). The Catholic Church is specifically chosen as the research site since there are very few coercive influences at the higher level of the organization, but coercive factors are prevalent at the lower level, which makes a good quasi-experiment. Disability accommodations are chosen as the focus because churches in the U.S. are exempt from the coercive forces of the Americans with Disabilities Act (ADA). This dissertation focuses on the presence of broad accommodations for any disability listed above. This dissertation does not cover all the types of accommodations that the Catholic Church offers for people with 
disabilities, but rather focuses on accommodations for the sacraments. In the Catholic Church sacraments are defined as: rituals to confer grace from God (Catholic Encyclopedia 1991). The sacraments are extremely important in the Catholic Church and have been debated over for centuries. Every Catholic needs to undergo some sacraments to be admitted as a full member of the Catholic Church. Some dioceses establish sacramental norms as best practices for instituting the sacraments. This dissertation analyses both sacraments and sacramental norms to examine how the Catholic Church accommodates people with disabilities because of how important they are to the organization.

The results indicate that there is no effect of coercive isomorphism and finds that parishes are three times as likely to accommodate people with disabilities when influenced by normative factors and twice as likely when influenced by mimetic factors. The normative and mimetic factors indicate strong influences from organizational relationships, either from organizations that aid a parish in accommodating people with disabilities or the openness of parishes to copy one another. The lack of coercive influences indicates a lack of power from the bishop to enact change in the diocese, which is contrary to existing literature. This is partially due to the nature of the policies used in this study and partially due to the Church's need to use resources selectively. Disabilities accommodations are a low priority except when there is a parishioner with a disability, in which case resources are used to accommodate that individual. 


\section{Structure of the Dissertation}

In chapter 2, I review the organizational literature pertaining to isomorphism and niche theory, which are the primary organizational theories utilized in this dissertation. I also review the religious organizational literature and apply all of it to the context of disability accommodations in the Catholic Church. To put that in context of disability accommodations I briefly review disabilities accommodation policies in the United States and how religious organizations have influenced those policies.

In chapter 3, I articulate the methods used in the dissertation. First, I review the organizational structure of the Catholic Church and why it is helpful for studying isomorphism. Then, I lay out the different methods by which I acquired the data for the dissertation and descriptive statistics for all the variables. The final portion of the chapter articulates the regression methods for analyzing the variables.

In chapter 4, I review the results of the regression. The main findings of the regression analyses are that normative isomorphism has the strongest influence on disabilities accommodations in the Catholic Church followed closely by mimetic isomorphism. Niche factors are relatively weak when compared with the isomorphism variables but still significant in most models. Coercive isomorphism does not have any effect on disabilities accommodations in any of the models.

In chapter 5, I discuss the potential reasons for the results and implications for the theory of isomorphism and religious organizational studies. The main reasons for the results are that the Catholic Church has a relatively weak coercive system in place and does not focus on disability accommodations. Therefore, the bishops largely trust the 
priests to implement accommodations. This shows a lot of potential for future isomorphism studies to address using religious organizations. 


\section{CHAPTER 2: LITERATURE REVIEW}

\section{Decision-Making}

The Catholic Church has not always accommodated people with disabilities. Covey (2005) examined the history of how Catholics viewed people with disabilities from the B.C. era until the $20^{\text {th }}$ century. Disabilities were widely regarded as a result of sin through the middle ages, when disability was associated with witchcraft and sorcery. In the $18^{\text {th }}$ and $19^{\text {th }}$ centuries this perspective changed and people with disabilities were regarded as children and Christians as their caretakers, but they were still excluded from many Catholic sacraments. It was not until the mid-1990s that people with certain disabilities could enter as full members of the Catholic Church. In 2013, Pope Francis stated that not only should the Catholic Church include people with disabilities as members, but should seek to improve accommodations for people with disabilities (Wooden 2016). Since this is a recent change some parishes are not built to physically accommodate people with disabilities at the entrance, bathroom, or sanctuary and many do not offer accommodations for all sacraments or events (Holland and Gaunt 2016a).

The disability accommodations process currently unfolding is an example of decision-making under regulatory uncertainty and after negative performance feedback. Greve (2003) articulated the process of how organizations respond when they receive negative feedback. He articulated three types of searching that organizations use to discover solutions to problems, each associated with an increasing level of organizational concern. The first is slack searching, in which an organization uses extra resources to 
search for a solution. Next is institutional searching, in which an organization forms a committee to brainstorm solutions to a problem. The final is problematic searching, which means that the entire organization implements ideas until a solution is found. However, if an organization does not receive negative feedback then the organization does not perform a search and usually everything remains consistent with how they operated in the past. Pope Francis has given negative feedback for the Church's current accommodations in a theological sense but has not given specific organizational instructions as to how parishes should improve. Therefore, parishes and dioceses must decide which accommodations are necessary according to the needs in the community and the prominence disabilities accommodations have compared to the other problems they face.

The main problem that dioceses and parishes face is the limited organizational resources available for implementing accommodations. If churches make accommodations for a specific disability when there are few people with that disability in the community, the cost of the accommodation may outweigh the benefit. This is particularly important for the Catholic Church, where members give relatively little compared to other Christian denominations (Zech et al. 2017). According to Greve's argument, the scarcity of organizational resources becomes less important if there is not a need in the community.

The decision-making literature has many theories about how organizations make decisions in uncertain situations when resources are scarce. Two of the most prominent theories are isomorphism and niche theory, which I review in detail in the following sections. Isomorphism and niche theory both address how organizations face uncertainty 
with limited resources in different ways. Isomorphism focuses on how organizations save resources by using insights from another organization, whether that is copying the other organization or following protocols from regulatory organizations (DiMaggio and Powell 1983). The concept of isomorphism, therefore, builds on March and Simon's (1958) work that described the problems with organizational rationality. The main problem organizations encounter with making a rational decision in uncertain conditions is that organizations do not know all the potential solutions or the consequences for those solutions. Therefore, it is often more practical to borrow solutions than to invent new solutions and try to brainstorm the consequences of those solutions.

Niche theory focuses on how organizations expand resources by moving into new, more resource-abundant niches within the market (Hannan and Freeman 1977). For example, a church finds that attendance is dropping at Sunday services. The church does some research and finds that no other church in the area accommodates people who are Deaf, so it finds someone who can speak American Sign Language to sign at one of their services. Now all people who are Deaf in the area can come to that church to attend a service that they understand, regardless of affiliation.

\section{Isomorphism}

The concept of isomorphism emerged from the larger organizational theory of new institutionalism. New institutionalism maintains that organizations have cultures and norms that guide actors within and exterior to the organization. The seminal works from the field strive to describe the consequences of culture. Zucker (1977), in an early work from this perspective, focused on the concept of institutionalization to explain how 
organizations transmit behaviors from one generation of workers to the next, maintain the culture of the organization, and resist attempts to change it. To further the cultural argument from a more organizational perspective, Meyer and Rowan (1977) focused on myths and ceremonial behaviors within organizations that reflect the culture and norms that have been passed down, and how these myths and ceremonies do not necessarily reflect day-to-day work activities. In this way the culture of the workplace becomes loosely coupled with work activities; workers officially support the myths and ceremonies of the organization while retaining the ability to work in a manner that best suites them (Weick 1976).

The concept of isomorphism itself stems from the work of DiMaggio and Powell (1983) who argued that organizations that face similar environmental factors will become similar to one another. They specified three types of isomorphism: mimetic (when one organization copies another organization), coercive (when one organization or cultural practices pressure another organization to perform an action or adopt a policy), and normative (when organizations adopt similar actions because their leaders are following a common set of norms established through professional or educational processes). This original typology is still in active use. Several scholars have attempted to add to the theory of isomorphism, but none have been successful, as I will articulate later in the dissertation.

\section{Uses of Isomorphism}

Many researchers have used isomorphism as a theoretical framework, and it is common to find studies that measure for the presence of one, two, or all three types of 
isomorphism. However, few have qualitatively ranked the three types of isomorphism in terms of their relative importance and none have quantified (i.e., numerically ranked) them. Part of the reason that the importance of each type of isomorphism has not been quantified may be the organizational sectors (for-profit, public, non-profit, and religious) scholars use to study isomorphism. The existing literature focuses heavily on the forprofit and public sectors, but intertwining relationships between sectors often makes the isolation of a particular type of isomorphism difficult (a point raised by DiMaggio and Powell 1983). Woelert and Croucher (2018) provided a good example of this. They examined how the three types of isomorphism are combined to study higher education. They explained that decisions are impacted by intertwining factors related to government regulations, executives' educational and professional experience, and the examples at other universities.

This section reviews studies of isomorphism by sector, the studies that seek to identify the presence of one or more types of isomorphism, the studies that rank the different types of isomorphism, and the deficit of literature quantifying the importance of each type of isomorphism.

\section{$\underline{\text { Organizational Sectors }}$}

The majority of the isomorphism literature analyzes the for-profit sector. An example of this sector is Davis (1991), who investigated poison pill adoption, a defense mechanism a firm adopts to make it more expensive for a hostile buyer to acquire the firm. The study found normative isomorphism through board network connections, which means board members from certain firms were more likely to endorse the idea. 
Gunarathne and Lee (2019) examined factors that contribute to environmental management practices. They found that coercive influences from government legislation majorly contributed to environmental management practices, as they seek to abide by the law. As these examples and many other studies not reviewed here show, for-profit practices are heavily influenced by government legislation and normative factors.

The public sector literature is mostly split between studies on governments and studies on government agencies. One example is Akaliyski (2019), who analyzed policies in countries within the European Union (EU). The author found that policies are becoming more isomorphic due to increasing cultural homogeneity within the EU, the increasing similarity provides a greater number of countries that can be mimicked. Dicen et al. (2019) explored experiential learning programs within hospitality departments in Thai universities. The author found coercive isomorphism from the government, as they want to increase revenue from the tourist industry. They also found mimetic isomorphism from hospitality programs around the world because Thai universities look outside the country for best practices. As these studies exemplify, studies in public sector organizations typically include mimetic forces since countries are sovereign and coercive forces stemming from government regulations.

The literature on the non-profit sector is limited to three studies. Townsend and Campbell (2007) studied homogeneity in rape prevention programs by measuring for all three types of isomorphism. They were able to rank the types of isomorphism and discovered that coercive factors from schools, which funded the programs, were more influential than mimetic factors or normative professional and training programs. Leiter (2005) studied isomorphic processes in a random sample of Australian non-profits and 
found surprisingly little isomorphism, although the isomorphism they did find was coercive (from government funding). Frumkin and Galaskiewicz (2004) studied a random sample of for-profit, non-profit, and public sector organizations for isomorphic factors. They found sporadic isomorphism among non-profits, although, like Leiter (2005), they found mostly coercive isomorphism due to government funding. Of the four sectors, coercive isomorphism appears to be most prominent in the non-profit sector.

There is only one known study that analyzed isomorphism in the religious sector and it shows a resistance to any type of isomorphism. This creates an interesting dynamic in this dissertation since the religious sector is closest to the non-profit sector, which shows the most evidence of coercive isomorphism. Nelson (1993) explored authority in multinational churches and a minor topic in the study is the presence of isomorphism. The article concluded that isomorphism is present, but it is resisted by core members of the congregation and that they are able to resist isomorphism because of the lack of connections with the for-profit and public sectors. These findings support the premise of the argument for the dissertation that religious organizations experience very limited coercive isomorphism. The religious sector differs from all other sectors because of the separation of church and state in the United States. This reveals a research gap in the existing literature on isomorphism since there is only one study that examines the religious sector (in a superficial way); all the other organizations that are studied are affected by coercive factors.

Isomorphism often operates between organizations from different sectors. Gunarathne and Lee (2019) showed how isomorphism in the public sector affects trends in the for-profit sector. They found that isomorphism in the public sector has little effect 
on the trends of the for-profit sector, but regulations from the public sector are highly effective. The for-profit and public sectors are highly connected and have a clear hierarchical relationship because of the government's power to regulate.

The largest isomorphic influence in the non-profit literature is coercive isomorphism from government regulations/funds and other organizations that fund them. This has important implications for the religious sector because, like the non-profit sector, churches receive money and services from other entities and focus on serving people outside of the organization. The difference is that most of the Catholic portion of the religious sector gains money from the donations of individuals (Zech et al. 2017) while non-profits gain most of their money from the for-profit and public sectors (Frumkin and Galaskiewicz 2004, Leiter 2005). This indicates that organizational relationships with the Catholic Church are less coercive and more cooperative.

While studies of organizations from the for-profit and public sectors have found little coercive isomorphism, it can never be completely ruled out because the public, nonprofit, and for-profit sectors are highly interconnected. For example, Burruss and Giblin (2014) studied the effects of the three types of isomorphism in the public sector with the adoption of innovations by police stations. The study mainly found normative pressures, but the authors note that they could not completely disregard the coercive pressures of the mayor/city council. Croucher and Woelert (2016) studied isomorphism of the Australian university structure. They initially found normative and mimetic isomorphism without coercive isomorphism but discovered that the Australian government coerced the universities into adopting a new structure, which was the catalyst for isomorphism. Yang et al. (2019) studied decision-making for environmentally friendly practices in Chinese 
firms. The study mainly found that Chinese firms sought to mimic foreign firms, but the authors note that they could not completely discount coercion from those foreign firms or the government. Because coercion is often hidden, it can be difficult for studies to fully parse out the effects of the three types of isomorphism.

\section{$\underline{\text { Presence of Isomorphism }}$}

A large majority of studies use the theory of isomorphism to explain a specific organizational decision. All of the studies that use qualitative methods found a type of isomorphism was present, although sometimes it was a different type than the authors predicted. Kallio and Kuoppakangas (2013) noted an increase in the number of municipal organizations that were becoming municipal enterprises. They interviewed 20 employees of these organizations to discover a bandwagon effect rather than a logical decision. The authors noted that if their study had been completed with a survey then they probably would not have found isomorphism (even though a bandwagon effect is still isomorphism) because they needed to probe for the origins of the decision. People who know others from many different social groups are more likely to know new and innovative information because they have ideas that come to them from different places (Burt 2005). Qualitative data can measure where people got their ideas and thus how organizations became isomorphic.

While the basic presence of the types of isomorphism does not give a clear picture of the importance of the different types in the individual studies, when the studies are aggregated coercive isomorphism is present more than the other types. Mizruchi and Fein (1999) articulated how DiMaggio and Powell spent more space and gave preference 
to normative and coercive isomorphism over mimetic isomorphism. In their article they conducted a systematic review of which types of isomorphism scholars tested for and found that mimetic isomorphism was the most popular type despite possible normative and/or coercive pressures ${ }^{1}$ found by the authors. After 2000 it appears that scholars have heeded Mizruchi and Fein's warning and have tested for which type of isomorphism is present, they often tested for all three types. Furthermore, it shows that testing for coercive forces has value since they are often present.

When studies check for all three types of isomorphism, coercive isomorphism is present more than any other type while normative and mimetic are present nearly equally. Most of the studies that measure for all three types of isomorphism are written after 2010. However, only a quarter of studies that include isomorphism tested for more than one type and the studies that only measured for a single type are the only ones that do not find isomorphism. Those that test solely for coercive isomorphism always find it. A good example is Amor-Esteban, García-Sánchez and Galindo-Villardón (2018), who studied corporate social responsibility and found that the main factor behind adopting social responsibility practices was a regulatory body coercing them to do so. This evidence suggests that coercive isomorphism is more important or evident than the other two types.

\section{Articulating Isomorphic Operations and Benefits}

Many studies that test for the basic presence of isomorphism are focused on fleshing out the picture of how isomorphism operates, the intertwining factors of the three

\footnotetext{
${ }^{1}$ It should be noted that Mizruchi and Fein (1999) used different selection criteria than the search criteria used for this literature review, and some of the articles they referenced are not in this literature review because of that search criteria. Therefore, their conclusions may not apply to the articles in this literature review.
} 
types of isomorphism, and the benefits of isomorphism. DiMaggio and Powell (1983) listed a few benefits of isomorphism: organizations can copy a similar organization when making changes, organizations have successful models to use when making decisions, and it creates a model for legitimacy in a field. Several articles expanded on other reasons organizations are becoming isomorphic.

Some scholars focused on periods when organizations are rapidly changing to see how isomorphism operates in this context. Arvidson (2018) compared and contrasted change and isomorphic pressures within non-government organizational niches. This clarified how isomorphism operates within different niches and how organizations made decisions based on norms within the niche. De Freitas and Guimarães (2007) interviewed people involved in the auditing process at the Court of Auditors in Brazil. While they searched for all three types of isomorphism the study found two: mimetic and coercive. The authors concluded that niche fields start with increasing mimetic isomorphism to informally establish legitimacy, while more formal legitimacy is established later by legislation, a form of coercive isomorphism. These studies add how the roles of the different types of isomorphism operate within a niche.

Studies have used the basic presence of the three types of isomorphism to explore how organizations negotiate their differing roles when bridging organizational fields. When organizations need elements from different organizational fields, they may gain legitimacy in both fields. Aurini (2006) discussed tutoring businesses which need to bridge the role of educator with the role of business in order to gain full legitimacy. Therefore, they needed to conform to schools' schedules to provide effective tutoring but they also had to make money. Fennell and Alexander (1987) examined normative 
isomorphism by studying the effect of hospital memberships to associations that link them to other organizations. The study analyzed how associations help hospitals link to other organizations and buffer against obstacles that come with those ties.

\section{$\underline{\text { Ranking the Explanatory Power of the Different Types of Isomorphism }}$}

Few scholars have ranked the different types of isomorphism to determine which type explains more of the reason behind why an organization makes a decision. All the studies that have ranked the types of isomorphism are qualitative, which makes quantifying the importance of each type difficult. The only studies that rank the importance of each type of isomorphism use interviews to ascertain what motivated the organizations to make decisions. Townsend and Campbell (2007) are the only authors that directly discussed the rankings of isomorphism in their analysis of a rape prevention program. They used the language of people in the interviews to describe their decisionmaking process and concluded that coercive factors from schools were the most influential factor for isomorphism. Lent et al. (2019) used interviews to analyze how home-based businesses in Pakistan seek legitimacy. They found all three types and concluded that coercion is the most prominent factor by the frequency and way people talk about government influences as more important than mimetic or normative factors. Scheid and Suchman (2001) analyzed the way employers discussed the consequences of disabilities regulations. The authors concluded that coercive isomorphism was more of a factor because employers wanted to avoid the penalties of disabilities regulations and the less they knew about them the more fearful they were. From these articles it is clear that ranking the types of isomorphism is based on how interviewees discuss motivations 
(Scheid and Suchman 2001) or the number of interviewees that list coercive factors as part of the decision-making process (Lent et al. 2019, Townsend and Campbell 2007). While this allows researchers to rank which type is most important from a qualitative perspective, the authors do not quantify the amount of importance of the types of isomorphism.

Quantifying the types of isomorphism is also difficult because the types are intermingled, and it is difficult to completely isolate one type. The only scholar this researcher found tried to isolate one type of isomorphism by studying policy transfers among countries in the European Union (EU) (Radaelli 2000). All countries in the EU are sovereign, yet the author noticed an isomorphic trend among laws in EU countries. The author concluded that as there are no coercive means by which a country can coerce another country to adopt a policy, it must be normative or mimetic. However, through interviews Radaelli (2000) found evidence of international coercion through money deals and pacts. In this dissertation, I seek to quantify the types of isomorphism by using quantitative analysis and isolating coercive isomorphism from part of the analysis through the religious aspect of the organization. Nelson (1993) showed this is possible through their analysis of multinational churches and how religious organizations resisted isomorphism because of the lack of connections with the for-profit and public sectors.

Quantitative data can rank importance by comparing the standardized coefficients in regression models, although no study that measured more than one type of isomorphism has done this. Zou et al. (2019) studied organizational characteristics, including social ties on the firm's board, that lead to increased policies regarding environmentally responsible behavior in Chinese firms that produce a lot of pollution. 
The authors used a GLS regression model to measure the effects of each type of isomorphism and found evidence for all three types. However, they did not report the standardized beta coefficients, so it is not possible to measure rank from the regression analysis. Two other authors did report the standardized coefficients, although they did not compare them. Taylor and Oylan (2008) analyzed normative and coercive isomorphism in environmental reporting in Australian governments with a multiple regression model. The authors found that public coercion is the best predictor of environmental reporting. The article reported the standardized coefficients for both types of isomorphism, which allows researchers to directly compare coefficients and thus rank them, but normative isomorphism was not significant, which clearly suggests the dominance of coercive isomorphism in the study. Ali and Frynas (2018) studied the role of corporate social responsibility forums in policy adoption of disclosure forms in Pakistan using OLS regression. They found normative isomorphism to be the best predictor of whether or not firms use disclosure forms. The authors reported the standardized coefficients necessary to rank the different types of isomorphism, although they only stated that each type was present. Fischer's Z transformation standardized score produces a value from negative infinity to positive infinity that enables a researcher to quantify the importance of the types of isomorphism. Had Ali and Frynas quantified the different types of isomorphism they would have found the measure for normative isomorphism as .315 and the measure for coercive isomorphism as .138 , meaning normative isomorphism had around twice as much impact on the decision compared to coercion. Taylor and Oylan would have coefficients of .372 for coercive isomorphism and .001 for normative isomorphism, although these scores would not change that only 
coercive isomorphism was significant. The problem with quantifying the influence of coercive and normative isomorphism in this way is that both studies use one variable as a measurement for normative isomorphism and one variable as a measurement for coercive isomorphism. There could be many more instances of coercive and normative isomorphism that the authors did not measure that would impact this measurement.

Attempts to Develop Isomorphism Measurement and Typology

Scholars have attempted to identify other types or isomorphism or otherwise contribute to the theory, but none of the contributions have stayed for a long period of time. For example, DiMaggio (1991) added clarification about where the organizational norms begin, but did not identify any type of isomorphism beyond the original three types. Beckert (2010) identified a fourth type called competitive isomorphism, which results when a set of organizations find the most efficient method and drive dissimilar organizations (i.e., those that do not adopt the method) out of the market. However, few scholars have cited this fourth type of isomorphism (Park 2014). A few scholars have explored the role of agency within isomorphism with explorations of the cognitive processes of decision-makers when isomorphic decisions are made (Dutta 2016), in which case the author characterized personalities that are more likely to be able to resist isomorphism. Yorozu (2017) studied independence amid isomorphic pressures from an organizational viewpoint, concluding that it is difficult for organizations to combat isomorphism since legitimacy and trust are tied to isomorphic tendencies. This attempt to add agency into the theory of isomorphism may prove to be successful as it has only recently been asserted and may not have enough time to become a major contribution. 
Scholars have also tried to supplement isomorphism with other theories in order to account for organizational behaviors isomorphism does not explain well. DiMaggio and Powell stated that organizations diverge at certain points in their life cycle and recognized the organizational ecology theorists who had articulated this theory (DiMaggio and Powell 1983:148). Isomorphism was posited as complementary to the organizational ecology literature, not as a critique. Subsequent scholars have attempted to further integrate isomorphism with other theories as well as organizational ecology. Galaskiewicz and Wasserman (1989) analyzed the reasons for-profit organizations give to non-profits. The article mainly discussed isomorphism, but also discussed network theory as a way to discuss organizational trust. They found organizations are more likely to trust another if they are linked by a board member or other significant network tie. All of the other articles link isomorphism with organizational ecology. Arvidson (2018) and Levitt and Nass (1989) used a theory of change, combined with isomorphism, to gain a more complete sense of organizational decision-making among non-profit organizations. Arvidson (2018) studied an English non-profit and how different pressures change at different times, setting up a complete conceptual view of the lifetime of the organization. At times the organization wants to differentiate itself to gain a subset of the population and other times become more similar to gain trust. Levitt and Nass (1989) formed an argument similar to Arvidson, that different stages of the lifecycle of an organization warrant different types of organizational strategies. However, Levitt and Nass focused on the effort of buffering against isomorphic pressures and when it is better not to expend that energy. Haveman (1993) studied how organizations enter newly deregulated markets. The author found that organizations entered a new niche when they were 
confident that they could copy other successful organizations and then became isomorphic to those organizations. There is only one article since 2000 that has sought to synthesize the concept of isomorphism with other theories, suggesting that it was a trend in the late 1980s and early 1990s that did not progress past that. While these studies have offered insight into the practical process of isomorphism, the concept of isomorphism is still used in the literature in a way that closely resembles DiMaggio and Powell's original work published in 1983.

\section{Niche Theory}

In this dissertation, I also include niche theory as a control theory by which to compare isomorphism. The intention is to include niche theory as a comparison for isomorphism rather than to advance the theory itself. Niche theory contends that organizations differentiate in order to find new, untapped resources in a market. This makes niche theory a good complement to isomorphism because they have different, complementary explanations for organizational decision-making. Niche theory emerged from organizational ecology theory, which posits that patterns in an organization's environment largely determine the decisions of the organization (Hannan and Freeman 1977). Organizational ecology seeks to understand the distribution of organizations within their environment considering the conditions and limitations. Hannan and Freeman (1977) generally described the niche as a section of the market in which an organization can use resources to reproduce and thrive.

Carroll (1985) majorly contributed to niche theory by studying how organizations change and the costs of taking advantage of new resources. Carroll developed four useful 
concepts from this article: the product niche, process niche, generalists, and specialists. The product niche focuses on how an organization's product differs from other organizations in the niche. The process niche is closely related to product niche and refers to how the production process is different than other organizations within the niche. Generalists are organizations that focus on the general market and seek resources from many different niches. Specialist organizations have a very specific market and pursue few types of resources. Eventually Carroll and Hannan (1989) articulated how a small number of organizations will pursue a resource and as the number of organizations that try to gain this resource increase regulations are imposed, which ultimately leads to the death of many organizations that subsequently enter the niche for the resource. Thus, the focus is on how organizations differentiate to gain a competitive advantage over their competition and how organizations develop niches within the environment in order to survive.

\section{Developing Niche Theory}

In contrast to isomorphism, niche theory has many ways in which the theory has evolved, although the areas that I focus on are polymorphism, the process niche, and capacity of performance because these concepts are most useful when considering how the Catholic Church accommodates people with disabilities. Niche theory has evolved in many ways by the original authors, such as niche overlap, niche width, resource-

partitioning, product niche, and process niche. Niche overlap measures the similarity of two niches and how the organizations within those niches obtain resources (Hannan and Freeman 1989, McPherson 1983). Niche width measures how many resources are used 
by a single niche (Freeman and Hannan 1983). Resource-partitioning is how resources are partitioned within a niche considering the organizations competing for those resources (Freeman and Hannan 1983).

Niche theory has also evolved outside of the core scholars to create concepts such as within-niche status, polymorphism, and capacity of resources. Status refers to the power of organizations within a specific niche to gain organizational resources and thus remain viable as an organization (Podolny, Stuart and Hannan 1996). Another evolution I focus on is polymorphism, which is creating a niche within a niche. A parent organization will create a niche in the larger national or international market while the subsections create a locally adapted niche within the parent organization's niche (Usher 1999). The final evolution that I focus on is capacity of resources, which is a largely theoretical reference to how much of a resource is available for an organization to gain (Hsu 2006).

\section{Uses of Niche Theory in the Literature}

A clear majority of the niche literature focuses on the for-profit sector rather than the non-profit, public, or religious sectors. All the developments of the theory have come from studies that analyze the for-profit sector. A good example is a study from Barroso and Giarratana (2013) that studied the automobile industry for niche product spaces, or the organizational space a firm needs for niche products. The studies that cover the nonprofit and public sectors mainly use it to test theory development such as niche overlap (Sohn 2001) and niche crowding (Lowery et al. 2012). Lowery et al. (2012) critiqued past studies that analyzed interest crowding, which is an organizational ecology term for 
the number of organizations that are represented as an interest group. The authors argued that past studies simply measure trends without measuring the intent of the organizations, which would explain the reason the niche is crowded. Therefore, the authors studied lobbying organizations to measure how much organizations are lobbying and the reasons they lobby for a more complete analysis. Both theories include terms unique to niche theory, but no one in the literature this researcher has found cited those terms. The articles that have developed niche theory that people cited have also come from the forprofit sector.

Similar to isomorphism, the religious sector has been understudied by niche scholars, and remains concentrated on Christianity. There are only two studies that focus on the religious sector in the niche literature. Dougherty and Mulder (2009) discussed two types of Christian churches: specialists that tailor to a specific demographic and do not adjust their tactics in reaction to the surrounding community and generalists, which change according to community demographics. Their analysis showed that churches with specific niches have an initial advantage, but if they do not adapt to the changing demographics eventually, they are more likely to fail. Reimer (2011) articulated how Christian churches try to avoid niche overlap by being aware of the theological orientation of nearby churches and finding a niche among the crowd. Reimer is one of the few studies that uses qualitative methods within the niche literature, as most of the literature is quantitative. This makes the religious sector valuable to study partly because of the hidden insights the field has not yet discovered. 


\section{Applying Organizational Theory to the Catholic Church Context}

The Catholic Church has a multidimensional hierarchy that serves two main purposes: theological (or doctrinal issues) and organizational. I will briefly explain the hierarchy here to provide context for the literature while a full organizational description is provided in the methods section. The Catholic Church has organized the world into territories called dioceses. The Pope is head of the Catholic Church for theological issues (issues that concern doctrine). The main organizational responsibility of the Pope is to appoint bishops, who each have organizational control of a diocese. All parishes (individual Catholic churches) within a diocese are under the bishop's jurisdiction. A bishop assigns priests in the diocese to a parish and they have organizational control of the parish.

The dynamic between the public and for-profit sectors is useful for informing the dynamic of the relationship between dioceses and parishes. Dioceses have formal or informal regulations that govern how parishes within the diocese can operate. This dynamic differs with respect to the disciplinary action that dioceses use to enforce the rules. If a for-profit firm does not abide by a regulation, they are typically fined money while a pastor will have a meeting with the bishop for not abiding by a regulation. While the penalties are different, the coercive forces are still there to dictate the actions of the subordinate organization.

Three concepts from niche theory are useful for conceptualizing the Catholic Church's accommodations for people with disabilities. The first concept is the process niche, which is used to describe how people become members in the Catholic Church. The Catholic Church has a different initiation process than protestant churches, as the 
Catholic Church has more sacraments (initiation rituals) that are needed to join. Some dioceses have sacramental norms as best practices for how priests should execute the sacraments. These sacramental norms are meant to be a goal for all priests to attain and are not necessarily punishable if a priest does not attain it (Priest 2020). However, if the bishop thinks that a priest is not adhering to a sacramental norm and it is possible for them to adhere to it, then the bishop can call priests into his office to discuss how to adhere to the sacramental norms in the future (Chancellor 2019). This dissertation covers how Catholic dioceses and parishes are seeking to establish a niche by making the process for membership more accommodating for people with disabilities. The second niche concept is polymorphism to describe the relationship between a diocese and a parish. The diocese can establish a niche in the area with general rules for accommodating people with disabilities, and parishes can establish a niche in their specific community. The third niche concept is capacity of resources. The number of people with a disability in a community is important because dioceses/parishes need to expend resources to provide accommodations and if there are a limited number of people in a community with a disability then resources may be better spent elsewhere.

I include niche theory in the analysis to isolate the relative importance of coercive isomorphism. Most of the research comparing isomorphism and organizational ecology theory (including niche theory) was conducted in the late 1980s and early 1990s (Galaskiewicz and Wasserman 1989, Haveman 1993, Levitt and Nass 1989) ${ }^{2}$. Only one study has combined both theories since 2000 (Arvidson 2018), which suggests that using both theories was a trend in the past that researchers used as an effort to explain more

\footnotetext{
${ }^{2}$ The articles that combine isomorphism and niche theory are described in the "Attempts to Develop Isomorphism" section.
} 
variation than one theory could explain. I renew this effort, using theories that are independent of one another, which contributes to a quasi-experimental design.

To quantify coercive isomorphism, I compare the same organization in two different situations. In the first situation, only Catholic dioceses are analyzed using variables that measure isomorphism theory. Catholic dioceses are exempt from most, if not all, coercive influences over sacramental norms; therefore, this model should not measure any coercive isomorphism. The second situation analyzes variables that measure isomorphism in Catholic parishes. Parishes have the same political exemptions as dioceses but are heavily coerced by their respective diocese in terms of how they accommodate people with disabilities in the sacraments. Comparing the two situations isolates the influence of coercive isomorphism to the parish model. The main limitation with this model is that all the focus is on organizational variables and it does not address the environmental factors the organization is reacting to. To address this problem, I add niche theory to each model to control for the environmental factors that contribute to the organization's decision, such as competition from other organizations and how many people with disabilities are in a community. Since the niche factors focus on a different explanation than isomorphism, they are less likely to be intertwined.

The main "resource" in this dissertation is people, because a majority of the money in a parish/diocese comes from contributions of parishioners (Zech et al. 2017). When the Catholic Church discusses accommodating people with disabilities, the language focuses on evangelization, which is an expectation of Catholics to tell people about Jesus and increase church membership (Catechism of the Catholic Church 1994). Currently, the Catholic Church is trying to gain members by getting people who have 
stopped going to Catholic events to start attending again. This is emphasized by the number of evangelization organizations that focus on evangelizing to people who have stopped going to Catholic events compared to those that focus on evangelizing to everyone. $21^{\text {st }}$ Century Catholic Evangelization (21stcenturycatholicevangelization.org 2020) is an umbrella organization for Catholic evangelization organizations that publishes a list of evangelical organizations that parishes and dioceses can contact for evangelization services. The website lists twenty-five evangelization organizations, of which nine focus on evangelization to people who have stopped going to Catholic events, ten focus on evangelization to everyone, and six focus on a mixture of the two. While it is not typically discussed in these groups, evangelizing to people who used to come to Catholic events is pertinent to the disabilities issue discussed in this dissertation since parishes are not subject to the ADA. According to the survey used in this dissertation, only $42 \%$ of parishes were originally built to accommodate people with disabilities (Holland and Gaunt 2016a). Many people who develop a disability leave due to the difficulty of getting in and maneuvering around the building (Dingle 2018). Therefore, installing accommodations may help them come back because they are able to get around the building.

Due to the structure of the church, Catholic parishes do not have to be as concerned about finances as protestant churches. If a parish does not have the money to operate, and the bishop deems it necessary for the parish to stay open then they will receive a diocesan subsidy, as eight percent of parishes did in 2013 (Zech et al. 2017). This is not to say that parishes do not have to worry about money altogether; the bishop is not required to give a parish a subsidy and could close the parish. However, it still gives 
Catholic parishes an advantage over protestant churches because most protestant churches operate independently, and if they do not have the money to remain open then the church will close. This allows for the Catholic Church to focus on people as a resource and reduce the ulterior motive of people as a means to money.

\section{$\underline{\text { Religious Organizational Literature }}$}

\section{Catholic Literature}

The Catholic Church is the most studied organization in the religious organizational literature. There are multiple reasons why the Catholic Church is an excellent organization to study, such as: the central hierarchical structure of the Church which allows researchers to easily discern managerial positions, the Church's excellent record-keeping practices, and the Catholic Church's complexity.

Among the literature about dioceses, half described the organizational circumstances of the Church in a managerial context in order to generalize to other organizational sectors. Schneider (1972) described job satisfaction of priests in the Diocese of Hartland, Connecticut as a model to generalize to small groups. Carey (1972) analyzed job satisfaction among priests in Chicago as a model to generalize to businessmen. Each author argued that the way the Catholic Church is organized makes it easy to study and test ideas that can be used elsewhere. At the time the articles were written priests had the same demographics as an average person in a business, but the demographics of priests have since grown older than average people in business. Vallier (1971) discussed how the Catholic Church's structure is unique among Christian denominations, which provides nations and cities a central figure to treat with. This 
increases the power of the Catholic Church because it gives them influence among the elite politicians of the world.

The other half of the Catholic literature about dioceses describes how changes occur within the Catholic Church, which is more in line with the goals articulated in this dissertation. The diocesan literature confirms the centralized power of the bishop. Szafran (1980) discussed different innovations that a random sample of priests have tried in response to different diocesan or parish problems and the chances they have for survival. The analysis discovered that the greatest factor for survival is whether the bishop approved the innovation. Szafran (1981) also discussed efforts from priests to decentralize diocesan power, both responsibilities of the bishop and organizational authority. Ultimately the success of the attempts depended on the bishop's reaction, not the vote of the priests in the diocese or lay people's reactions. This demonstrates the coercive power bishops have over their dioceses, which is central to coercive isomorphism. While much of the literature discusses a bishop's power to allow implementation or block it, no literature was found pertaining to a bishop's ability to enact change in parishes. Nor was literature found on norms pertaining to accommodations for people with disabilities or the influence Catholic leadership groups have on an individual bishop/priest.

Research on parishes focuses on people's reactions and changes that have happened since the Second Vatican Council, which proposed many changes to how parishes perform sacraments (Bartunek 1984). One of these changes is that laypeople can become the pastor of a parish. Gilmour (1997) discussed how parishioners react differently to lay pastors, as opposed to pastors that are priests, because they are less 
coercive and more communal, rather than hierarchical, in their leadership style.

Organizationally, lay pastors are subject to the same coercive forces from the bishop as a priest, but they do not have the theological power priests do. Only two percent of the pastors of parishes in the data for this dissertation are laypeople.

While the bishop's power seems absolute, the literature about dissent in the Catholic Church shows limits on the bishop's power. Gutierrez, Howard-Grenville and Scully (2010) analyzed the origins of Voice of the Faithful (VOTF), an organization that advocates for laypeople to have greater representation in the Catholic Church. The group's origins came about despite condemnation from the bishop. While the group is not officially sanctioned by the Church, it is part of the Church in terms of membership. Piazza and Jourdan (2018) focused on consequences that bishops faced from secular society, such as governments and the media due to public outcry from the sex scandals. These analyses give a sense of the limits of the bishop's power in the Catholic Church because while the bishops tried, they could not stop the people reporting stories to the media, which led to the sex abuse scandal becoming public.

The Catholic Church has a hierarchy of priests and bishops (described above) as well as consecrated religious, such as nuns and monks with a separate hierarchical system. Consecrated religious operate outside of the diocesan structure, the only figure that links the two structures is the Pope (Catholic Encyclopedia 1991). This structure and the studies that analyze it are not reviewed in this dissertation because they are not pertinent to the discussion as the two systems are separate and the data for this dissertation only includes the diocesan system. 


\section{Protestant Literature}

A clear majority of the remainder of the literature analyses protestant denominations, making Christianity the most studied religion in the organizational literature. Only one article covers another religion: Hearn (2004) who analyzed the role of the Afro-Cuban religion in providing social services in Cuba. Despite the services it offered to the government, the two organizations are still not on good terms.

Most of the protestant literature used descriptive analysis to analyze leadership styles and the congregation's reaction to the leadership style. Langley and Kahnweiler (2003) discussed different leadership styles in an African context, which is highly politicized. The leadership styles helped encourage members of a congregation to political action, although the analysis also showed that in a congregation that is already highly political a non-political leadership style mostly leads to frustration. StewartThomas (2010) studied the effects of female pastors on congregations since the number of female pastors in the U.S. has been increasing since 2000 (Campbell-Reed 2017). The main finding showed that congregations led by female pastors are more likely to engage in community service. Sturges et al. (2019) analyzed the role of the "calling," which is a Christian concept that emphasizes a higher power's will for a person to occupy a certain position. The author described how it changed the leadership style of pastors to become more authoritarian because they believe that they are designed for the position. This was correlated with a higher rate of people who felt unwelcome in the congregation. This literature is useful for this dissertation because it shows how leadership styles affect how laypeople perceive pastors and if they feel welcome. 
Relatively few studies analyze change in protestant churches even though the great majority of protestant churches have the capability to change faster than Catholic parishes due to the lack of central authority outside of a specific church. The majority of the literature about change in protestant churches is about congregational reactions to church changes and some reactions from church leadership. Darko (2013) reviewed the literature about change in churches and applied it to Christian congregations in Africa. He explained that the change is mostly organic due to changing circumstances within the continent and that it is a good place to study organizational change. McCormack (2012) discussed changes occurring in protestant churches in the U.S. He described how congregational consultations help laypeople feel heard during times of organizational change, which improves overall morale. Consultations also help church leadership to understand what the congregation is asking for. Silverman (1983) conducted a survey in protestant churches that had added religious activities in the recent past. The survey measured satisfaction with the church overall as well as the religious activities of the church. The survey was meant as a pilot to measure an organization overall as well as different aspects of the organization and how well people can differentiate them. This literature showed how protestant churches were reacting to a rapidly changing world. While these changes apply equally to Catholic and protestant churches, there is a limitation for the generalizability to Catholic parishes. Protestant leadership must be more reactive to congregational approval since members of the congregation have the power to fire protestant pastors while in the Catholic Church the bishop has complete control of the placement of priests. The bishop gives some consideration to congregational approval when making these decisions, but it his decision in the end. 


\section{Accommodations for People with Disabilities and the ADA}

\section{Laws About Accommodations for People with Disabilities}

I do not fully cover the issues surrounding accommodations for people with disabilities in this dissertation but use them as a means to study organizational isomorphism. This section provides a history of the background for and laws about disabilities rights. To contextualize this, Verbrugge and Jette (1994) articulated what they called "The Disablement Process" (Verbrugge and Jette 1994:1), which is an articulation of disabilities as medical and social. The medical portion of disabilities can be diagnosed and aided with medicine, but each person's personal and social factors also impact the severity of their experience with the disability. This pertains to this section by contextualizing how hostile laws are to people's disability experience. I compare that to people's experiences who are exempt from the law throughout the rest of the dissertation.

Nielsen (2012) articulated the background and history of disability legislation well. The Puritans enacted laws articulating that it is acceptable for people with disabilities not to work although they took away some decision-making rights, deeming them unable to make rational decisions for themselves. These laws carried into the 1900s, in which case it was not only acceptable for people with disabilities to refrain from work, but desirable since few employers were willing to hire them. This created an unwelcoming atmosphere for people with disabilities in the U.S. and many people chose to closet family members with severe disabilities due to this ostracization. In the $1940 \mathrm{~s}$ and 1950s doctors would recommend that families that had a child with disabilities should institutionalize them and then forget about the child because of the strain it could cause the marriage and family. In the early 1950s parents started to rebel again this 
advice and housed the child; eventually they came together and formed the National Association for Retarded Children in 1952. These events contributed to people with disabilities joining with employment activism groups after WWII and fighting for a right to work and a right to be heard.

Once people with disabilities started to fight for a right to work, they realized the barriers they faced to enter and navigate certain buildings, which lead to fights for legislation to eradicate these barriers. There were three laws passed within a ten-year period that accomplished this goal. The first was the 1968 Architectural Barriers Act, which mainly argued for accommodations to be made for people with physical disabilities to enter and navigate through buildings. The next was the Rehabilitation Act of 1973, which mainly prohibited employment discrimination toward people with disabilities within federal agencies and organizations that receive federal funding. The third was the Individuals with Disabilities Education Act of 1975, which articulated that all children have the right to an education regardless of disability status and provided special education programs. Senator Hubert Humphrey and Congressman Charles Vanik introduced bills to amend the Civil Rights Act to include people with disabilities, but they were unsuccessful. Despite the legislative success of these groups, the laws largely lacked enforcement, but they paved the way for the American with Disabilities Act (ADA) in 1990. The ADA is the most significant legislation passed by Congress that advocates for people with disabilities. The law “...provides that services, programs, activities, employees, benefit providers, and other public opportunity providers may not discriminate against otherwise qualified individuals with disabilities." (Rothstein and Irzyk 2017:43-44). 
Throughout this history leading up to the ADA, religious groups participated sparingly, if at all, in the political debate. The Catholic Interracial Council is the only religious group Nielsen (2012) mentions that advocated for people with disabilities. Other religious groups do not have any formal interactions, favorably or unfavorably, with disabilities advocacy. One exception is the discussion surrounding Section 307 of the ADA, which states "the provisions of this title shall not apply to ... religious organizations or entities controlled by religious organizations, including places of worship." (ADA 1990:Section 307). William Bentley Ball represented the Association of Christian Schools International and argued against the ADA because of the cost to implement accommodations in schools and government interference in religious organizations (Dingle 2018). He also argued that churches have a moral responsibility to exclude those with HIV and AIDS who have contracted it through immoral means. Dozens of religious groups signed a letter against this reasoning (Switzer 2003), but despite their efforts Ball's language was implemented into the religious exemptions section of the ADA (Dingle 2018). The last significant impact religious groups had with disability advocates was to join forces to ban aborting babies with disabilities.

There are a few considerations to the ADA's religious exemption as they apply to this dissertation. If a religious organization hosts a public event, such as a concert, then the venue must be ADA compliant and all parts of a school operated by a religious organization that are open to the public also must be ADA compliant (Rothstein 2018). The policies I analyze for this dissertation do not include public venues or issues related to schools, only sacraments which are under the full control of the Catholic Church 
(Chancellor 2019). Therefore, the ADA has no influence on the accommodations I analyze in this dissertation.

The Catholic Church is exempt from federal laws as they pertain to accommodations for people with disabilities, but the Church is not exempt from all state laws regarding these accommodations. States are free to exempt religious organizations as they see fit. There are one hundred fifteen laws passed or bills being considered that pertain to disability-related issues and none of them attempt to control religious organizations' policies that only affect members of the religion (NCSL.org 2019). This could be because of constitutional issues regarding freedom of religion and how religious organizations may challenge a government if they tried to place restrictions on sacraments (Chancellor 2019). Regardless, there are no known sources of coercion from the government to the Catholic Church in the context of accommodations for people with disabilities.

There are also groups that challenge the religious exemption of the ADA. One of the more prominent groups is RespectAbility, a nonprofit organization that "fights stigmas and advances opportunities so people with disabilities can fully participate in all aspects of community." (RespectAbility 2019). RespectAbility has advocated for disability accommodations for religious institutions, mainly appealing to their sense of morality since they are exempt from the law. Other local groups (both inside and outside of the Catholic and Christian churches in general) have challenged religious exemptions and some have won in certain states (Dingle 2018). However, none of these groups have successfully challenged sacramental norms nor how the sacraments are implemented. A chancellor indicated that the Catholic Church would fight challenges to any government 
influence to the sacraments on religious freedom grounds (Chancellor 2019). Therefore, while it is still under contention, there remains no coercive influences for accommodating people with disabilities in the Catholic Church in the United States.

\section{Religious Accommodations for People with Disabilities Outside of the Law}

The accommodations the Catholic Church provides are important for the mental health of its members. Dengah (2017) studied Christians in Brazil and found that people who are religious are more likely to be healthier if they belong to a welcoming and supportive congregation. Moreira-Almeida, Lotufo Neto and Koenig Harold (2006) conducted a meta-analysis of religiosity and mental health and one of the key findings was that people with disabilities were more likely to be healthy if people in their congregation were more accepting of their disability. Krause, Pargament and Ironson (2017) analyzed data from a nationally representative survey that examined the mitigating effects of socioeconomic status and health. They found that while health effects are mitigated by socioeconomic status, religiosity is still a positive predictor for better mental health. In contrast, Nie and Olson (2016) studied the effects of the belief in demons on health. While belief in demons had a negative effect on health, it is mitigated by the way people in the congregation view people with disabilities as they are more likely to believe the disability has demonic origins.

Historically, the Catholic Church has marginalized people with disabilities. Covey (2005) articulated two traditions of how the Catholic Church has interpreted disabilities. The first tradition is that disabilities are the result of sin, therefore people with disabilities should be ostracized due to the severity of their sin. The second tradition 
is that people with disabilities are like children that need to be welcomed and cared for within the church. Pope Francis recently emphasized accommodations for people with disabilities, which could lead to structural changes (Wooden 2016). However, it is still important to study the reaction of individual parishes to people with disabilities and not just the entire Catholic Church because people's health is connected to feeling welcomed by a congregation rather than the overarching organization (Dengah 2017, Nie and Olson 2016, Proeschold-Bell et al. 2015).

\section{Accommodations from Other Religions}

Regarding accommodations for people with disabilities, the Catholic Church is similar to Jewish synagogues. In 2018 RespectAbility conducted the Faith and Disability Inclusion Survey (2018) of 2,500 Jewish people about their opinions of how the Jewish community accommodates people with disabilities. According to the survey around $18 \%$ of Jews responded that the Jewish community is doing "extremely" or "very" well at including people with disabilities in activities with the same percentage responding "not well" and $42 \%$ responding "somewhat". When asked where in the community people find the most difficulty $14 \%$ responded at synagogues and $25 \%$ responded at community events. They were also asked if the accommodations had gotten better and 56\% respond that they had. While this is not directly comparable to the Catholic Church survey, it has the same narrative that the Jewish community is mediocre at accommodating people with disabilities but getting better and still not where they would prefer to be. Although the fact that most Jews said the community was improving suggests that it is a common goal. 
While little has been researched regarding people with disabilities in Islam Mosques in the U.S., from the little that is provided, the Catholic Church is also similar to Islam. The group Muslims Understanding \& Helping Special Education Needs (MUHSEN) distributed a self-selecting survey to measure to what degree Muslims with disabilities feel included in masjid-related events (events at a Mosque) (MUHSEN 2020). The survey asked how included they felt on a scale of one to ten and the median was a three. This survey is not directly comparable to the survey used for this dissertation or the Jewish survey as the surveys ask different questions and use different methods to obtain data. However, it shows that accommodations need to be improved across the board in the religious context.

\section{$\underline{\text { Research Questions }}$}

The research questions are written in a way to isolate coercive isomorphism within the Catholic Church's structure and to measure it. To measure the influence of coercive isomorphism, I articulate three thesis questions. The first question addresses measuring isomorphism without coercive influences: How much influence do mimetic/normative isomorphism have on diocesan decisions to adopt sacramental norms concerning accommodations for people with disabilities when coercive factors are not present? To measure this question, I use binary logistic regression to test the variables that best predict if a diocese has sacramental norms that address issues related to disabilities. Normative and mimetic isomorphic factors are used along with controls to determine their importance. Since there are no coercive factors that can influence a diocese' decision to implement sacramental norms that address issues related to 
disabilities the regression tests the influence of mimetic and normative isomorphism when coercive factors are not present.

To account for the influence of coercive isomorphism the second question is, how much influence does coercive isomorphism have on Catholic parishes' accommodations for people with disabilities in the sacraments combined with mimetic and normative isomorphism? To measure this question, I use ordered logistic regression to test the variables that best predict if a parish accommodates people with disabilities in the sacraments. Normative, mimetic, and coercive factors will be used along with controls to determine their importance. Measuring the importance of coercive isomorphism compared to mimetic and normative along with the diocesan model allows the researcher to ascertain the relative importance of coercive isomorphism.

To account for the forces that differentiate organizations, the third question is, how much influence do niche factors have compared to isomorphic factors when dioceses and parishes decide on sacramental norms and sacramental accommodations pertaining to people with disabilities? Niche factors act as a control in the quasi-experiment as a comparison for how much the importance of isomorphism shifts from one model to the other. The niche factors that are added do not change between the diocesan and parish studies. They measure environmental factors that affect diocesan/parish accommodations for people with disabilities. The impact of isomorphism changes between the diocesan and parish studies as coercive isomorphism is added to the parish factors. If the isomorphic factors shift in significance compared to ecological factors between the diocesan and parish studies, then there is a high likelihood that it is because of coercive isomorphism. In this way the study measures the impact of coercive isomorphism by 
using the Akaike Information Criterion, which allows a researcher to compare two models for best fit. 


\section{CHAPTER 3: METHODS}

While the research questions just articulated at the end of the literature review will be revisited in the discussion chapter, the methods and results sections are organized by the regression tables (on pages 82,87 and 91 ) in order to place everything in the same section that pertains to dioceses in one section then everything that pertains to parishes in another section and thus separate them conceptually. The discussion section will return to the research questions to contextualize the findings in the framework of the research questions.

\section{$\underline{\text { The Catholic Context }}$}

I argue that the Catholic Church has a unique organizational position, which makes it a good fit to isolate and study coercive isomorphism. To demonstrate this, I describe the three types of power that most directly affect this dissertation as well as the units of analysis for this dissertation: U.S. Catholic arch/dioceses and U.S. Catholic parishes.

The U.S. Catholic Church has split the world into territories called dioceses. In the U.S., dioceses are named for the largest city within the diocese. Each diocese is headed by a bishop and all parishes within a diocese are under the jurisdiction of the bishop. Dioceses are grouped into archdiocesan territories that includes one archdiocese headed by an archbishop. The borders of the archdiocese do not overlap with any other diocese, it is a separate diocese. 


\section{Three Types of Power}

There are three types of power that are directly relevant to this dissertation: power over theological issues, power to issue executive orders, and power structures outside of the U.S. Catholic Church that can exert control or influence over U.S. arch/dioceses and parishes.

\section{Power Over Theological Issues}

The first type of power relative to this dissertation is theological power. This type of power is the one that most people are familiar with. Doctrine or dogma is a written teaching of the Catholic Church that must be believed to be in communion with the Catholic Church. While Popes, archbishops, and bishops ${ }^{3}$ have some flexibility in how they interpret Catholic dogma and doctrine, they are constrained from openly defying Catholic teachings that have been codified by the Catholic Church. Examples of doctrine that are codified are the Catechism of the Catholic Church and Canon Law. The Catechism does address disabilities issues in statements such as, "Sick or handicapped persons should be helped to lead lives as normal as possible." (Catechism of the Catholic Church 1994:2276). These kinds of statements of dogma/doctrine have some force and bishops who openly deny them risk being pulled from their positions or in extreme cases they are excommunicated from the Catholic Church. Additionally, Popes can issue a statement on a theological issue (most often in the form of an encyclical) and this has more authority than a normal pronouncement. ${ }^{4}$ In such cases, interpretation of the

\footnotetext{
${ }^{3}$ After this, 'bishops' will refer to both archbishops and bishops unless specifically noted and 'dioceses' will refer to archdioceses and dioceses unless specifically noted.

${ }^{4}$ In rare cases, the teachings within an encyclical can be declared "infallible" by a pope, effectively becoming dogma or doctrine immediately. Generally, such declarations of infallibility are reserved for
} 
statement is still allowed and, in some cases, welcome, but open defiance of it can lead to a Pope rescinding an appointment and/or replacing someone with another person more agreeable to that Pope's position.

Figure 1 (constructed from information in the Catechism of the Catholic Church (1994) and the Catholic Encyclopedia (1991)) shows the power dynamic regarding theological matters related to disabilities issues. In the figure there are four tiers of theological power: at the top is the Pope, followed by: cardinals, bishops, and priests. The theological power generally flows from top to bottom, as shown. Appointments are slightly different, but also fall in that order. The Pope has the power to appoint cardinals and bishops to their position and to their station. Cardinals have the power to vote the Pope into his position, which is why the line is dotted. Priests have to initiate the process to become a priest and a bishop must approve it but a bishop cannot tell someone to be a priest, which is why the line is dotted. Once they are a priest the bishop has full authority over the station of the priest. ${ }^{5}$

\footnotetext{
important doctrinal issues, such as the assumption of the Virgin Mary into Heaven at the end of her earthly life and that she has born free of $\sin$ (know as the Immaculate Conception).

${ }^{5}$ The structure articulated here is only the diocesan structure. The Catholic Church also includes religious orders, which include sisters, nuns, monks, and brothers and are largely separate from dioceses. Religious orders include their own organizational structure which is not included in this dissertation because I do not analyze religious orders in this dissertation, only dioceses.
} 


\section{Appointment/Theological Power in the Catholic Church}

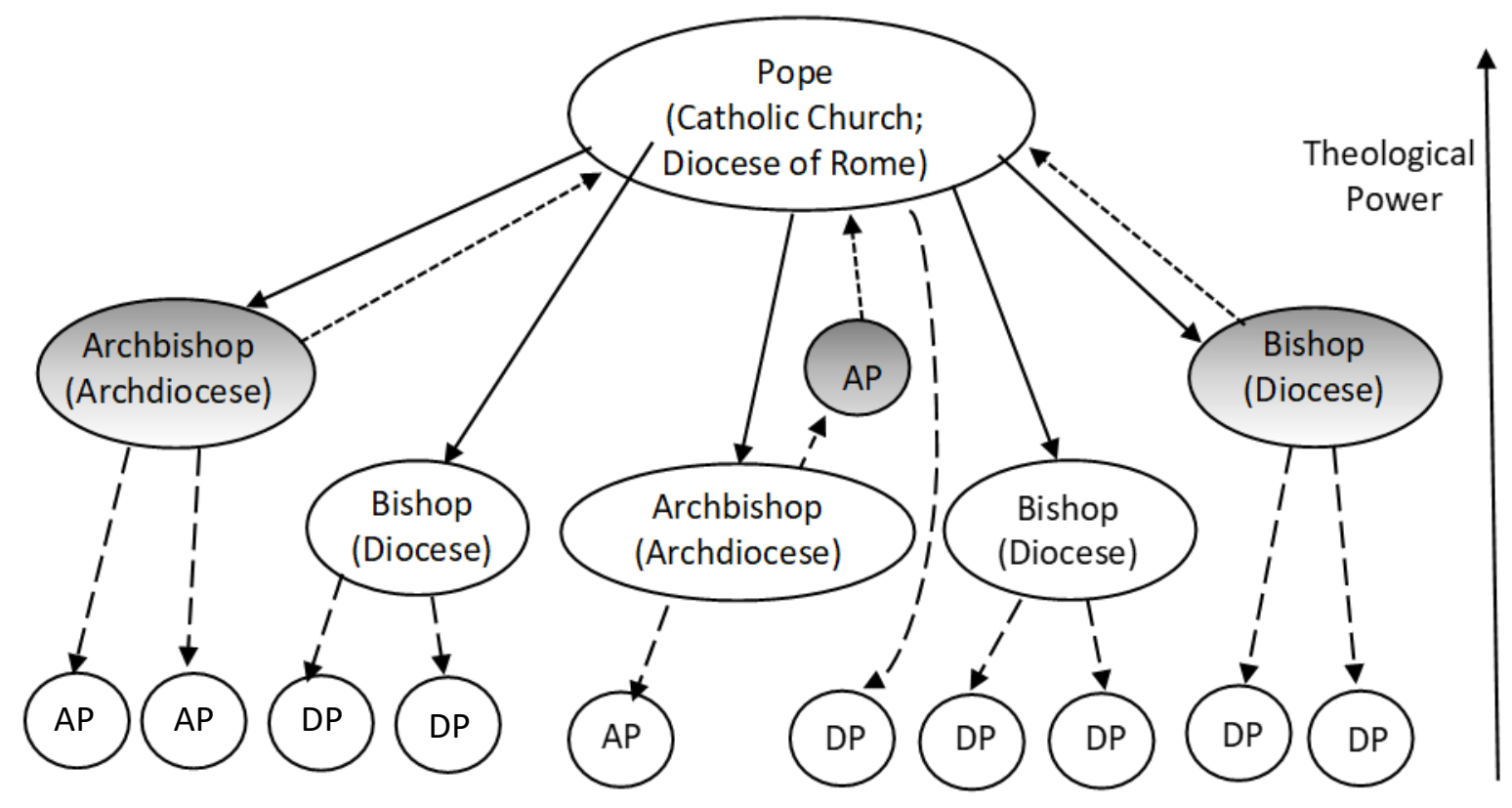

$\mathrm{DP}=$ Diocesan Priest

$\mathrm{AP}=$ Archdiocesan Priest

* Shading indicates Cardinal status, which is a largely theological position that has theological status above a bishop, but still has the organizational role of bishop or priest.

*Solid arrow indicates power to appoint someone to their position and station. Short dotted line indicates power to vote person into their station. Long dotted line indicates power to appoint someone to their station, but incomplete power to appoint someone to their position.

No doctrines have been passed from the Catholic Church about how parishes and dioceses must accommodate people with disabilities, although individual bishops can specify such accommodations. The Pope and fraternal regional conferences like the United States Conference of Catholic Bishops (USCCB) exert influence on dioceses and parishes to minister to those with disabilities in certain way but have not done so via a theological decree. The situation is different for pastors, as a bishop can issue a decree within a diocese and that decree must be obeyed by all pastors and priests. These decrees have been issued by individual bishops and have direct bearing on this study. 


\section{The Power to Issue Executive Orders}

The second of the three types of power relevant to our study is the power to issue an executive order, or organizational power, that must be obeyed by those holding positions lower than the person issuing the order. These orders can concern administrative and/or how theological doctrine is carried out.

Figure 2 (constructed from information in the Catechism of the Catholic Church (1994) and the Catholic Encyclopedia (1991)) shows the organizational power structure. Atop the pyramid of the international Catholic Church sits the Pope who resides in the Diocese of Rome in Vatican City. The Pope is mostly the titular head of the Catholic Church, as he appoints cardinals and bishops after which he allows the bishop to run the diocese as he sees fit. The cardinals advise the Pope as far as making the appointments and other theological issues (stated above in the theological power section). The main organizational power resides with the bishops, as they have the power to dictate to priests outside of theological issues into organizational issues. 
Figure 2

Organizational Structure of the Catholic Church

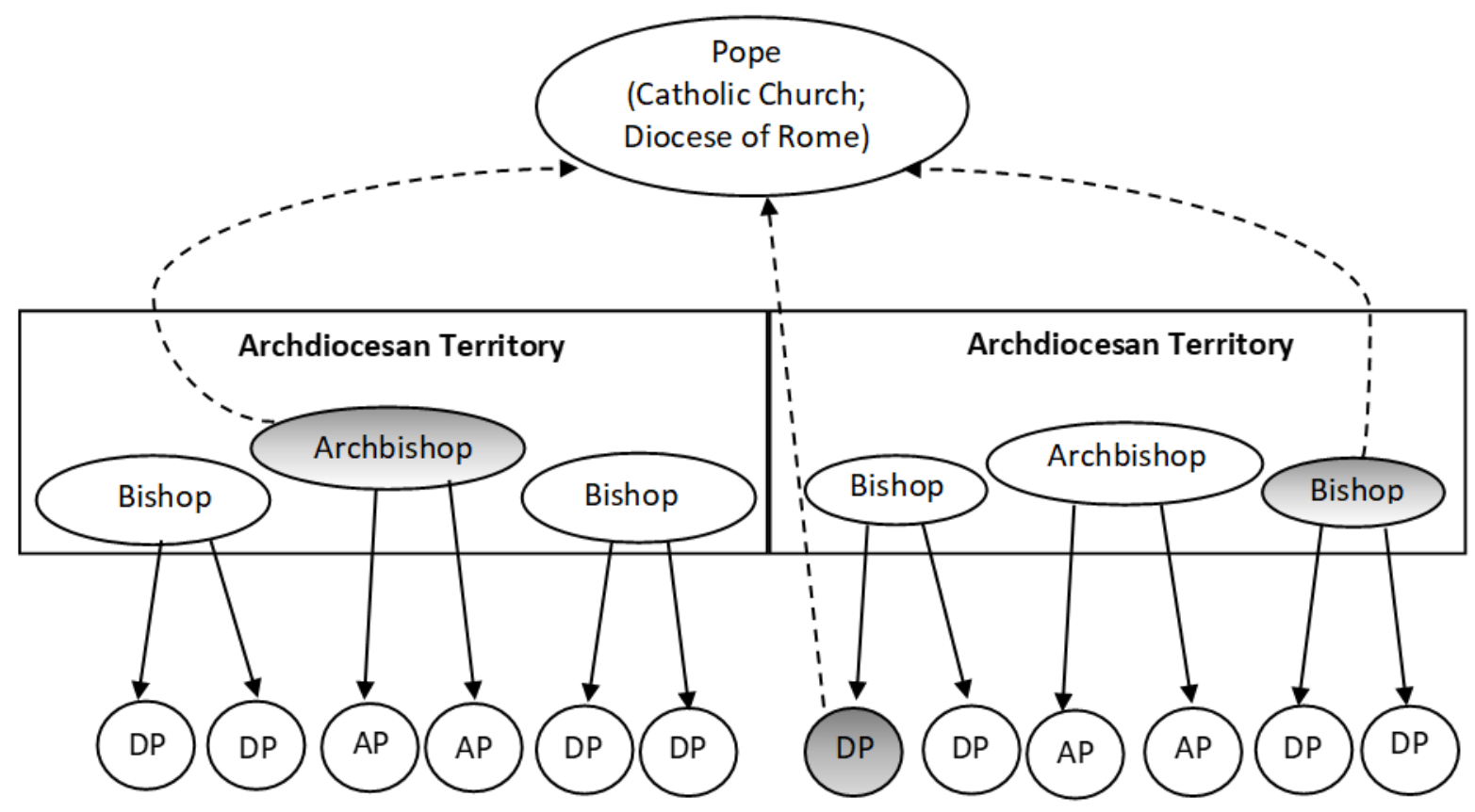

$\mathrm{DP}=$ Diocesan Priest

$\mathrm{AP}=$ Archdiocesan Priest

*Shading indicates Cardinal status, which is a largely theological position that has theological status above a bishop, but still has the organizational role of bishop or priest.

*Solid arrow indicates power to administer executive orders. Dotted line indicates an advisory position.

The first level of analysis is Catholic dioceses, which are headed by a bishop.

Organizationally, bishops have complete control to enact policies that they see fit, as

indicated by the arrows in Figure 2. Bishops have power to refuse the Pope for

organizational purposes and issues of sacramental norms in their dioceses (Chancellor

2019, CRUX 2018), which is another reason why there are no arrows from the Pope in

Figure 2. The Pope does not interfere because the bishop is appointed to manage the

organizational aspects of the diocese and knows the organizational context better than the

Pope. Bishops also have the right to refuse orders from an archbishop within their

archdiocesan territory. The archbishop's main purpose organizationally is to be on a

committee if a diocese needs to be investigated within their archdiocesan territory. 
Therefore, organizationally, those above bishops can advise them but not issue executive orders in the context of their diocese.

The other unit of analysis is Catholic parishes. Whether archdiocesan or diocesan, they have the same power dynamic and usually they are headed by someone holding the title of pastor. The Pope, cardinals, and bishops other than their own bishop cannot issue executive orders to them; only the cardinal or bishop in charge of their

diocese can. This is codified by the vows pastors take when ordained to the priesthood, a vow of obedience to the head of their diocese.

Relative to this study, the power to issue an executive order concerning ministry to those with disabilities can be summarized as: 1) Within one of our units of analysis, those in charge of diocese - bishops - cannot be ordered to do something related to ministry for those with disabilities by those higher than they in Figure 2, but instead can only be advised to do something. 2) Through their vow of obedience to the head of their diocese, the pastors of parishes - the other unit of analysis - can be ordered to do something related to ministry to those with disabilities by their respective bishop.

\section{Structures and Organizations Outside the Catholic Church that Exert Power and} Influence

Another kind of power directly related to ministry to those with disabilities is the power of external organizations to order or influence parishes and dioceses.

The state and federal government do not have jurisdiction over parish or diocesan sacramental policies in the case of disabilities or otherwise (Chancellor 2019, Rothstein and Irzyk 2017). Diocesan sacramental norms pertaining to disabilities are exempt from 
U.S. national laws and the Vatican so there are very few coercive influences over diocesan sacramental norms. Parishes, like dioceses, are exempt from the coercive influences of U.S. national law but are heavily coerced by their diocese's sacramental norms or orders from the bishop. Examining the differences between diocesan and parish policies to accommodate people with disabilities provides a quasi-experimental model of examining different parts of an organization with differing constraints while holding most other factors constant because it is the same organization. This makes the Catholic Church an ideal setting to quantify coercive isomorphism.

\section{$\underline{\text { Data Sources }}$}

\section{Dioceses}

To operationalize the diocesan measures, I use a survey administered by the Center for Applied Research in the Apostolate (CARA) in 2016 which surveyed the population of dioceses in the U.S. (Holland and Gaunt 2016b). The survey measures diocesan policies and accommodations used for teaching children with disabilities, how dioceses include people with disabilities into the sacraments, how dioceses evangelize to people with disabilities, and the construction of diocesan facilities to accommodate people with disabilities (Holland and Gaunt 2016b). The survey was sent to the chancellor of each diocese, which is the person directly under the bishop within the diocesan hierarchy. An online copy was sent to 82 chancellors for which CARA had an email address and a physical survey was sent to all 178 diocesan chancellors.

Chancellors that did not respond were sent reminder emails/mailings up to four times. CARA received surveys from 134 out of the 178 dioceses for a response rate of $75 \%$. 
To measure variables related to bishops in the U.S. I use a study that surveyed bishops and was administered by CARA in 2016 (Fichter et al. 2019). The survey was sent to the population of active bishops in the U.S. A physical copy of the questionnaire was sent to all 178 ordinary bishops. An initial questionnaire was sent in April and a reminder was sent in May. The USCCB did not formally endorse the survey since the researchers wanted the study to be independently administered; although a few prominent bishops privately encouraged other bishops to participate. Data collection was completed in October of 2016 and 140 bishops returned the survey for a response rate of 79\%.

To measure variables among the general population I use the American Community Survey (ACS) administered in 2014 by the United States Census Bureau. The ACS contacts a stratified random sample of 3.5 million Americans each year to continuously monitor changing demographics in the United States (U.S. Census Bureau 2019) The 2014 ACS had a special focus on the demographics of people with disabilities and defined disabilities as anyone who has "hearing difficulty (deaf or having serious difficulty hearing)", "vision difficulty (blind or having serious difficulty seeing, even when wearing glasses)", cognitive difficulty (because of a physical, mental, or emotional problem, having difficulty remembering, concentrating, or making decisions)", "ambulatory difficulty (having serious difficulty walking or climbing stairs)", "self-care difficulty (having difficulty bathing or dressing)", and "independent living difficulty (because of a physical, mental, or emotional problem, having difficulty doing errands alone such as visiting a doctor's office or shopping)" (U.S. Census Bureau 2017). These definitions of disability include all the definition measures that the diocesan and parish surveys include. The survey was sent in 2014 but the U.S. Census Bureau made 
projections until 2017. I use the 2016 data since that is when dioceses filled out the survey. The ACS has four methods of contacting people: internet, telephone, mail, and personal visit (U.S. Census Bureau 2014). One follow-up is sent to people, who are legally required to respond to the survey. Thus, the ACS had a response rate of $96.7 \%$ in 2014.

To measure whether states are considering legislation on disabilities issues I use the website of The National Conference of State Legislatures (NCSL) (NCSL.org 2019) which tracks the state legislature of every state in the U.S. The organization posts every law in state legislatures on their website, therefore they record all of the state laws in the U.S.

\section{Parishes}

To operationalize the parish measures, I use another survey conducted by CARA in 2016 which surveyed a random sample of parishes stratified by state which measures how parishes accommodate and include people with disabilities (Holland and Gaunt 2016a). The survey was written to measure how parishes teach children with disabilities, include people with disabilities in the sacraments (rituals of initiation and vocations), evangelize to people with disabilities, and how parish facilities are built to accommodate people with disabilities (Holland and Gaunt 2016a). CARA successfully contacted 5,242 parishes out of the 7,002 parishes selected, with a letter or email written to the pastor. Parishes that did not respond were sent a reminder email/letter up to four times. CARA received a response from 789 parishes for a response rate of $15 \%$. 
Information from the Homeland Infrastructure Foundation-Level Data (HIFLD) is used to determine the number of churches in an area. HIFLD is a subcommittee established to address improvements in "collection, processing, sharing, and protection of homeland infrastructure geospatial information" (Homeland Infrastructure FoundationLevel Data 2018). The subcommittee is mainly associated with the Department of Homeland Security but is also associated with other government organizations. HIFLD has information on locations of 49,328 Christian churches (Catholic and non-Catholic) throughout the nation.

Internet searches are used to determine information about if there is another parish in the same city and diocese a parish is located that is known for accommodations for people with disabilities.

\section{$\underline{\text { Models }}$}

To enable comparisons between diocese and parishes (which enables the quasiexperiment discussed earlier), I use corresponding measurements for both sets of models. The variables are described in the "Diocesan Model" and "Parish Model" sections. This paragraph explains how the variables correspond across dioceses and parishes. The variables in the same row in Table 3.1 correspond across dioceses and parishes. The mimetic variables measure if a diocese or parish has another diocese or parish that accommodates people with disabilities that is close enough that a priest/bishop can travel there to see the disabilities accommodations. The normative variables measure seminary background, if the diocese/parish partners with another organization to accommodate people with disabilities, and if the bishop/priest interacts with someone with a disability 
on a regular basis. The parish normative variables do not measure a priest's seminary background because the information is unavailable. The variable that measures if a bishop/priest regularly encounters someone with a disability is slightly different. The diocesan variable measures if the diocese employs someone with a disability while the parish variable measures if someone is on a parish committee. The coercive variable is not present in the diocesan model because that is the variable that is measured by the experiment. The niche variables measure the competition for dioceses/parishes, the number of people with a disability in the area, and how the organization was founded. The competition variable is different between models because a diocese and parish have different sources of competition; dioceses compete with state governments while parishes compete with other local churches. There is no variable about the founding of a diocese. There are three control variables that are directly comparable between dioceses and parishes: the size of the diocese/parish, wealth of the diocese/parish, and if the diocese/parish runs a school. The size of the diocese is measured by the number of parishes while parish size is measured by the number of households in the parish. The wealth of the diocese is measured by "mission" status, which is determined by the Church while wealth of the parish is determined by the number of parish staff. 


\begin{tabular}{|c|c|}
\hline Parishes & Dioceses \\
\hline \multicolumn{2}{|c|}{ Mimetic Isomorphism } \\
\hline $\begin{array}{l}\text { Regional dioceses have disability } \\
\text { sacramental norm }\end{array}$ & $\begin{array}{l}\text { Other parish in diocese known for } \\
\text { disability accommodations }\end{array}$ \\
\hline $\begin{array}{l}\text { Neighboring dioceses have disability } \\
\text { sacramental norms }\end{array}$ & $\begin{array}{l}\text { Other parish in same city known for } \\
\text { disability accommodation }\end{array}$ \\
\hline \multicolumn{2}{|c|}{\begin{tabular}{|l} 
Normative Isomorphism \\
\end{tabular}} \\
\hline \multicolumn{2}{|c|}{\begin{tabular}{|l|l} 
Bishop's Seminary Background & \\
\end{tabular}} \\
\hline \multicolumn{2}{|l|}{ Catholic University } \\
\hline \multicolumn{2}{|l|}{ Gregorian University } \\
\hline Disability Partner Organization & Disability Partner Organization \\
\hline Catholic Organization & Catholic Organization \\
\hline Non-Catholic Organization & Non-Catholic Organization \\
\hline Has personnel with disability & $\begin{array}{l}\text { Parish committee member with a } \\
\text { disability }\end{array}$ \\
\hline \multicolumn{2}{|c|}{ Coercive Isomorphism } \\
\hline & $\begin{array}{l}\text { Parish's diocese has a disability } \\
\text { accommodation policy }\end{array}$ \\
\hline \multicolumn{2}{|c|}{ Niche Controls } \\
\hline State disability law & $\begin{array}{l}\text { Number of Christian churches in 6-mile } \\
\text { radius }\end{array}$ \\
\hline \multirow[t]{2}{*}{ Number in diocese with a disability } & Number in city with a disability \\
\hline & $\begin{array}{l}\text { Parish founded with disability } \\
\text { accommodation }\end{array}$ \\
\hline \multicolumn{2}{|c|}{ Other Controls } \\
\hline Number of parishes in diocese & Number of households in parish \\
\hline Mission diocese & Number of parish staff \\
\hline Diocese runs a school & Parish runs a school \\
\hline \multicolumn{2}{|l|}{ Number of elderly in diocese } \\
\hline & Disability position \\
\hline & Parish location \\
\hline & Rural \\
\hline & Suburban \\
\hline & Urban \\
\hline
\end{tabular}

\section{Diocesan Model (Table 4.1)}

This model measures the policies of dioceses as they pertain to accommodations for people with disabilities. Therefore, the unit of analysis for this model is dioceses in 
the U.S. The study measures the influences on the organizations that would pressure them to enact policies to accommodate people with disabilities.

\section{Dependent Variable}

The dependent variable (Sacramental Norms) that is used to measure diocesan policies is a question used in the CARA diocesan study, "does the (arch)diocese have sacramental norms/guidelines that address issues related to disabilities?" 6 Dioceses could answer "yes" or "no." 7 The survey articulated the types of disabilities at the beginning of the survey. After the survey was completed the researcher confirmed the values for all the diocese from public records on diocesan websites, including those that did not respond to the survey, therefore this question has a response for every diocese in the U.S. However, not all dioceses answered the survey and not all dioceses answered every question on the survey, therefore the regressions that use this variable as the dependent variable have 94 cases in the analysis. As shown in Table 3.2, of those 94 cases, $60 \%$ of dioceses have a sacramental norm that addresses disability issues.

\footnotetext{
${ }^{6}$ In the survey the question is split into two parts: "Does the (arch)diocese have sacramental norms/guidelines?" and "If yes, do they address issues related to disabilities?"

${ }^{7}$ All binary questions will be coded 1 for "yes" and 0 for "no".
} 


\section{Table 3.2: Descriptive Statistics of Diocesan Variables Measuring Isomorphism}

$\mathrm{n}=94$ dioceses

\begin{tabular}{|l|c|c|c|}
\hline Variables & Central Tendency & $\begin{array}{c}\text { Standard } \\
\text { Deviation }\end{array}$ & Range \\
\hline Dependent Variable & & & $0-1$ \\
\hline $\begin{array}{l}\text { Diocese has sacramental } \\
\text { Norm }\end{array}$ & $59.57 \%$ & & \\
\hline Mimetic Isomorphism & & & $0-100$ \\
\hline $\begin{array}{l}\text { Regional dioceses have } \\
\text { disability sacramental norm }\end{array}$ & 52.48 (mean) & & $0-100$ \\
\hline $\begin{array}{l}\text { Neighboring dioceses have } \\
\text { disability sacramental norm }\end{array}$ & 54.41 (mean) & & \\
\hline Normative Isomorphism & & & $0-1$ \\
\hline $\begin{array}{l}\text { Bishop's Seminary } \\
\text { Background }\end{array}$ & $18.09 \%$ & & $0-1$ \\
\hline Catholic University & $26.60 \%$ & & $0-1$ \\
\hline Gregorian University & & & $0-1$ \\
\hline $\begin{array}{l}\text { Disability Partner } \\
\text { Organization }\end{array}$ & $78.72 \%$ & & $0-1$ \\
\hline $\begin{array}{l}\text { Catholic organization } \\
\text { Non-Catholic organization }\end{array}$ & $52.12 \%$ & & \\
\hline Has personnel with disability & $45.74 \%$ & & \\
\hline
\end{tabular}

\section{Independent Variables}

\section{Mimetic Isomorphism}

I use a mixture of methods to measure mimetic isomorphism. Burruss and Giblin (2014) studied mimetic isomorphism among police stations by measuring how many other stations in the area adopted a policy. Li (2018) measured mimetic isomorphism as the number of peer organizations that adopted a policy, regardless of proximity. These studies show two different types of measurement for mimetic isomorphism that I utilize. The first is to measure similar organizations in the area and the second is to measure peer organizations, regardless of proximity. The two measures of mimetic isomorphism at the 
diocesan and parish levels include one measure of proximity and another to measure peer dioceses/parishes that the Catholic Church has grouped together.

I use two variables in this dissertation to measure mimetic isomorphism at the diocesan level. The first mimetic isomorphism variable (Regional dioceses have disability sacramental norm) for dioceses measures the percentage of diocese within a diocese's archdiocesan region that have a sacramental norm that addresses issues related to disabilities. Archdiocesan regions range from three to ten dioceses in size (United States Conference of Catholic Bishops 2019). As shown in Table 3.2, on average, 52\%, or around half, of the dioceses in a diocesan region have sacramental norms that address disabilities issues.

The second mimetic isomorphism variable (Neighboring dioceses have disability sacramental norm) for dioceses measures if adjacent dioceses have a sacramental norm that address issues related to disabilities (neighbor dioceses are not necessarily in the same archdiocesan region). Both diocesan mimetic isomorphism variables will use the question from the dependent variable to determine if dioceses have sacramental norms that address issues related to disabilities. Also shown in Table 3.2, 54\%, or around half, of a diocese's neighbors will have a sacramental norm that addresses disabilities issues. Both variables vary from 0 to $100 \%$.

\section{$\underline{\text { Normative Isomorphism }}$}

The dissertation includes five measures of normative isomorphism for dioceses. The first two variables are most closely modeled off of Li's (2018) analysis of the factors that influenced privacy disclosure information. The study measured where top managers 
in a company went to school as a measure of professionalization. The variables used to measure normative isomorphism is whether the organization has a code of managerial ethics. Priests learn ethics at seminary, therefore a measure of where bishops went to seminary will be used. The first normative isomorphism variables for dioceses are binary measures of whether the bishop of a diocese went to Catholic University (Catholic University) or Gregorian University (Gregorian University). These universities are the most common places in which U.S. bishops are educated (Fichter et al. 2019) and create norms for how to address problems within an organization. The question is from the bishops' survey and is worded, "Please list any Graduate Degrees (M.A., M.Div., Ph.D., S.T.D., etc.) and the University attended." As shown in Table 3.2, roughly 18\% of bishops went to Catholic University and 27\% of bishops went to Gregorian University.

The third and fourth measures are based on Galaskiewicz and Wasserman's (1989) analysis of how different subcultures form within an organization. The authors used corporate network analysis to measure the links between corporations and the effects of those links on organizational policies. I also measure the effects of outside organizations on dioceses. Binary variables measure whether a diocese works with a Catholic organization (Catholic Organization) or non-Catholic organization (NonCatholic Organization) to accommodate people with disabilities. These organizations would also create a normative atmosphere within a diocese as to how to accommodate people with disabilities and could affect the way bishops write sacramental norms. The question about Catholic organizations a diocese works with is in the diocesan disabilities survey and is worded, "Does the (arch)diocese work with any Catholic organizations to serve people with disabilities, e.g. Catholic Charities, Scouts, Knights of Columbus?" 
The question about non-Catholic organizations that dioceses work with is in the diocesan disabilities survey and is worded, "Does the (arch)diocese work with any non-Catholic organization(s) to serve people with disabilities, e.g. The ARC, Special Olympics, Best Buddies?" As shown in Table 3.2, $79 \%$ of dioceses work with a Catholic organization to serve people with disabilities and $52 \%$ of dioceses work with a non-Catholic organization for the same purpose.

The final measure of normative isomorphism for dioceses is based most closely to Zou et al. (2019) and their analysis on personal social ties with board members that initiate corporate policies. I also measure how people influence a policy, while the people in this study may not have a lot of organizational power they are directly associated with the policy as they have a disability. A binary variable measures if an employee in the diocesan office has a disability (Has personnel with disability), as this would change the norms in the office because the bishop is forced to accommodate that individual because they work in his office. This question is from the diocesan disabilities survey and is worded, "are there people with disabilities who work in the (arch)diocesan office?" As shown in Table 3.2, 46\% of dioceses have a person with a disability who works in the diocesan office.

\section{Niche Theory Controls}

Two variables will measure niche factors for dioceses. The central tendency, standard deviation, and range of the control variables is summarized in Table 3.3. For dioceses, a binary variable that measures if the state a diocese is in has a law which addresses issues related to disabilities is added (State disability law). This means the 
state is the closest competition for the dioceses for legitimacy for which organization has the best accommodations. A chancellor confirmed dioceses look to state laws as a benchmark if they care about an issue and will try to go beyond them if possible (Chancellor 2019). As shown in Table 3.3,65\% of dioceses are in a state that was considering or passed a law in 2015 regarding disability issues.

Table 3.3: Descriptive Statistics of Diocesan Control Variables
n=94 dioceses

*The state disability law serves as a measure for diocesan competition, since that is one of the only organizations large enough for diocese to truly compete with.

**A mission diocese is one which, "cannot provide basic pastoral services to Catholics without outside help. Basic pastoral services include Mass and sacraments, religious education, and ministry training for priests, deacons, religious sisters and lay people.” (usccb.org).

The purpose of creating a niche for an organization is to obtain resources that other organizations are not trying to obtain or are unavailable to other organizations. To measure niche, the number of people with disabilities in each diocese will be calculated from U.S. Census Bureau data (Number in diocese with a disability). This shows that people with disabilities are available as a resource within the diocese. As shown in Table 
3.3 , the average diocese has 248,007 people with disabilities in the diocese and a wide variation from a minimum of 31,604 to almost 2 million $(1,746,264)$.

\section{Other Controls}

There are four diocesan controls summarized in Table 3.3. The number of parishes in a diocese (Number of parishes in diocese) affects if a diocese needs a policy to effectively lead parishes. Dioceses with more parishes would not be able to meet with an individual pastor with as much regularity as a smaller diocese, therefore the diocese needs policies to effectively communicate the diocese's instructions. The question that measures this variable is from the diocesan disabilities survey and is worded, "Number of parishes in the (arch)diocese." As shown in Table 3.3, the average diocese has 95 parishes; the smallest has 27 and the largest has 287 . This variable is divided by ten to make it easier to interpret in the regression model because otherwise the odds ratio is close to 1.0 because it shows an increase of a single parish.

The number of people in a diocese who are elderly (65 and older) (Number of elderly in diocese) who reside in a diocese affect the number of people with disabilities in the diocese because disabilities increase in a population as people age. This variable comes from the U.S. Census Bureau. As shown in Table 3.3, the average diocese has 250,785 people who are 65 or older within its borders. The diocese with the least number has 36,327 while the diocese with the most has over a million at 1,328,373. Like the previous variable, this variable is divided by 1,000 to make it easier to interpret because the number would be very close to 1.0 since it measures percentage increase per person with a disability. 
Another variable is a binary measure of whether the diocese has a school associated with the diocese (Diocesan School). Unlike dioceses, schools are subject to the ADA (Rothstein and Irzyk 2017). This forces a bishop to consider disabilities accommodations because they must think about the issues in regard to the school. This question comes from the diocesan disabilities survey and is worded, "does the (arch)diocese have any non-parish based Catholic schools associated with it?" As shown in Table 3.3, 75\% of dioceses have a school associated with the diocese.

The final control variable for dioceses is a binary variable measuring if the diocese is a mission ${ }^{8}$ diocese (Mission diocese). There are few groups that oppose disabilities accommodations (Chancellor 2019), the main obstacle is the resources to install the accommodations. Therefore, the number of resources a diocese has affects whether it will force the parishes in the diocese to accommodate people with disabilities because they may not have the resources to do so. This information will be provided by Catholic Extension (Catholic Extension 2019) . As shown in Table 3.3, 37\% of dioceses are mission diocese. This number is exactly the percentage of mission diocese there are in the United States.

\section{Statistical Method}

I use regression analysis to measure the relationship between policies regarding accommodations for people with disabilities and the independent variables. Regression analysis is a method to explain how independent variables explain variation in the

\footnotetext{
${ }^{8}$ A mission diocese are identified as "isolated and/or financially under-resourced dioceses in the U.S." Extension, Catholic. 2019, "Mission Dioceses": Catholic Extension. Retrieved 5/8/2019, 2019 (https://www.catholicextension.org/mission-dioceses).
} 
dependent variable (Schroeder, Sjoquist and Stephan 2017). I aim to test the factors that affect if a diocese/parish has a policy to accommodate people with disabilities, therefore regression is a good method.

\section{$\underline{\text { Regression Method }}$}

In the diocesan models I use binary logistic regression since the dependent variable is binary. Binary logistic regression shows, "the increase or decrease in the predicted probability of having a characteristic or experiencing an event due to a one-unit change in the independent variables." (Pampel 2000:1-2). The analysis shows the probability that a diocese has a sacramental norm that addresses issues for people with disabilities while accounting for all the independent variables. This model does not show p-values because it measures a population rather than a sample. The purpose of a p-value is to show the likelihood of rejecting the null hypothesis in the population from a sample. Since these models measure the population there is no need to know how likely the results are to be able to extrapolate to the population because the population is measured.

I use a parsimonious model with all the models in this dissertation. The parsimonious model removes the variables that are not significant/important to the model. This removes the "noise" of the model and allows a clearer picture of the variables that have an impact on the dependent variable. The technique to get the parsimonious model is omitting the variable with the highest $p$-value ${ }^{9}$ (the least significant variable in the model) and checking the AIC value for an increase (worse model) or decrease (better

\footnotetext{
${ }^{9}$ The $p$-value is used despite their omission in the model because when the $p$-value is used the lowest AIC score is achieved. A parsimonious model based on odds ratios was attempted but it did not produce a better model than using the $p$-value.
} 
model). Using this technique, the model with the lowest AIC value is the best-fitting model.

Data sources, variables, level of measurement, and statistical method are summarized in Table 6.1 in Appendix I.

\section{$\underline{\text { Model Comparisons }}$}

To compare the models I use the Akaike Information Criterion (AIC), which measures the amount of information lost between models (Burnham, Anderson and Huyvaert 2011). The standardized score (achieved by dividing by $\mathrm{n}$ ) allows a researcher to compare models and which model has the least information lost. The test distinguishes between variation explained by good-fitting variables, which are typically significant, and those that are simply "noise," which are typically not significant. Therefore, a better AIC score (meaning a lower AIC score) is not necessarily achieved by adding more variables to a model, as the variables need to explain a significant amount of variation. In this way, adding variables which do not explain a significant amount of variation can produce a worse (or higher) AIC score. The information lost can be converted into a percentage between the model with coercive isomorphism and the model without. This is the percentage that coercive isomorphism adds to the decision-making process.

\section{$\underline{\text { Robustness Checks }}$}

Two robustness checks are completed for every model: variance inflation factors (VIF) and the Box-Tidwell test. The variance inflation factor (VIF) is a measure of how much explained variance is shared by different variables. Therefore, if two variables 
explain the same variance for the dependent variable, they both receive a high VIF score, whereas those variables that explain unique variation receive low VIF scores. The BoxTidwell test measures if a variable has a linear relationship with the dependent variable or a curved relationship. A linear relationship means that the independent variable steadily increases or decreases with the dependent variable. A curved relationship means the independent variable increases initially and then at some point decreases, or vice versa, as the dependent variable increases.

The final robustness check for the diocesan models is the missing cells test. The missing cells test measures if low cell counts are excessive for the dependent variable. To accomplish this the standard error of all variables in the model are checked to make sure they do not exceed 2.0.

\section{Parish Models (Table 4.2 and Table 4.3)}

These models measure the policies of parishes as they pertain to accommodations for people with disabilities. Therefore, the unit of analysis for this study is parishes in the U.S. The models measure the influences on the organizations that would pressure them to enact policies to accommodate people with disabilities.

\section{Dependent Variables}

The first dependent variable (Sacramental Prep) that is used to measure parish policies is a question in the CARA parish study, "Does the parish offer accommodations to include those with disabilities for sacramental preparation such as RCIA, First Reconciliation, First Communion, and Confirmation?" (Sacramental Prep). Parishes 
answered on a Likert scale: 1 "Not at All", 2 "Only a Little", 3 "Somewhat", and 4 "Very Much". The categories "Not at All" and "Only a Little" are combined due to a low frequency in both categories, leaving three options available for the variable: 1 "Not at All/Only a Little", 2 "Somewhat", and 3 "Very Much". As shown in Table 3.4, on average, parishes answer 2.48 for this question, or between "Somewhat" and "Very Much". Due to nonresponse rates for this question and the isomorphic variables the regression models that use this variable as the dependent variable have 593 cases and when the niche variables are included the models have 573 cases due to nonresponse rates for the niche variables. 


\begin{tabular}{|l|c|c|c|}
\hline \multicolumn{3}{|c|}{ Table 3.4: Descriptive Statistics of Parish Variables Measuring Isomorphism } \\
$\mathrm{n}=593$ parishes
\end{tabular}

*Marriage preparation data was available for only 558 parishes, as the response rate was somewhat lower than for Initiation policy.

**When the 35 cases are taken out in the Marriage Prep model the percentages do not change beyond a percent and the means do not change significantly, therefore a separate table is not constructed because the numbers are the same.

The second dependent variable (Marriage Prep) that is used to measure parish policies is another question used in the CARA parish study, "does the parish offer accommodations for people with disabilities for marriage preparation?" Parishes could answer on a Likert scale: 1, "Not at All", 2 "Only a Little", 3 "Somewhat", and 4 "Very Much". These two dependent variable questions cover most of the sacraments that a parish administers and require an implied or written policy to accommodate (Stone 2012). As shown in Table 3.4, on average, parishes answer 2.86 for this question, or 
between "Only a Little" and "Somewhat" trending toward "Somewhat". Due to nonresponse rates for this question and the isomorphic variables the regression models that use this variable as the dependent variable have 558 cases and when the niche variables are included the models have 539 cases due to nonresponse rates for the niche variables.

Independent Variables (identical for both Model 2 and Model 3)

\section{$\underline{\text { Mimetic Isomorphism }}$}

I include two variables that measure mimetic isomorphism at the parish level. The mimetic isomorphism variables for parishes are binary measures for if there is a parish on the first page of a Google search in the same city (Other parish in same city known for disability accommodations) or diocese (Other parish in diocese known for disability accommodations) that is known for accommodating people with disabilities. According to Puttick (2017) people usually don't go past the first page of a Google search, which is one cause of isomorphism. The search terms are "disab*", "parish", and the city/diocese the parish is located ${ }^{10}$. This is evidence that the parish has another accessible parish that it can mimic for best practices. As shown in Table 3.4, 13\% of parishes have another parish in the same city that is known for accommodating people with disabilities and 23\% of parishes have a parish in the same dioceses that is known for accommodating people with disabilities.

\footnotetext{
${ }^{10}$ In Louisiana the search terms changed to "disab*", "Catholic Church", and the city/diocese the parish is located since a county is commonly called a parish in Louisiana.
} 


\section{Normative Isomorphism}

I include three measures of parish normative isomorphism for the second and third research questions. The first two variables are also based on Galaskiewicz and Wasserman's (1989) use of corporate network analysis to measure the links between corporations and the effects of those links on policies. In the same way the disability partner organization variables in this dissertation measure the effects of other organizations on parish policies. Binary variables measure whether a parish works with a Catholic (Catholic Organization) or non-Catholic organization (Non-Catholic Organization) to accommodate people with disabilities as these organizations could have a normative influence on the way the parish accommodates people with disabilities in the sacraments. The questions come from the parish disabilities survey and are binary "Yes" and "No" responses. The question to measure if a parish works with a Catholic organization is worded, "does the parish work with any Catholic organizations to include those with disabilities, e.g. a local Catholic school, Scouts, Knights of Columbus?" The questions to measure if a parish works with a non-Catholic organization is worded, "Does the parish work with any non-Catholic organization(s) to serve people with disabilities, e.g. The ARC, Special Olympics/Best Buddies, or other developmental disabilities service provider in your community?" As shown in Table 3.4, 61\% of parishes work with a Catholic organization to serve people with disabilities while $34 \%$ of parishes work with a non-Catholic organization for the same purpose.

Similar to the final diocesan measure of normative isomorphism, the final parish measure of normative isomorphism is also based on Zou et al. (2019) and their analysis on personal social ties with board members that initiate corporate policies. The variable 
in this dissertation measures the influence of a prominent parish member on a parish policy. The variable is a Likert measure to test how often people with disabilities are on parish committees (Committee Members). The more people that are on a parish committee the more it would change the norms in the parish because the pastor is forced to accommodate those individuals. This dynamic may affect the way people with disabilities are accommodated in the sacraments. The question is in the parish disabilities survey and is worded, "Are there parishioners with disabilities who are members of parish committees?" The responses are "Not at All", "Only a Little", "Somewhat", and "Very Much". As shown in Table 3.4, on average, parishes responded with a 2.49, which is right between "Only a Little" and "Somewhat".

\section{Coercive Isomorphism}

I use one binary variable to measure coercive isomorphism that most closely resembles Taylor and Oylan's (2008) analysis of environmental reporting practices. They found if the mayor was involved in the decision the board was more likely to decide to adopt certain practices. In this case a high government official was involved with the decision. In the analysis for this dissertation, the bishop is the higher official that has influence through diocesan policies. The variable measures if the diocese that a parish is part of has a policy that addresses issues for people with disabilities (Diocesan Policy). If a diocese has such a policy then it has direct coercive influence over the pastor to conform to the policy or find himself in a meeting with the bishop (Chancellor 2019). As shown in Table 3.4, 63\% of parishes are in a diocese that has a sacramental norm that addresses disabilities issues. 


\section{Niche Theory Controls}

Three variables are used to measure the effect of niche variables. To measure competition for parishes the number of Christian churches within a six-mile radius of the parish will be calculated with data from HIFLD (Number of places of worship in six-mile radius). According to Dougherty (2017) the median distance Catholics drive to church is six to fifteen minutes. The average speed limit within cities is 30 miles per hour, accounting for traffic lights, around 25 miles per hour. A car can travel six miles in 15 minutes while travelling at 25 miles per hour. Therefore, churches within a six-mile radius of the parishes compete with the studied parish for people in the area. Dougherty and Mulder (2009) and Reimer (2011) show that interdenominational competition happens more often than interreligious competition, therefore only Christian churches will be measured. As shown in Table 3.5, the average parish has 18 Christian churches within a six-mile radius, although some have none while others have up to 258 . 


\begin{tabular}{|c|c|c|c|}
\hline \multicolumn{4}{|c|}{ Table 3.5: Descriptive Statistics of Parish Control Variables } \\
\hline \multicolumn{4}{|l|}{$\mathrm{n}=573$ parishes $* *$} \\
\hline Variables & $\begin{array}{l}\text { Central } \\
\text { Tendency }\end{array}$ & $\begin{array}{l}\text { Standard } \\
\text { Deviation }\end{array}$ & Range \\
\hline \multicolumn{4}{|l|}{ Niche } \\
\hline $\begin{array}{l}\text { Number of Christian churches } \\
\text { in six-mile radius }\end{array}$ & 18.14 (mean) & 32.55 & $0-258$ \\
\hline Number in city with a disability & 20,924 & 69,737 & $0-869,068$ \\
\hline $\begin{array}{l}\text { Parish founded with disability } \\
\text { accommodation }\end{array}$ & $40.78 \%$ & & $0-1$ \\
\hline \multicolumn{4}{|l|}{ Other Controls } \\
\hline Number of households in parish & 1252.98 (mean) & 1,619 & $26-24,000$ \\
\hline Number of parish staff & 10.33 (mean) & 13.10 & $0-160$ \\
\hline Disability position $* * *$ & $23.78 \%$ & & $0-1$ \\
\hline \multicolumn{4}{|l|}{ Parish location } \\
\hline Rural & $36.93 \%$ & & $0-1$ \\
\hline Suburban & $37.10 \%$ & & $0-1$ \\
\hline Urban & $25.97 \%$ & & $0-1$ \\
\hline Parish runs a school & $39.63 \%$ & & $0-1$ \\
\hline
\end{tabular}

*Marriage preparation has 558 cases, as the response rate was much lower than for Initiation policy. When the 35 cases are taken out in the Marriage Prep model the percentages do not change beyond a percent and the means do not change significantly, therefore a separate table is not constructed because the numbers are the same.

** The $\mathrm{n}$ from table 3.3 is different from the $\mathrm{n}$ from table 3.5 because the niche variables omit data from 20 additional cases. This is also noted in the Results section when discussing the regression tables.

***This variable measures whether the parish has a position to accommodate people with disabilities.

The purpose of creating a niche for an organization is to obtain resources that other organizations are not trying to obtain or are unavailable to other organizations. To measure niche, the number of people with disabilities in each city will be calculated from U.S. Census Bureau data (Number in City with a Disability). This shows that people with disabilities are available as a resource within the city. Table 3.5 shows that the average parish has 20,924 people with disabilities in their city. This has a wide variation from no people with disabilities in the city to 869,068 people with disabilities in the city. This variable is divided by 100 to make the interpretation easier since the odds ratio will likely 
be close to 1.0 since the regression measures an increase per person in the city with a disability.

The niche literature articulates organizational inertia by describing organizations that start with a certain practice as being more likely to be successful with that practice because they have experience with the issues that accompany the practice (Carroll and Hannan 1989). A binary variable will measure if a parish was founded accommodating people with disabilities (Parish founded with disability accommodation). As shown in Table $3.5,41 \%$ of parishes were founded with a disability accommodation.

\section{Other Controls}

There are five control variables for the parish studies in the second and third research questions. The first control variable is the number of households registered in the parish (Number of households in parish). Parishes with more households are more likely to accommodate more people with disabilities. The question comes from the parish disabilities survey and is worded, "Number of households registered at this parish." The average parish has 1,253 households in the parish. The smallest parish has 26 households while the largest has 24,000.

Another variable is the number of people who work in a parish office (Number of parish staff). A parish with more staff is better able to accommodate people with disabilities simply because of the number of workers. The question comes from the parish disabilities survey and is a combination of two questions, the first is "number of full-time staff employed at this parish" and the second is, "number of part-time staff employed at this parish." On average, parishes have about ten people on staff. This 
includes the smallest parish that has no staff to the largest that has one hundred sixty staff members.

To measure if anyone at the parish is responsible for the parish effort to accommodate people with disabilities (Disability position) is important because the pastor will have a fresh perspective of how to accommodate people with disabilities. The question comes from the parish disabilities survey and is worded, "do you have someone on staff, paid or volunteer, who is/are responsible for parish efforts to include people with disabilities? Check all that apply." The responses are "yes, paid", "yes, volunteer", and "no". The "yes" responses will be combined to a binary variable of "yes" and "no" due to the low frequency of parish responding "yes" to either paid or volunteer staff who are responsible for including people with disabilities. Table 3.5 shows that $24 \%$ of parishes have a full- or part-time position to accommodate people with disabilities.

I also include a binary measure of the parishes' location. The variable measures if the parish is rural (Rural), suburban (Suburban), or urban (Urban). The type of location that the parish is in could affect the perceptions that parishioners have toward people with disabilities as urban settings are more accommodating. This variable comes from the parish disabilities survey and is worded, "How would you describe the location of the parish?" The responses are "rural", "suburban", and "urban". Urban is omitted in the regression model as the reference category because many disabilities movements started in large, urban areas. Therefore, I measure if those areas are more likely to accommodate people with disabilities. Around $37 \%$ of parishes are rural and $37 \%$ are suburban, while $26 \%$ of parishes are urban. 
The final variable is a binary measure of whether the parish has a school associated with it (Parish runs a school). Schools are not exempt from the ADA (Rothstein and Irzyk 2017), which would mean that the pastor would need to consider children with disabilities more than a pastor who does not have a school. The variable is a yes/no question that comes from the parish disabilities survey and is worded, "Does the parish have a Catholic school associated with it?". Table 3.5 shows that $40 \%$ of parishes have a school associated with them.

\section{Statistical Method}

When studying parishes, I use ordered logistic regression since the dependent variables are ordinal. Ordered logistic regression shows different "splits" in the dependent variable and the predicted probability that a parish is above different thresholds depending on the independent variables (O'Connell 2006b). The analysis shows the probability of the level of accommodation a parish is likely to offer considering the independent variables. The parish models also use a parsimonious technique, for a full description of the technique see the "Statistical method" section in the diocesan model description.

Data sources, variables, level of measurement, and statistical method are summarized in Table 6.2 in Appendix I.

\section{$\underline{\text { Model Comparisons }}$}

To compare the models I use the Akaike Information Criterion (AIC) again. For a full description see "Model comparisons" in the diocesan section. 


\section{$\underline{\text { Robustness Checks }}$}

Two robustness checks were completed for every model: variance inflation factors (VIF) and the Box-Tidwell test. For a full description of these methods see "Robustness Checks" in the Diocesan section.

For the parish models, three additional tests were done: outlier statistic, Brant test, and generalized estimation equation (GEE). The test to measure if outliers are a problem is the Studentized Pearson Residual, which measures if any case is significantly higher or lower than other cases. This can skew the significance and the coefficient of a variable. The Brant test measures if the lines from the binary model in the ordered logistic regression are parallel. If they are not, then it violates the assumptions of the test and the results are no longer valid. The GEE is another type of regression that checks for underlying correlations in clusters of cases. In this case, the clusters are the diocese a parish is part of. While the ordered logistic regression checks for coercive influences that come through sacramental norms, the GEE checks for other underlying influences from the diocese. The proper method to use in this instance is the GEE, but the GEE test does not exist for ordered logistic regression in STATA and the effectiveness of the method in other programs is contested. Therefore, the GEE was run using binary logistic regression for each split in the dependent variable and compared to the ordered logistic regression model as a check. 


\section{CHAPTER 4: RESULTS}

All the tables in this section (Tables 4.1, 4.2, and 4.3) are split into four models. The first two models (labeled 1.1 and 1.2 in the first table, 2.1 and 2.2 in the second table, and 3.1 and 3.2 in the third table) focus on the isomorphism variables and include everything except the niche controls. This is to measure the effects of isomorphism without the effects of niche factors to answer the first and second research questions, which measure the effect of isomorphism by measuring isomorphism with a clear path for coercive isomorphism (parishes) and without a clear path for coercive isomorphism (dioceses). The second model $(1.1,2.1$, and 3.1) shows all the isomorphism and control variables that do not measure niche variables that were included in the model. This is to show how all the variables fit into the model and which are significant, either in magnitude or statistical significance. This model typically has a worse AIC score when compared to Model 2 since it includes a lot of "noise" (variables that do not have much impact on the dependent variable) in the model. The researcher uses a parsimonious model, omitting variables until obtaining the lowest AIC score. The second model (1.2, 2.2, and 3.2) is a parsimonious model, the author omits variables until the lowest AIC score is obtained. Thus, the second model always has a better AIC score because it omits the variables that produce the "noise" and only the variables that have a significant impact on the dependent variable remain. Therefore, almost all the variables in the bestfitting model are statistically significant. The next two models are set up the same way, 
although the niche variables are included to answer the third research question. The third question inquires about the impact of the niche variables compared to the isomorphism variables. The third model $(1.3,2.3$, and 3.3) includes all the variables (niche, isomorphic, and control). The fourth model (1.4, 2.4, and 3.4) is the best-fitting model with the lowest AIC score and only includes variables that have a significant impact on the dependent variable.

\section{Dioceses}

\section{Table 4.1}

The main takeaway from Table 4.1 is that normative influences dominate diocesan decisions to adopt sacramental norms concerning accommodations for people with disabilities. As mentioned in the methods section, the dioceses in this table comprise a population, therefore statistical significance is not considered since it is only relevant for samples when projecting to a population. Since this table measures a population only magnitude is considered. In the full models (Model 1.1 and Model 1.3) the only variables with odds ratios above 2.0 or below 0.5 (indicating that a dioceses is more than twice as likely or half as likely to adopt a sacramental norm if the independent variable is present; this is an unofficial rule for how to judge numbers that are not based on p-values) are variables measuring normative isomorphism. These variables measure if the bishop of a diocese went to Catholic University of America (odds ratio of 2.0), the diocese partners with a non-Catholic organization to accommodate people with disabilities (odds ratio of 2.4), and if the diocese has someone with a disability on staff ${ }^{11}$

\footnotetext{
${ }^{11}$ The standard error for Personnel with a Disability is above 2.0 in the full model (Model 1.2), which violates the missing cells test. However, it dips to 1.5 in the best-fitting model (Model 1.1), which is the
} 
(odds ratio of 4.1). Therefore, if a diocese is headed by a bishop that went to Catholic University of America the diocese is twice as likely to adopt a sacramental norm that addresses disability issues, a diocese that partners with a non-Catholic organization to accommodate people with disabilities is two and a half times as likely to adopt a sacramental norm that addresses disability issues, and a diocese that has someone on staff with a disability is roughly four times as likely to adopt a sacramental norm that addresses disability issues. No variable has an odds ratio below 0.5 . The best-fitting models (Models 1.1 and 1.3) also give support for the influence of normative factors. In the best-fitting models two out of the three variables measure normative isomorphism. Dioceses that partner with non-Catholic organizations to accommodate people with disabilities has an odds ratio of 2.1 and dioceses that have someone on staff with a disability has an odds ratio of 3.0. This means that if a diocese partners with a nonCatholic organization to accommodate people with disabilities they are twice as likely to have a sacramental norm pertaining to disabilities and if the diocese has someone on staff with a disability they are three times as likely to have a sacramental norm pertaining to disabilities. To measure the full impact of normative isomorphism both normative factors are combined. This is achieved by multiplying the odds ratios, so 2.135 is the odds ratio for partnering with a non-Catholic organization and 3.000 is the odds ratio for a diocese that has someone on staff with a disability. These numbers are multiplied, in which the product is 6.405 or six and a half times as likely. This number represents the odds ratio of when a diocese partners with a non-Catholic organization and has someone on staff with a disability whereas the separated odds ratios represent when those

main model discussed in this dissertation; therefore the violation has been fixed by taking out the other variables. 
experiences occur separately. This means that when a diocese partners with a nonCatholic organization and has someone on staff with a disability the diocese is six and a half times as likely to adopt a sacramental norm concerning disability issues compared to diocese that do not have either of these factors. 
Table 4.1: Binary Logistic Regressions Predicting the Presence of Sacramental Norms for Persons with Disabilities within a Catholic Diocese

\begin{tabular}{|c|c|c|c|c|}
\hline & Isomorph & Yodels & Isomorphism - & iche Models \\
\hline & Model 1.1 & Model 1.2 & Model 1.3 & Model 1.4 \\
\hline & Odds Ratio & Odds Ratio & Odds Ratio & Odds Ratio \\
\hline Independent Variables & (Std. Err.) & (Std. Err.) & (Std. Err.) & (Std. Err.) \\
\hline Mimetic Isomorphism & & & & \\
\hline Regional dioceses have & 0.988 & & .989 & \\
\hline disability sacramental norm & $(.014)$ & & $(.014)$ & \\
\hline Neighboring dioceses have & 1.004 & & 1.003 & \\
\hline Disability sacramental norm & $(.011)$ & & $(.012)$ & \\
\hline Normative Isomorphism & & & & \\
\hline Bishop's Seminary Background & & & & \\
\hline Catholic University & 1.896 & & 2.015 & \\
\hline & $(1.485)$ & & 1.594 & \\
\hline Gregorian University & 1.125 & & 1.262 & \\
\hline & $(.768)$ & & $(.802)$ & \\
\hline Disability Partner Organization & & & & \\
\hline Catholic organization & 0.829 & & 0.848 & \\
\hline & $(.589)$ & & $(.601)$ & \\
\hline Non-Catholic & 2.478 & 2.135 & 2.440 & 2.135 \\
\hline Organization & (1.330) & $(.994)$ & (1.330) & (.994) \\
\hline Has personnel with disability & 4.145 & 3.000 & 4.230 & 3.000 \\
\hline & (2.366) & (1.464) & $(2.427)$ & $(1.464)$ \\
\hline Niche & & & & \\
\hline State disability law & & & 0.722 & \\
\hline & & & $(.384)$ & \\
\hline Number in dioceses with a disal & bility & & 1.000 & \\
\hline & & & $(.000)$ & \\
\hline Controls & & & & \\
\hline Number of parishes in diocese ${ }^{1}$ & 0.877 & & 0.870 & \\
\hline & $(.081)$ & & $(.081)$ & \\
\hline Number of parishes in & 1.000 & & 1.000 & \\
\hline diocese, squared & $(.000)$ & & $(.000)$ & \\
\hline Number of elderly in diocese ${ }^{2}$ & 1.005 & 1.004 & 1.007 & 1.004 \\
\hline & $(.000)$ & $(.000)$ & $(.000)$ & $(.000)$ \\
\hline Diocesan runs a school & 1.486 & & 1.414 & \\
\hline & $(.902)$ & & $(.867)$ & \\
\hline Mission diocese & 0.939 & & 0.915 & \\
\hline & (1.189) & & $(.574)$ & \\
\hline Constant & 0.939 & 0.736 & 1.854 & 0.736 \\
\hline & $(.583)$ & $(.315)$ & $(1.559)$ & $(.315)$ \\
\hline AIC & 1.378 & 1.239 & 1.415 & 1.239 \\
\hline$\underline{\mathrm{n}}$ & 94 & 94 & 94 & 94 \\
\hline
\end{tabular}


The only other variable that is in the best fitting models is a control variable, the number of people who are 65 and older (in thousands). The odds ratio is 1.004, which means that for every 1,000 people in the diocese they are $0.4 \%$ more likely to have a sacramental norm. The researcher divided by 1,000 people because the smallest dioceses have around 30 thousand elderly people and only the largest two dioceses have more than 1 million elderly people. Therefore, the researcher chose 1,000 as a number that is easily interpretable at both levels. While $0.4 \%$ is small, when multiplied by 100 it means that when a diocese increases by 100,000 elderly people then they are $40 \%$ more likely to have a sacramental norm that addresses disability issues and when a diocese increases by 1 million elderly people they are five times (400\%) more likely to have a sacramental norm that addresses disability issues. Practically, this means that large dioceses are much more likely to have a sacramental norm that addresses disability issues.

There is little evidence that mimetic variables have much influence when predicting if a diocese has a sacramental norm that addresses disability issues. The two variables included in the model, the percentage of dioceses in their diocesan area that have a sacramental norm and the percentage of dioceses that neighbor a diocese that has a sacramental norm, do not increase the chances that a diocese will have a sacramental norm by more than .1\% more likely and neither of the variables are in the best-fitting model.

There is also little evidence that niche factors contribute significantly to the diocesan model. The best fitting models (Model 1.2 and 1.4) are identical, which means that none of the niche variables are in the best-fitting model. The odds ratios for the niche variables do not indicate an influence beyond $28 \%$ more or less likely. This could 
be an indication that a diocese is unique in structure for a religious organization and therefore does not have any true competition at that level. 


\section{Parishes}

\section{Table 4.2}

The main takeaway from Table 4.2 is that mimetic and normative factors have the largest impact on how likely a parish is to accommodate people with disabilities in initiation sacraments. Unlike Table 4.1, the variables in Table 4.2 are based on a sample rather than a population, therefore the statistical significance and magnitude of the variables are considered. The only difference between the full models (Models 2.1 and 2.3) and best-fitting models (Models 2.2 and 2.4) is that the Number of people in the community with a disability is not significant in the Model 2.3 while it is in Model 2.4. However, the odds ratio and standard deviation are the same, therefore only the bestfitting models are discussed in this section. Normative isomorphism is the strongest predictor in the model since two normative variables are significant, even though they are each weaker than the mimetic variable, when combined they have more impact than the single mimetic factor. The significant variables measuring normative isomorphism are moderately strong. Parishes that partner with a Catholic organization to accommodate people with disabilities has an odds ratio of 1.67 and parishes with a person with a disability on their parish committee has an odds ratio of 1.79 . This means parishes that partner with a Catholic organization to accommodate people with disabilities are $67 \%$ more likely than those who do not partner with a Catholic organization to accommodate people regarding initiation policies. Similarly, parishes with a person that has a disability on a parish committee are $79 \%$ more likely than those who do not have a person with a disability on a parish committee to accommodate people with disabilities. When the odds ratios are combined, the total influence of normative isomorphism is 2.99 , which means 
that parishes with both normative factors are roughly three times (or 199\% more likely) as likely to accommodate people in the initiation sacraments compared to those parishes that have neither normative factors. This is similar to the variable in the diocesan model that measure if someone in the bishop's office has a disability. If the bishop/pastor knows of someone with a disability they are more likely to make general accommodations for people with disabilities with sacramental norms or sacramental accommodations. A variable measuring mimetic isomorphism is the strongest predictor of accommodations for initiation sacraments at the parish level, with an odds ratio of 2.04. This means that if parishes have another parish in the diocese that accommodates people with disabilities and those accommodations are visible on the internet then they are around twice as likely (or 104\% more likely) to implement accommodations for people with disabilities in initiation sacraments. 
Table 4.2: Ordered Logistic Regression Predicting Initiation Sacramental Policies ${ }^{1}$ with Catholic Parishes

\begin{tabular}{|c|c|c|c|c|}
\hline \multirow{3}{*}{ Independent Variable } & \multicolumn{2}{|c|}{ Isomorphic Models } & \multicolumn{2}{|c|}{ Isomorphism + Niche Models } \\
\hline & Model 2.1 & Model 2.2 & Model 2.3 & Model 2.4 \\
\hline & $\begin{array}{l}\text { Odds Ratio } \\
\text { (Std. Err.) }\end{array}$ & $\begin{array}{l}\text { Odds Ratio } \\
\text { (Std. Err.) }\end{array}$ & $\begin{array}{l}\text { Odds Ratio } \\
\text { (Std. Err.) }\end{array}$ & $\begin{array}{l}\text { Odds Ratio } \\
\text { (Std. Err.) }\end{array}$ \\
\hline \multicolumn{5}{|l|}{ Mimetic Isomorphism } \\
\hline $\begin{array}{l}\text { Other parish in same city known } \\
\text { for disability accommodations }\end{array}$ & $\begin{array}{l}0.739 \\
(.189)\end{array}$ & & $\begin{array}{l}0.748 \\
(.196)\end{array}$ & \\
\hline $\begin{array}{l}\text { Other parish in diocese known } \\
\text { for disability accommodations }\end{array}$ & $\begin{array}{l}1.981 * * \\
(.439)\end{array}$ & $\begin{array}{l}2.042 * * \\
(.445)\end{array}$ & $\begin{array}{l}2.016^{* *} \\
(.452)\end{array}$ & $\begin{array}{l}2.059 * * \\
(.453)\end{array}$ \\
\hline \multicolumn{5}{|l|}{ Normative Isomorphism } \\
\hline \multicolumn{5}{|l|}{ Disability Partner Organization } \\
\hline Catholic organization & $\begin{array}{l}1.695 * * \\
(.330)\end{array}$ & $\begin{array}{l}1.672 * * \\
(.296)\end{array}$ & $\begin{array}{l}1.701 * * \\
(.341)\end{array}$ & $\begin{array}{l}1.625^{* *} \\
(.296)\end{array}$ \\
\hline Non-Catholic & 1.123 & & 1.112 & \\
\hline organization & $(.224)$ & & $(.226)$ & \\
\hline $\begin{array}{l}\text { Parish committee member with } \\
\text { a disability }\end{array}$ & $\begin{array}{l}1.781 * * * \\
(.160)\end{array}$ & $\begin{array}{l}1.788 * * * \\
(.158)\end{array}$ & $\begin{array}{l}1.779 * * * \\
(.165)\end{array}$ & $\begin{array}{l}1.769 * * * \\
(.162)\end{array}$ \\
\hline Coercive Isomorphism & & & & \\
\hline $\begin{array}{l}\text { Parish's diocese has a disability } \\
\text { Accommodation policy }\end{array}$ & $\begin{array}{l}1.030 \\
(.189)\end{array}$ & & $\begin{array}{l}1.037 \\
(.195)\end{array}$ & \\
\hline \multicolumn{5}{|l|}{ Niche } \\
\hline $\begin{array}{l}\text { Number of Christian churches in } \\
\text { six-mile radius }\end{array}$ & & & $\begin{array}{l}1.001 \\
(.004)\end{array}$ & \\
\hline Number in city with a disability ${ }^{2}$ & & & $\begin{array}{l}0.999 \\
(.000)\end{array}$ & $\begin{array}{l}0.999^{*} \\
(.000)\end{array}$ \\
\hline $\begin{array}{l}\text { Parish founded with disability } \\
\text { accommodation }\end{array}$ & & & $\begin{array}{l}1.546^{*} \\
(.294)\end{array}$ & $\begin{array}{l}1.513^{*} \\
(.277)\end{array}$ \\
\hline \multicolumn{5}{|l|}{ Controls } \\
\hline Number of households in parish & $\begin{array}{l}1.062 \\
(.112)\end{array}$ & & $\begin{array}{l}1.007 \\
(.110)\end{array}$ & \\
\hline Number of parish staff & $\begin{array}{l}0.999 \\
(.007)\end{array}$ & & $\begin{array}{l}0.999 \\
(.007)\end{array}$ & \\
\hline Disability position & $\begin{array}{l}1.799^{*} \\
(.419)\end{array}$ & $\begin{array}{l}1.860 * * \\
(.421)\end{array}$ & $\begin{array}{l}1.750^{*} \\
(.412)\end{array}$ & $\begin{array}{l}1.789^{*} \\
(.410)\end{array}$ \\
\hline \multicolumn{5}{|l|}{ Parish Location } \\
\hline Rural & $\begin{array}{l}0.971 \\
(.232)\end{array}$ & & $\begin{array}{l}0.810 \\
(.224)\end{array}$ & \\
\hline Suburban & $\begin{array}{l}1.037 \\
(.239)\end{array}$ & & $\begin{array}{l}0.860 \\
(.221)\end{array}$ & \\
\hline Parish runs a School & $\begin{array}{l}0.811 \\
(.165)\end{array}$ & & $\begin{array}{l}0.819 \\
(.171)\end{array}$ & \\
\hline $\begin{array}{l}\text { Intercept between Somewhat } \\
\text { and Only a little }\end{array}$ & $\begin{array}{l}9.107 \\
(.136)\end{array}$ & $\begin{array}{l}9.000 \\
(.136)\end{array}$ & $\begin{array}{l}9.263 \\
(.140)\end{array}$ & $\begin{array}{l}9.679 \\
(.143)\end{array}$ \\
\hline $\begin{array}{l}\text { Intercept between Very Much } \\
\text { and Somewhat }\end{array}$ & $\begin{array}{l}1.618) \\
(.092)\end{array}$ & $\begin{array}{l}1.618 \\
(.091)\end{array}$ & $\begin{array}{l}1.598 \\
(.094)\end{array}$ & $\begin{array}{l}1.677 \\
(.096)\end{array}$ \\
\hline AIC & 1.728 & 1.706 & 1.723 & 1.696 \\
\hline$\underline{\mathrm{n}}$ & 593 & 593 & 573 & 573 \\
\hline
\end{tabular}


${ }^{1}$ In the survey the dependent variable used the categories "Not at All", "Somewhat", "Only a little", and

"Very Much". Only 6\% of parishes responded "Not at All", so that category was combined with

"Somewhat".

${ }^{2}$ Number of people in the community with a disability is divided by 100 so the odds ratio is easier to interpret.

There is little evidence supporting the influence of coercive isomorphism. The coercive variable is not significant regardless of whether niche factors are in the model or not. Despite the significance, the odds ratios do not show that coercion influences the variable beyond 0.07 or $7 \%$ more or less likely. The coercive variables are also not in the best-fitting models.

Unlike the diocesan model, the niche factors are significant at the parish setting, although they have a smaller role than the isomorphism variables. The models measuring niche factors (Models 2.3 and 2.4) have 20 fewer cases (593 in the isomorphism models and 573 in the niche models) than the models that only measure isomorphism because the niche variables have 20 more missing cases. The AIC score improves the model slightly over the model that only includes variables measuring isomorphism. This, combined with the fact that the niche factors are significant means that the niche factors contribute to whether a parish accommodates people with disabilities in the initiation sacraments. There are two niche variables that are significant, although neither are strong, especially in comparison to the variables measuring isomorphism. The first significant variable is if the parish was founded with disability accommodations, with an odds ratio of 1.51 meaning that if a parish was founded with disability accommodations they are 51\% more likely to have a policy to accommodate people with disabilities in their initiation sacraments. The other significant variable is the number of people in the community with a disability with an odds ratio of 0.999 meaning that for every 100 people in the city 
with a disability a parish is $0.01 \%$ less likely to have a policy regarding accommodating people with disabilities in the initiation sacraments. While this difference is not large in regard to 100 people, when discussing 100,000 (the city with the most people with disabilities has more than 800,000 ) it could mean that a parish is $50 \%$ less likely, or half as likely, to have a policy regarding accommodating people with disabilities in the initiation sacraments. Practically, this means that parishes in larger cities are less likely to have a policy regarding accommodations for people with disabilities in the initiation sacraments.

One control variable in the models with initiation variables is significant. The variable, if a parish has a position explicitly to accommodate people with disabilities has an odds ratio of 1.9. This means that parishes which have made a part-time or full-time position to accommodate people with disabilities are roughly $90 \%$ more likely or almost twice as likely than those that do not have such a position to accommodate people in the initiation sacraments.

The intercepts for all the models in the table signify that parishes are more likely to respond that they accommodate people with disabilities "Very Much" in initiation sacraments. The intercept between "Somewhat" and "Only a little"/"Not at All" is 9.00 for Model 2.2 and 9.68 for Model 2.4. This means that parishes are around nine times more likely to respond that they "Somewhat" or "Very Much" accommodate people with disabilities in the initiation sacraments rather than "Only a little"/"Not at All". The intercept between "Somewhat" and "Very Much" is 1.62 in Models 2.2 and 1.68 in Model 2.4. This means that parishes are around 60-70\% more likely to respond that they "Very Much" rather than "Somewhat" or "Only a Little"/"Not at All" accommodate 
people with disabilities in initiation sacraments. Therefore, the most common response is that parishes "Very Much" accommodate people with disabilities in the initiation sacraments. 


\section{Table 4.3}

Table 4.3 is supportive material for Table 4.2 because of statistical issues with all the models in the table, although the variables that are similar to Table 4.2 bolster the argument that they are significant. The original reason for including two parish tables was to be able to compare and contrast the variables to see which variables were consistent across models and which variables were specific to a certain policy. However, this table has a major issue because the dependent variable removes more than $10 \%$ of the cases from all the models (for a full discussion of the issue see the Limitations section). Despite this statistical issue, the model is still useful for comparative purposes to support the parish findings in Table 4.2. 
Table 4.3: Ordered Logistic Regression Predicting Marriage Preparation Policies ${ }^{1}$ with Catholic Parishes

\begin{tabular}{|c|c|c|c|c|}
\hline \multirow[b]{4}{*}{ Indenendent Variable } & \multicolumn{2}{|c|}{ Isomorphic Models } & \multicolumn{2}{|c|}{ Isomorphism + Niche Models } \\
\hline & Model 3.1 & Model 3.2 & Model 3.3 & $\overline{\text { Model } 3.4}$ \\
\hline & Odds Ratio & Odds Ratio & Odds Ratio & Odds Ratio \\
\hline & (Std. Err.) & (Std. Err.) & (Std. Err.) & (Std. Err.) \\
\hline \multicolumn{5}{|l|}{ Mimetic Isomorphism } \\
\hline \multicolumn{3}{|c|}{ Other parish in same city known 0.894} & \multirow{2}{*}{\multicolumn{2}{|c|}{$\begin{array}{l}0.932 \\
(233)\end{array}$}} \\
\hline & \multirow{2}{*}{\multicolumn{2}{|c|}{$(.233)$}} \\
\hline \multirow{3}{*}{\multicolumn{5}{|c|}{$\begin{array}{l}\text { Other parish in diocese known } 1.093 \\
\text { for disability accommodations }(.207) \\
\text { Normative Isomorphism }\end{array}$}} \\
\hline & & & & \\
\hline & & & & \\
\hline \\
\hline \multirow[t]{2}{*}{ Catholic organization } & $1.599 * *$ & $1.659 * *$ & $1.533^{*}$ & $1.561^{*}$ \\
\hline & $(.286)$ & $(.280)$ & $(.282)$ & $(.270)$ \\
\hline Non-Catholic & 1.039 & & 1.020 & \\
\hline organization & $(.183)$ & & $(.183)$ & \\
\hline \multirow{2}{*}{$\begin{array}{l}\text { Parish committee member } \\
\text { with a disability }\end{array}$} & $1.768 * * *$ & $1.787 * * *$ & $1.805 * * *$ & $1.818 * * *$ \\
\hline & $(.149)$ & $(.149)$ & $(.157)$ & $(.156)$ \\
\hline \multicolumn{5}{|l|}{ Coercive Isomorphism } \\
\hline \multirow{2}{*}{$\begin{array}{l}\text { Parish's diocese has disability } \\
\text { accommodation policy }\end{array}$} & 0.926 & & 0.922 & \\
\hline & $(.156)$ & & $(.159)$ & \\
\hline \multicolumn{5}{|l|}{ Niche } \\
\hline \multirow{2}{*}{\multicolumn{2}{|c|}{$\begin{array}{l}\text { Number of Christian churches } \\
\text { in 6-mile radius }\end{array}$}} & & 0.999 & \\
\hline & & & $(.003)$ & \\
\hline \multicolumn{2}{|l|}{ Number in City with a } & & 0.999 & $0.999 *$ \\
\hline disability $^{2}$ & & & $(.000)$ & $(.000)$ \\
\hline \multicolumn{2}{|l|}{ Parish founded with disability } & & $1.507^{*}$ & $1.451 *$ \\
\hline accommodation & & & $(.260)$ & $(.243)$ \\
\hline \multicolumn{5}{|l|}{ Controls } \\
\hline \multirow[t]{2}{*}{ Number of households in parish } & 0.949 & & 0.882 & \\
\hline & $(.092)$ & & $(.088)$ & \\
\hline \multirow[t]{2}{*}{ Number of parish staff } & 0.997 & & 0.997 & \\
\hline & $(.006)$ & & $(.006)$ & \\
\hline Disability position & 1.282 & & 1.236 & \\
\hline & $(.248)$ & & $(.243)$ & \\
\hline Parish Location & & & & \\
\hline Rural & 1.368 & 1.425 & 1.085 & 1.183 \\
\hline & $(.310)$ & $(.300)$ & $(.278)$ & $(.266)$ \\
\hline Suburban & 0.826 & 0.807 & 0.674 & $0.637 *$ \\
\hline & $(.172)$ & $(.161)$ & $(.154)$ & $(.137)$ \\
\hline Parish runs a school & $0.668 *$ & $0.631 * *$ & $0.675^{*}$ & $0.607 * *$ \\
\hline & $(.123)$ & $(.107)$ & $(.127)$ & $(.105)$ \\
\hline Intercept between Not at All & 6.007 & 5.977 & 6.246 & 6.203 \\
\hline And Only a Little & $(.121)$ & $(.121)$ & $(.124)$ & $(.125)$ \\
\hline Intercept between Only a Little & 1.900 & 1.898 & 1.896 & 1.893 \\
\hline and Somewhat & $(.093)$ & $(.093)$ & $(.095)$ & $(.095)$ \\
\hline Intercept between Somewhat & 1.784 & 1.781 & 1.839 & 1.831 \\
\hline and Very Much & $(.092)$ & $(.092)$ & $(.094)$ & $(.094)$ \\
\hline $\mathrm{AIC}$ & 2.582 & 2.563 & 2.575 & 2.552 \\
\hline $\mathrm{N}$ & 558 & 558 & 539 & 539 \\
\hline
\end{tabular}


$* \mathrm{p}<.05 * * \mathrm{p}<.01 * * * \mathrm{p}<.001$

${ }^{1}$ In the survey the dependent variable used the categories "Not at All", "Somewhat", "Only a little", and "Very Much".

${ }^{2}$ Number of people in the community with a disability is divided by 100 to make the odds ratio easier to interpret.

The results predicting marriage preparation policies show around the same level of normative isomorphism than the results in Table 4.2 but do not show evidence for mimetic isomorphism. The significant variables in the best-fitting model, which measures isomorphic variables (Model 3.2) does not differ from the full model (Model 3.1). The best-fitting model that measures isomorphic and niche variables (Model 3.4) differs slightly from the full model (Model 3.3); the only difference is that the suburban variable becomes strongly significant (p-value is below .05) instead of moderately significant (p-value is between .05 and .1). Therefore, only the best-fitting models will be discussed in this section. The same variables measuring normative isomorphism in Table 4.2 are also significant in Table 4.3 and the odds ratios largely stay the same at moderately strong. The odds ratio is 1.66 if a parish partners with a Catholic organization to accommodate people with disabilities and 1.79 if someone with a disability is on a parish committee. This means that a parish that partners with a Catholic organization to accommodate people with disabilities is $66 \%$ more likely than those that do not accommodate people with disabilities in the marriage preparation process. Likewise, if someone with a disability is on a parish committee the parish is $79 \%$ more likely to accommodate people with disabilities in the marriage preparation process. When these factors are combined to measure the total impact of normative isomorphism, the odds ratio is 3.0 (achieved by multiplying the odds ratios for both variables, so $1.659 \times 1.787=2.964)$. Therefore, a parish with both normative factors is $244 \%$ more 
likely, or around three and a half times as likely to accommodate people with disabilities in marriage preparation. This means that all the models measuring isomorphic factors show support for the power of a personal connection to the head person in power within the parish/diocese. No measures of mimetic isomorphism are significant in Table 4.3 and the percentage change does not exceed $11 \%$ more or less likely.

Like Table 4.2, there is little evidence supporting the influence of coercive isomorphism in Table 4.3. The coercive variable is not significant regardless of whether niche factors are in the model or not. Despite the significance, the odds ratios do not show that coercion influences the variable beyond 0.7 or $7 \%$ more or less likely. The coercive variables are also not in the best-fitting models.

The same niche factors are significant in Table 4.3 that are significant in Table 4.2: number of people with a disability in a parish's city and if the parish was founded with disability accommodations. The models measuring niche factors (Models 3.3 and 3.4) have 19 fewer cases (558 in the isomorphism models and 539 in the niche models) than the models that only measure isomorphism because the niche variables have 19 more missing cases. The AIC score improves the model slightly over the model that only includes variables measuring isomorphism. This, combined with the fact that the niche factors are significant, means that the niche factors contribute to whether a parish accommodates people with disabilities in marriage preparation. Both variables are weak predictive measures. The odds ratio for if the parish was founded with disability accommodations is 0.45 , which means that if a parish was founded with a disability accommodation then they are $45 \%$ more likely to have a policy to accommodate people with disabilities in regard to marriage preparation. The odds ratio for the number of 
people with a disability in a parish's city is 0.999 , which means that as people with disabilities in the community increase by 100 a parish is $0.001 \%$ less likely to have a policy to accommodate people with disabilities. This is a very weak measure, but as discussed before, it is significant in cities where the population of people with disabilities is 100,000 or more, in which case a parish would be half as likely to have such a policy. Practically, this amounts to parishes in large cities are less likely to have a policy regarding disabilities accommodations for marriage preparation. The niche variables are not as strong as the normative isomorphism variables, both niche variables combined are 1.45 (they are multiplied, so $1.45 \times 0.999=1.45$ ). This $45 \%$ difference from the niche variables is dwarfed by the $244 \%$ difference of the normative variables.

There are two significant control variables in the table, but one differs for significance by model, although the variable makes each model better according to the AIC score. The significant control variable that is consistent across models is whether a parish has a school associated with the parish, for which the odds ratio is around 0.6. This means a parish with a school associated with it is around $40 \%$ less likely to accommodate people with disabilities for marriage preparation than a parish that does not have a school associated with it. The other variable that varies in significance by model is location, specifically if the parish is in a suburban location. While suburban is not considered "strong" in terms of significance (p-value of less then .05) it is moderately significant (p-value of .05-.1) in the other models. The odds ratio for suburban varies from .64 (Model 3.3) to .81 (Model 3.1) in the models, which means that a parish in the suburbs is $19-36 \%$ less likely to accommodate people with disabilities in marriage preparation. These variables are not significant in Table 4.2, therefore while they 
indicate that future research should be done as to their role in disability accommodations, they are not discussed further in this dissertation.

Similar to Table 4.2, the intercepts for Table 4.3 signify that parishes are most likely to respond they "Very Much" accommodate people with disabilities for marriage preparation. The odds for the intercept between "Not at All" and "Only a Little" are 6.0 (Model 3.1) and 6.2 (Model 3.3). This means that parishes are six times more likely to respond that they "Very Much", "Somewhat", or "Only a Little" accommodate people with disabilities for marriage preparation rather than "Not at All". The intercept between "Only a Little" and "Somewhat" is 1.90 (Models 3.1 and 3.3), which means that parishes are $90 \%$ more likely to respond they "Very Much" or "Somewhat" accommodate people with disabilities for marriage preparation rather than "Only a Little" or "Not at All". The intercept between "Somewhat" and "Very Much" is very similar, 1.78 for Model 3.1 and 1.83 for Model 3.3. This means that parishes are $78 \%$ more likely to respond they "Very Much" accommodate people with disabilities for marriage preparation rather than any other category. This means parishes are more likely to respond toward the higher end ("Somewhat" or "Very Much") of accommodating people with disabilities rather than the lower end ("Only a little" or "Not at all"). 


\section{CHAPTER 5: DISCUSSION}

This dissertation began with a discussion of the three types of isomorphism and how each have been measured, but few studies compared the types to measure which is strongest. The studies that had compared the types of isomorphism to determine which types are strongest were all qualitative. Townsend and Campbell (2007) are the only researchers to explicitly compare the types of isomorphism in their study of a rape prevention program. Lent et al. (2019) and Scheid and Suchman (2001) compared the different types of isomorphism, although they were not as deliberate as Townsend and Campbell (2007). All these studies found that coercive isomorphism was the most influential for organizational decision-making among the three types of isomorphism. The analysis in this dissertation presents contradictory evidence since coercive isomorphism has no effect in any of the models.

The goal of the dissertation is to isolate different types of isomorphism in order to quantify them, thus measuring which type of isomorphism is most important. Mizruchi and Fein (1999) suggested in their meta-analysis of isomorphism studies that coercive isomorphism has been underrated as a factor as they found evidence for it even in studies that did not measure for it. I measured a situation in which there is a clear avenue for coercive isomorphism from the upper level of the organization to the lower level, although it is also the only apparent avenue for coercion. As I discuss in greater detail after reviewing the three research questions, the results for this dissertation found no 
evidence of coercive isomorphism and found that normative isomorphism overall has the most influence on sacramental accommodations.

This section revisits each research question and provides an answer to the questions using the results from the regression tables. The section continues with implications for isomorphism and the religious context. Then it concludes with the limitations of the study and ideas for future research.

\section{First Research Question}

How much influence do mimetic/normative isomorphism have on diocesan decisions to adopt sacramental norms concerning accommodations for people with disabilities when coercive factors are not present?

Normative factors heavily influence a diocese's decision of whether to adopt sacramental norms that address disabilities issues while mimetic factors have very little influence. This is consistent with Ali and Frynas's (2018) article that studied corporate social responsibility measures in Pakistan and found that when corporations act on their own, normative isomorphism is strongest. The results from Table 4.1, which measure diocesan decision-making, show that normative isomorphism is the major influence in a diocese's decision to adopt sacramental norms when coercive factors are not present. Dioceses that partner with a non-Catholic organization to provide disability accommodations are twice as likely to have a sacramental norm that addresses disability accommodations and dioceses that have someone in the diocesan office with a disability are three times as likely to have a sacramental norm that addresses disability accommodations. If a diocese has both factors, they are almost six and a half times as 
likely to have a sacramental norm that addresses disability accommodations. Mimetic factors are not nearly as influential; the presence of either of the two mimetic factors within a diocese only increased the likelihood that it will have a sacramental norm addressing disability issues by $10 \%$, compared to $540 \%$ for the combination of the two normative factors. The only other important factor identified in the results is the number of elderly people in the community, which only affect dioceses with very large populations.

Normative isomorphism may be the most influential factor because it forces bishops to focus on a particular problem. Bishops have to make many decisions in the course of their job since they are head of the diocese, therefore anything that can run smoothly without their interference they tend to leave alone (Chancellor 2019). Zucker (1977) described this process as cultural persistence in organizations, in which case transmitting and maintaining organizational practices make them resistant to change. Similarly, Hannan and Freeman (1977) described the concept of organizational inertia, which is when an organization keeps going in a direction unless the organization purposefully changes direction. Organizations use ceremonies to perpetuate both cultural persistence and organizational inertia (Meyer and Rowan 1977). The Catholic Church is steeped in 2,000 years of ceremonies, which make it particularly susceptible to inertia. According to Greve's (2003) model, when organizations do not receive negative feedback they submit to organizational inertia and solve more pressing issues, such as the sexual abuse scandal. The normative factors in the best-fitting models are similar to each other in the respect that they force a bishop out of the ordinary mode of operation. This forces bishops to confront how they have been making sense of the situation and how that 
is not working. Weick, Sutcliffe and Obstfeld (2005) described this process as sensemaking, in which one of the key tenents is that people will keep doing what they are doing until they are forced out of it and only then will they try to think about other solutions or think about the problem more deeply to its structural core. The Catholic Church engages in sensemaking more than most organizations because the main function of the organization is to interpret meaning in world events and people's position in life. However, the sensemaking the Church engages in on a regular basis pertains mainly to doctrinal issues, such as if the Catholic Church should accommodate people with disabilities. This issue has been resolved within the Church by Pope Francis' critique of how the Catholic Church is not welcoming people with disabilities (Wooden 2016). The sensemaking this dissertation covers is about if dioceses and parishes should take concrete steps to accommodate people with disabilities, not changing doctrine for people with disabilities. Because the focus is organizational rather than doctrinal, the results should be generalizable to other organizations within and outside the religious sector.

Typically, bishops are forced to rethink their sensemaking when they have a personal connection with someone with a disability. The question in this dissertation that measured normative isomorphism asked if the diocese has someone in their office with a disability. Dalton (1959) discussed how personal relationships can influence the formal processes of an organization because relationships help people perceive what is happening in an organization. Since the survey went to the chancellor, they were forced to answer the question based on their knowledge of the employees in the office, which means the employee's disability would be obvious or they made it well-known. This changes the norms around the bishop and forces him to accommodate the person in the 
office, which would focus his attention to disability accommodations more broadly. This serves as the catalyst for change within the Catholic Church that other organizations experience through coercion from the ADA. The ADA states that organizations must make reasonable accommodations for people with disabilities. In this case organizations must determine what is reasonable and the ADA gives employees the power to challenge their decision. The person that a priest/bishop encounters on a regular basis serves the same function, informing them that reasonable accommodations need to be put in place for people with disabilities to function within the church. This means that the way the Catholic Church searches for solutions to accommodate people with disabilities could mirror how other organizations experience the process. The Catholic Church simply has a different catalyst for change.

Once the bishop has acknowledged the problem he is forced to search for a solution. March and Simon (1958) discussed how organizations cannot know all the solutions to problems or the consequences to those solutions. One of the ways to gain more perspective about a problem and potential solutions is to increase an organization's network. Granovetter (1985) described how increasing the number of organizations that an organization is connected to is a good way of bringing in more novel ideas. It is not uncommon for a diocese to partner with a Catholic organization because the diocese knows it has basic principles in common, although it is uncommon to partner with a nonCatholic organization. If a diocese is networking with a non-Catholic organization it can be assumed that the diocese is networking to solve a problem. Powell (1990) described networking as a catalyst for change because it expands the opportunities that are available to an organization. In this instance the Catholic Church benefits from the ideas that other 
organizations have implemented to accommodate people with disabilities. The results show that typically a personal connection would convince the bishop to network with another organization to implement formal solutions (Dalton 1959). This would probably be someone who works closely with the bishop and has convinced him verbally or showed him that disability accommodations need to be made. This process does not differ substantially from organizations in the other sectors because, while the catalyst may be different, the process to search for a solution is the same.

\section{Second Research Question}

How much influence does coercive isomorphism have on Catholic parishes'

accommodations for people with disabilities in the sacraments combined with mimetic and normative isomorphism?

Coercive factors have little influence on whether a parish implements disability accommodations for initiation sacraments, although normative and mimetic factors have a lot of influence, especially when they are combined. Tables 4.2 and 4.3 show no coercive influences from the diocese on parishes to enact policies addressing disability issues since none of the models show that the diocesan sacramental norm has significant influence. The normative and mimetic factors are very influential, as parishes that partner with a Catholic organization to accommodate people with disabilities are $67 \%$ more likely to have an accommodation in the initiation sacraments and parishes that have someone with a disability on a parish committee are $79 \%$ more likely to have an accommodation in the initiation sacraments. Table 4.3, which measures marriage preparation, supports these findings. When parishes have both factors, they are three 
times as likely (or 198\% more likely) to have an accommodation in the initiation sacraments. Mimetic isomorphism also has a significant influence on a parishes' decision. If another parish in the diocese has a reputation for disability accommodations, then a parish is twice as likely to accommodate people with disabilities in their initiation sacraments. When normative and mimetic factors are combined, which is when a parish has all three factors, then the parish is six times as likely (or 510\% more likely) to implement disability accommodations in their initiation sacraments.

Other factors to consider include if the parish has a position to accommodate people with disabilities, in which case the parish is $86 \%$ more likely to accommodate people with disabilities in the initiation sacraments. This has the same amount of influence as the normative factors, although not as much as all the isomorphic factors combined. The location of the parish and whether the parish has a school associated with it should also be considered, although these factors need more research to clarify their impact as they were only significant in Table 4.3 (which measures if a parish accommodates people in marriage preparation and that model has statistical limitations, which are fully discussed later in the Limitations section).

I argue that coercive isomorphism is not significant because the sacramental norms are more akin to best practices than enforceable laws; unless there is a problem the bishop gives priests jurisdiction over their parishes. Within the Catholic Church, sacramental norms are intended to be guidelines that help priests know how to lead a parish (Priest 2020). Some dioceses do not have sacramental norms because they allow priests to determine the best way to perform the sacraments. The norms are mainly there so that priests have a reference guide of how to properly perform sacraments and so 
bishops can reference a diocesan policy if a priest does not properly perform a sacrament (Priest 2020). The norms are not enforced, partly because the bishop understands that some priests and parishes can do more than others depending on their financial circumstances. In this way, the accommodations priests make are loosely coupled with the sacramental norms of the diocese, which means that a priest is largely left to manage a parish without much interference from the diocese. This renders the sacramental norms documents similar to the rhetorical documents that Clarke (1999) described for organizational disasters. While this dissertation does not analyze an organizational disaster, it does analyze an organizational failure and the process addressing the failure is similar to the process many organizations use to address a disaster. Clarke (1999) described how an organization will create logic around how they are supposed to handle a disaster and create documents articulating that logic. However, the documents do not have any real power and are usually not implemented. The Church has created theological logic around disability accommodations, but that theology does not necessarily make any concrete recommendations. Since there are few who consider it bad theology to accommodate people with disabilities, the main problem is the financial constraints it imposes on the parish and sacramental norms do not change that situation. This point is supported by the mimetic factors: if the parish has another parish in the diocese that is known for accommodations for people with disabilities then the parish is more likely to make an accommodation as well. DiMaggio and Powell (1983) also made it clear that mimetic isomorphism is more likely in instances with a lot of uncertainty. Palmer (2012) described this uncertainty in an organizational failing context as a fog that organizations exist in and until a regulatory organization addresses the failing, the 
organization will continue to operate as it has. Pope Francis has addressed the organizational failing, but in a broad way, therefore each pastor is uncertain if their parish is failing. According to Palmer (2012) it will take regulatory efforts to get all parishes to implement accommodations.

Similar to dioceses, the significant normative factors in the parish models suggest a personal connection to the priest is important for implementing disability accommodations for initiation sacraments. The most influential normative factor is if someone with a disability is on a parish committee then a parish is more likely to have an accommodation for initiation sacraments. As stated in the first question, this goes back to Dalton's (1959) argument about informal relationships influencing formal rules. Being present on a parish committee makes a person more visible to the pastor, who can then see and listen to feedback about problems for people with disabilities, such as getting to the baptismal font. The other significant factors are opportunities available to the pastor once he decides to implement accommodations, such as partnering with a Catholic organization or hiring someone to implement disability accommodations. As stated in the diocesan section, this is consistent with Powell's (1990) analysis that networks are a good catalyst for organizational change. Once they take these steps to accommodate people with disabilities then they are more likely to have the resources to know which accommodations to implement and which are most useful. Therefore, these factors are not as influential as the mimetic factor because they are interconnected and supply a different piece of the explanation and together explain a great deal of the influence. All of the decision-making power remains with the pastor, which is similar to the situation that Dobbin and Kelly (2007) elaborated on with sexual harassment in corporations. 
They described how complaints of sexual harassment were dealt with internally and did not go to the courts. The corporations ultimately got a lot of power in these cases because they were able to solve the problem according to how they wanted to, not according to the demands of officials that represent the public. This is similar to how priests are able to implement accommodations; they can choose which accommodations to implement with limited input from people with disabilities. This is compounded on the inequalities from the history of inequalities that people with disabilities have encountered, which follows Tilly's (1998) argument that these inequalities build over time into structural barriers; in this case both physical and metaphorical. The fact that Tilly (1998)described the situation so well indicates that this is not something unique to the religious sector; therefore these results from parishes can be generalized outside of the religious sector.

\section{Third Research Question}

How much influence do niche factors have compared to isomorphic factors when dioceses and parishes decide on sacramental norms and sacramental accommodations pertaining to people with disabilities?

Niche factors do not influence the different parts of the Catholic Church in the same ways, as they have almost no effect on dioceses, although they have a small but significant effect on parishes. Table 4.1 shows that there are no niche factors in the bestfitting diocesan model, and they do not influence dioceses' decision beyond a $30 \%$ change in the odds. This suggests that the influence of niche factors is close to nothing. The effect of niche factors for parishes is small, but significant and included in the best- 
fitting models. If a parish is founded with disability accommodations, then it is $51 \%$ more likely to adopt a disability accommodation for initiation sacraments. However, as the number of people in the community with a disability increase, parishes are slightly less likely to adopt policies to accommodate people with disabilities although this only applies to parishes in larger cities. The results from Table 4.3, which measure accommodations for marriage preparation support these findings.

The total effect of niche factors is far below the effect of isomorphism factors when considering dioceses or parishes. The effect of niche factors for dioceses is almost nothing while isomorphic factors improve the chances that a diocese will adopt disability accommodations in the sacramental norms by $500 \%$. This could be because dioceses do not have much true competition. There are few churches that have a hierarchical structure similar to that of a diocese in which a bishop can enact a policy which pastors need to follow. The government is also an imperfect competitor because people are members of both organizations, therefore dioceses do not have true competition like parishes. When combined, the effects of niche factors on parish decision-making is $51 \%$. This is dwarfed by the effects of isomorphic factors, which is around ten times as much influence at $510 \%$.

This suggests that pastors and bishops do not focus on competition as much as they focus on their parish and do not perceive competition as much of a threat to the wellbeing of the organization. This is the opposite of what Reimer (2011) found in their analysis of how churches stayed apprised of nearby churches and did not overlap the niches they occupy too much. Niche theory and isomorphism were written for for-profit businesses, in which case competition is a major factor for how the business operates 
because they must stay ahead of the competition to remain viable. The diocese is more akin to an umbrella organization and governs members of the Catholic Church through parishes, therefore the diocese has membership through another part of the organization. The Catholic Church also has a unique structure in the way it is set up when compared with other denominations that may not have an umbrella organization, only a single church.

Another ecological argument that shows mixed evidence is Carroll's (1985) concept of capacity of resources. Carroll (1985) discussed the effect of resources on organizational decision-making and this dissertation measures some of the ideas behind those resources but as discussed earlier in the dissertation, they are not comprehensive. As discussed in the literature review, Catholics give less money to their parish than their protestant counterparts (Zech et al. 2017), which provides a parish with few resources for the sacraments and few chances to improve accommodations regardless of any policies the bishop makes. However, the size of a parish's staff does not have any effect on accommodations, which argues against this point because a parish with more staff has more resources to hire such a large staff. The only staff-related variable that is significant is if the parish has someone on staff that focuses on disability accommodations for their job, which is a resource and may be a proxy for wealth of the parish. A parish still needs the resources to hire such a person, so I argue that the accommodations are at least partially dependent on parish resources.

Parishes have competition from outside the Catholic Church and inside because several Catholic Churches can function within a short distance of each other. However, for the Catholic Church competition is not as much of a factor as for-profit businesses 
because a person could use more resources than they contribute (which is rarely the case in for-profit organizations). For this reason a pastor/bishop could wait to establish accommodations in the diocese/parish until they can establish them correctly, which is what Haveman (1993) found in their analysis of when organizations enter newly deregulated markets; they waited until they could secure the resources for a good chance of success. I also argue that parishes may not use disability accommodations to differentiate themselves. Hannan and Freeman (1977) argued that the reason there are so many different kinds of organizations is because they are responding to different environments. The cultural history of Christianity suggests churches compete over theological doctrines, not physical buildings. This suggests that parishes are using theology to differentiate themselves, not disability accommodations. Carroll and Hannan (1989) also discuss the process for establishing legitimacy and since the critiques of the Pope and media have occurred recently, parishes may also be establishing that legitimacy with disabilities accommodations. Therefore, this research would describe the legitimating process rather than how parishes compete to differentiate themselves. All the results for niche factors in this dissertation are not generalizable to organizations in other sectors and may not be generalizable within the religious sector since the results for this dissertation suggest that bishops/priests do not focus on competition from outside organizations in the same way that other organizations do. Hannan and Freeman (1977) and (Carroll and Hannan 1989) show very convincing evidence that organizations from other sectors focus on competition while Reimer (2011) found that even religious organizations focus on their competition. Future research will need to reevaluate the effects of niche factors for organizations other than the Catholic Church in this context. 


\section{Implications for Isomorphism}

The overarching methodological goal of this dissertation is to quantify the relative influence of the different types of isomorphism. The results show that normative isomorphism is the strongest type, about one and a half times as influential as mimetic isomorphism. The results also show that, within the Catholic context of disability accommodations, coercive isomorphism has no effect. In the parish model the influence of normative isomorphism is 2.99 while the influence of mimetic isomorphism is 2.04 , which means the multiple normative factors are about one and a half times as influential as the single mimetic factor. I do not find any effect of coercive isomorphism on accommodations for initiation sacraments, despite a direct avenue from the diocesan level to the parish level, which is contrary to the predictions. Therefore, the most accurate way to quantify the influence is to state that the coercive factors are not significant while the other isomorphic factors are significant. For the diocesan models, the mimetic variables did not make it into the best-fitting models. In the full model the combined influence of normative isomorphism is 5.01, which is roughly 400 times as influential as the mimetic influences of .99 . However, since the mimetic variables were not in the best-fitting model it is more accurate to state that the normative variables are substantial while the mimetic variables are not.

The results show outside organizations influence the decision-making of dioceses and parishes, although an unexpected lack of evidence for coercive isomorphism in this instance. Usually when an organization influences another organization by helping them with a process such as an accommodation it involves some amount of coercion. Mizruchi and Fein (1999) show in their review that coercive forces are usually present, which is 
why they issue a call to test for each type of isomorphism. This dissertation tests for all three types and finds no evidence of coercive isomorphism. Additionally, multiple sources have made it clear that parishes and dioceses would resist coercion from outside organizations (Chancellor 2019, Nelson 1993, Priest 2020). Therefore, it makes sense that the priest or bishop seeks to invite the norms in the parish/diocese to change and facilitate the change. This is significant within the isomorphism literature because typically when change is detected from one organization to another the author concludes that coercive isomorphism is responsible. One exception is Fennel and Alexander's (1987) analysis of how norms are transmitted through hospitals via membership organizations, which help to buffer the organization from obstacles. This can inform this instance because parishes/dioceses are seeking a way to buffer the accommodations process but are unsure of how to proceed and thus look to another organization for guidance. This also explains why mimetic isomorphism is less influential than normative isomorphism, but still significant. Parishes look for guidance from many different sources, including other parishes. Other parishes can provide a model by which to provide accommodations but cannot provide the assistance that another organization can provide. A common template is available through the USCCB, therefore dioceses do not need to mimic another diocese for their sacramental norms. Mimetic isomorphism also lacks the relationship that is prevalent in normative isomorphism which can spur change through the framing of policies (Dalton 1959). This provides an example of how organizations can influence one another through norms but not coerce each other.

I also compare the effects of isomorphism against the effects of niche theory to clarify the effects of coercive isomorphism. The variables that measure niche theory are 
not as comprehensive as the variables that measure isomorphism; therefore, this dissertation does not show a true comparison of the theories, nor is it a goal of this dissertation. Even so, it can contribute to the literature about how isomorphism and niche theories combine to provide a more complete representation of organizational decisionmaking. Since coercive isomorphism does not have any influence on the parish or diocesan policies the niche factors do not clarify the coercive influence as intended but do clarify the Church's resistance to coercion, organizational or cultural. Coercive forces can come from another organization as well as cultural forces. While the niche factors do not contextualize the coercive factors by the method intended, they provide key cultural insights into Catholic decision-making by measuring the effects of factors outside of the Catholic Church. The results of the dissertation show that neither dioceses nor parishes attend to factors outside of the Church as much as they attend to the members and internal factors, which is why the niche factors are not as influential as the isomorphism factors. This supports Nelson's (1993) argument that churches resist cultural forces. In the diocesan model none of the niche factors were in the best-fitting model. This further limits opportunities for coercive isomorphism because while cultural coercive isomorphism cannot be completely ruled out, it suggests that the chances for cultural coercive isomorphism are reduced because parishes and dioceses pay far more attention to internal factors than cultural factors.

Isomorphism has limited utility in the religious sector, especially regarding the Catholic Church because of the theory's focus on profits for organizations. Coercive isomorphism focuses on "political influence and the problem of legitimacy" (DiMaggio and Powell 1983:150). The Church does not have a problem with legitimacy for the 
sacraments and largely has political influence because of its structure. Normative isomorphism is typically "associated with professionalization" (DiMaggio and Powell 1983:150) and "formal education" (DiMaggio and Powell 1983:152). There is no evidence that formal education is a contributing factor to decision-making in the diocesan models. While the parish models do not measure for formal education very few seminaries implement disability accommodations into their curriculum (Gautier, Holland and Newman 2017). Professionalization is shown to be a well-supported explanation because priests and bishops are controlling the conditions of their work, which inherently involves people. Therefore, they must take those people into consideration since they are part of the workplace. Although the data in this dissertation shows a more nuanced approach that involves allowing others to influence that control, including the people they serve and other professionals that they work with to implement the accommodations. These factors are explained best with theorists in the networking (Dalton 1959, Granovetter 1985, Powell 1990) and decision-making literatures (Greve 2000, March and Simon 1958, Weick, Sutcliffe and Obstfeld 2005). Therefore, isomorphism could benefit from expanding beyond the for-profit and public sectors into the non-profit and religious sectors. The mimetic factors apply to the situation well, as DiMaggio and Powell stated they result, "from standard responses to uncertainty." (1983:150). The Church in the U.S. is responding to uncertainty and it shows in the results as the strongest variable in the parish model.

Niche theory has less value than isomorphism in the religious sector, as shown in all the models. Niche theory focuses on competition and how to gain resources that other organizations have neglected to survive. While this can apply to the Catholic Church, the 
leadership in the Church does not think about it in those terms. They consider how to gain membership, but it is to genuinely help people, not to gain a resource that another church does not have. This is not to say that the Catholic Church does not care about money as they require funds to function, but as discussed before, people may take more resources than they contribute. Therefore, niche theory has limited utility in this context and needs to be expanded to be applicable.

\section{Implications for Organizations in a Religious Context}

Much of the Catholic religious organizational literature discusses the organizational power of the bishop in the diocese; the results of this dissertation show the limits of the bishop's power. In the Catholic literature the bishop has been the focal point of change, as he could allow or stop change in the diocese (Szafran 1980, Szafran 1981). The only limits to his power came from outside the diocese (Gutierrez, Howard-Grenville and Scully 2010, Piazza and Jourdan 2018). This dissertation shows limits to the bishop's ability to implement change within the diocese. Even when a rule is written, such as a sacramental norm, the bishop does not successfully implement change in all parishes, as there is no significant effect of coercion on parish decision-making.

This dissertation can also address how norms and best practices in non-profit and religious organizations may differ from the for-profit literature. As stated in the Introduction, sacramental norms have a purpose of providing an ideal of what should be done, as in a European system (Priest 2020). In this case the norms would simply rearticulate what priests already know should be done and already try to do with limited resources. The sacramental norms provide a system for a bishop to indicate a diocesan 
policy if a pastor discriminates against someone with a disability but not necessarily a pastor that implements accommodations at a slow pace (Priest 2020). The bishop trusts the pastor to know what they are supposed to be doing to manage parish resources accordingly. This is consistent with a tenet of high reliability organizations, decisionmaking is pushed down to the lower levels of the organization where the expertise is greatest (Roberts 1990). In this case pastors are the experts in their parishes, so they are trusted with how the resources are allocated for disabilities accommodations. This is also related to what Dobbin and Kelly (2007) described with the sexual harassment lawsuits in that priests are allowed to govern accommodations because they know the situation of the parish best. However, the priests also may not know which accommodations to implement, which increases inequality in the parish. To fully measure for this the dissertation would need to measure when the norms were written and at what pace the parishes implemented the policy. However, since Pope Francis provided negative feedback in 2013 (Wooden 2016) and priests did not receive negative feedback from bishops, it may be too soon to judge the effects of the Pope's feedback in 2016. This is also not the way that all bishops and priests perceive sacramental norms since they live in the U.S. and have a U.S. interpretation of norms/laws, in which case this would not provide an adequate explanation of why the sacramental norms have no effect (Priest 2020).

To contrast the utility of isomorphism for the religious sector, this dissertation shows that the religious sector has a lot to offer organizational theory by analyzing how organizations work toward the public good. As stated at the beginning of the dissertation, isomorphism and new institutional theory in general formed to show some of the 
limitations of the "Iron Cage" of bureaucratic competition and efficiency (DiMaggio and Powell 1983). The findings of this dissertation diverge sharply from bureaucracy as they show collaboration and an unhurried adoption of disabilities accommodations. I test two theories for a plausible explanation of Church decision-making and find that the more the theory contrasts with bureaucracy the more plausible it is as an explanation for how the Church decides how to implement disability accommodations. Niche theory is an explanation of how organizations compete and articulates how they find resources other organizations are not utilizing, which is consistent with bureaucracy and the weakest theory in the dissertation. Isomorphism shows how organizations are becoming more similar but not necessarily to compete. Isomorphism shows some limitations of bureaucracy and is used to evaluate several plausible avenues for how the Church decides to implement disability accommodations. Therefore, the religious sector can show how an organization stays viable in the current economic climate while disregarding some bureaucratic principles. Further analysis of the religious sector could greatly increase the explanatory power of organizational theory especially the organizational socially responsibility literature (Gransow and Price 2019, Gunarathne and Lee 2019, Li 2018). This analysis can also increase some explanatory power of for-profit organizations by analyzing how the actions of organizational actors in the non-profit, religious, and government sectors influence for-profit decision-making. It is already well established that these sectors, especially the government sector and watch-dog non-profits, influence the actions of for-profit organizations. Establishing how well-intentioned actions from the other sectors have influenced for-profit actions could greatly improve explanations of how to increase gender and race equality, social mobilization, and environmental 
responsibility. Thus, it would improve organizational theory in general to study the intentions and actions of religious organizations.

\section{$\underline{\text { Limitations }}$}

One limitation of the dissertation is the wording of the question for the dependent variable about parish disabilities accommodations, "Does the parish offer accommodations to include those with disabilities for sacramental preparation such as RCIA, First Reconciliation, First Communion, and Confirmation?" The question is ambiguous as far as the types of accommodations the parish uses to include people with disabilities in the initiation sacraments and allows the pastor to define "accommodations". The question uses a four-point scale to allow the pastor to indicate how sophisticated the accommodations are, which helps to define the degree of accommodation the parish provides. However, there is also a narrow scope of preparations to accommodate for many parishes because it mainly covers the preparation classes and physically getting to the sanctuary (where many initiation sacraments occur). Therefore, the question is not completely ambiguous but still enables the pastor some amount of interpretation.

A limitation that is related to the point above is that the dissertation covers all disabilities together and only applies to the sacraments. As stated in the Introduction, the definition of disabilities is broad and covers many different types of disabilities, which have a wide variety of accommodations. This affects the disablement process that Verbrugge and Jette (1994) discuss because the way that people's lives are affected by their disability varies so widely. While the results and discussion are a good framework 
for how dioceses and parishes inquire about how to practically implement accommodations, it may vary by type of disability.

The results also only apply to disability accommodations as they apply to the sacraments. This could include access for people with physical disabilities, but it does not necessarily since some preparatory work for the sacraments is mainly mental; as stated above, it depends on how the priest interpreted the question. There are also more coercive measures that affect the physical structure of a parish. If a parish rents space to an outside organization for any reason, then the space that is rented must be compliant with the ADA. This does not affect the sacraments directly, but it does affect access to the parish. However, the dissertation does not measure any of the coercive influences that affect that decision-making because they do not pertain directly to the sacraments.

Another limitation is that the dependent variable, if the parish offers accommodations for marriage preparation, has more than $10 \%$ of the cases missing. For a regression model to be generalizable the sample needs to be randomly selected from the population. When a lot of participants do not answer a certain question but respond to the rest of the survey (partial nonresponse), it biases the sample toward people who want or are able to answer that question. Generally, best practices suggest that beyond $10 \%$ of a partial nonresponse does not bias the results (Smith 1983). The dependent variable for Table 4.3 , stated above, has a partial nonresponse of $12 \%$, which is past the generally accepted level and means that the model is not representative. Therefore, the models that use this dependent variable are only used to bolster arguments made from the models in Table 4.2. Although the models are not completely skewed and offer some insight into what predicts a parish adoption of accommodations for sacramental preparation, the 
variables that do not correspond with Table 4.2 are not used in this dissertation as they require further research to determine their relationship to sacramental accommodations for people with disabilities.

Another limitation of the dissertation is the binary coding of the sacramental norms: "yes" indicates that the sacramental norm addresses disabilities issues in some way and "no" indicates that there are no norms or the norms do not address disabilities issues. Collectively, the sacramental norms pertain to a large variety of disabilities, but individually could only address one issue. Some of the sacramental norms pertain solely to chronic illnesses, such as Celiacs disease while others pertain to a broad range of disabilities such as physical and/or intellectual disabilities. The only commonality between all the sacramental norms that are coded as "yes" is that the norms address disabilities issues in some way. There is too much variation in the sacramental norms to code them according to subject, which is why they is coded as a binary variable. Therefore, the sacramental norms may not address all the sacraments of initiation or marriage preparation. The other limitation with a binary variable is that "no" indicates the diocese either does not have sacramental norms or that the sacramental norms do not include disabilities issues. This means that the dissertation is a poor measure of the power of sacramental norms in general. However, the goal of the dissertation is not to address the power of the sacramental norms but address their presence. Therefore, it does not take away from the overall argument, but it is a limitation for generalizability. 


\section{Diagnostics}

\section{All Models}

Variance Inflation Factors (VIF) are run in the model to check for multicollinearity. Independent variables can explain the same variation as other independent variables, and this is normal. If more than one variable explains too much of the same variation, then the odds ratios will decrease, and the p-value will increase for all variables involved (Fox 1991). This creates a skewed representation of which factors impact the dependent variable. If multicollinearity is not tested for, then key variables could be undetected because the odds ratios and p-values are not significant or substantial. Multicollinearity was tested using the VIF test, the results for the test are in Appendix II. The results of the VIF test show that none of the variables are above five, which is the standard threshold for concern. One variable in the diocesan model is close to five, number of elderly in the diocese has a VIF score of 4.12. This is probably because many other variables give an approximate measure for how many people are in the diocese. When the variable was omitted from the analysis the other variables did not change substantially, so it remains in the final analysis.

The next test that is measured in all the models measured for non-linearity. Regression analyses measure the best line to fit the scatterplot of points that occur in the data. When an independent variable does not have a linear relationship with the dependent variable (for example, the independent variable increases and decreases as the dependent variable consistently increases) then the odds ratio measures the best line for the data, which often does not fit as well and negatively affects the odds ratio and p-value (Fox 1991). The only variables that are significantly non-linear are in the diocesan 
model: number of parishes in the diocese and number of people in the diocese with a disability. When number of parishes in the diocese is squared it decreased the AIC score and makes the model fit better, therefore it is kept in the model. There are no changes in number of people in the diocese with a disability that made the model better, therefore the variable remains unchanged in the models.

A dependent variable test that is run on all the models is the empty cells check. When there are too many low cell counts in a model it inflates the standard errors, which affects the p-value (Houbiers 2004). A standard error value above 2.0 is considered problematic. The only time when this is a problem is for the variable if someone in the diocesan office has a disability in the diocesan model. However, the standard error drops below 2.0 in the best-fitting models, which are the main models discussed, therefore the variable is not dropped. It should also be noted that the p-value is not used in the diocesan models because they measure a population.

\section{Parish Models}

The first test that is only run on the parish models is for outliers. When certain cases significantly set themselves apart from the analysis these are called outliers. This happens when one or a few cases has/have an unusual relationship with the dependent variable and does not accurately represent the rest of the cases (Fox 1991). If outliers separate themselves enough it can skew the regression line to fit the outliers rather than the majority of the points, which affects the regression line and the p-value. To measure for outliers the Studentized Pearson Residual is used. In this test anything that measures higher than an absolute value of 3.0 is an outlier, the tests are shown in Appendix II. To 
measure this accurately using STATA the dependent variables were converted into binary variables, or different "cut points" similar to the intercepts in the regression tables. Therefore, more than one maximum and minimum are included for all the models. All the models include some outliers except some of the models for marriage preparation. However, when the outliers are excluded from the model none of the models change, therefore the outliers are always retained.

The test for the dependent variables in the parish models measures if the binary models that comprise the dependent variable are parallel, which is an assumption of ordered logistic regression. The assumption for ordered logistic regression is that the different binary models that it runs in conjunction are parallel, which is why it is able to define the relationship with one number (O'Connell 2006a). This means that if the binary models were run separately then they would all have approximately the same results. To test this assumption, I use the Brant test, shown in Appendix II. The Brant test measures this assumption and if the p-value is significant $(>.05)$ then the assumption is not valid. A good standard measure for this is if a majority of variables are not significant then the model is valid. As shown in Appendix II, only one variable in Table 4.2 is significant (if the parish partners with a Catholic Organization) and no variables from Table 4.3 are significant. Therefore, the parallel lines test is not violated in any of the models. I also run generalized estimating equations (GEE) to test the cultural factors in parishes' diocese. The ordered logistic regression directly analyses the relationship of the independent variables to the dependent variable but does not measure any of the underlying cultural factors. The generalized estimating equation (GEE) measures the relationship between the independent variables and dependent variables and measures 
some of the underlying cultural factors in the mathematical equation. There is more to a diocesan culture than simply the sacramental norms and the GEE can measure some of that variation. This means that the GEE could offer more insight into and beyond the effects of the independent variables. The reason that the GEE is not used as the primary regression model for this dissertation is because the validity of the current GEE models that are compatible with ordered logistic regression are debated (Stokes et al. 2012). Additionally, the AIC test that is used for the dissertation, which allows the researcher to compare model fit between models, does not work with the GEE. The AIC is vital to the intended purpose of the dissertation. Considering both of these reasons, the researcher decided to use the GEE as a secondary regression model to test if there are any cultural factors in dioceses that the ordered logistic regression does not measure, but keep the ordered logistic regression as the main model. Since the GEE only works with binary logistic regression the researcher split the dependent variables for parishes into binary variables and ran the GEE on each split, the results are shown in Appendix II. The results of the GEE are largely the same as the ordered logistical regression, which confirms the findings of this dissertation. The isomorphic variables remain significant in all the Tables although in certain models they may not be significant, such as if the parish partners with a Catholic organization. This confirms the importance of the isomorphic variables. Neither of the niche variables, number in city with a disability or parish founded with a disability accommodation, are significant in Table 7.13. Parish founded with a disability accommodation is significant in Table 7.14 although number in city with a disability is not. In the marriage preparation models none of the niche variables are significant in any of the models. This confirms that the niche variables are not as 
important as the isomorphic variables because the isomorphic variables remain significant throughout the models. The variable, if the parish has someone on staff with the responsibility to accommodate people with disabilities, is not significant in Table 7.13 although it is significant in Table 7.14, which confirms that the variable is important. The same pattern is seen with the marriage preparation models. Additionally, if the parish runs a school is only significant in Table 7.25 , which confirms the need for more research to determine the significance of Catholic schools on disability accommodations.

\section{Future Research}

In this dissertation, I reviewed factors that are associated with parishes implementing accommodations for people with disabilities, and the results show that pastors are largely responsible for making decisions. However, it is unknown how pastors decide whether to implement accommodations. This goes back to DiMaggio's (1991) original work on how organizations establish norms. This line of questioning would benefit greatly from a qualitative or mixed methods analysis of how parishes accommodate people with disabilities. A strength of quantitative data is to create a finely tuned instrument to ask a specific question and to distribute the instrument to many people (Brannen 1992). One of the strengths of qualitative data is to be flexible with data collection and allow the respondent to give an open-ended interpretation of how they perceive events. I provide key elements that affect a pastor's decision, but not how those elements fit together to become a decision. The CARA client report that was written from the data this dissertation uses indicates that there were many open-ended responses in which pastors provide unexpected answers as to how they accommodate people with 
disabilities (Holland and Gaunt 2016a). Therefore, a qualitative analysis that is open to probe those reasons would better analyze the pastor's decision-making process.

The reason this dissertation is able to be constructed as a quasi-experiment is because of the unique situation of the Catholic Church; this limits the generalizability of the research but also opens a new path for future research. Dioceses and parishes are exempt from two separate sets of coercive influences: coercion from outside the Church (ADA) and influences from inside the church (the Vatican). This severely limits the generalizability of the research in this dissertation because very few organizations have both of those exemptions. The organizations that are directly comparable would be evangelical churches and local private clubs since those organizations are not subject to the ADA and have no umbrella organization that governs them (adainfo.org 2017). The reason that I add this limitation in the "Future Research" section is because the organizations that I classify below require future research to determine how the results of the dissertation apply to them. All religious organizations are exempt from the ADA, although more research needs to be conducted on the coercive pressures their respective umbrella organizations exert and how it compares with pressures from dioceses/Vatican. Religious organizations are not the only organizations that are exempt from the ADA and more research also needs to be done for non-religious organizations that are exempt but are part of a larger umbrella organization. The reason that I mention these separately is because state, county, or city governments may have their own regulations that govern these entities. Unlike religious organizations, these organizations cannot claim that a government is overstepping its authority through the separation of church and state, therefore a government could impose more authority than with religious 
organizations. Research has been conducted on organizations that need to comply with the ADA, but the umbrella organization has not provided any clarification on how the organization will implement the accommodations. I argue this is the same as an organization that is not part of an umbrella organization because there is no clarification about how to practically implement disability accommodations. Scheid and Suchman (2001) articulate how organizations were unsure of how to accommodate people with disabilities and the uncertainty caused more stress than the accommodations process. This research can be used to test how organizations address the uncertainty of disabilities accommodations once they decide to accommodate people with disabilities since I posit that most of the model pertains to how the church decides to implement accommodations. Future research should explore the coercive forces that impact the practical implementation of accommodating people with disabilities.

As stated in the "Limitations" section, this dissertation does not cover any specific disability, but covers all disabilities together; future research needs to be done to address how dioceses and parishes accommodate specific disabilities and how that process differs from disabilities overall. While pastors could have responded that their parish accommodates any type of disability, the types of disabilities that they would most likely accommodate for the sacraments listed would be sensory or intellectual. Preparation for the initiation sacraments and marriage require that people learn about the Catholic Church and those types of disabilities are most likely to be a barrier to learning in a class setting. More research would need to be done to determine which types of disabilities parishes accommodate during those sacraments. I looked up all the dioceses to determine which types of disabilities they refer to in the sacramental norms and the types of 
recommendations vary widely (from only listing recommendations for Celiac disease to listing a recommendation for every type of disability). Future research could categorize these types of recommendations to determine their effect on specific sacraments and other parish accommodations.

To address changes in health concerns in the Church and U.S. more broadly, this research should be replicated in the future to ascertain how these changes have impacted disabilities accommodations. As discussed previously, the results of the dissertation could be impacted by the fact that the Pope's critique of the way the Church accommodates people with disabilities was given in 2013 and the surveys used in this dissertation were conducted in 2015 and 2016. Bishops/priests may not have been given enough time to react to negative feedback. This suggests that the study should be replicated in the future when the Church has time to implement disability accommodations. Additionally, the coronavirus pandemic has changed the way many people perceive disabilities accommodations. The United States Conference of Catholic Bishops issued a statement urging bishops to consider creating guidelines for parishes to implement the sacraments in a socially distant environment and that people did not have to attend mass if they are sick or are immunocompromised (Noguchi and Guilarte 2020). This has created a new situation in which people with disabilities have become a major point of discussion because of a pandemic. The new guidelines along with the Pope's negative feedback will hopefully spur dioceses and parishes to consider additional accommodations for people with disabilities. All of this suggests that accommodations will improve for people with disabilities in the future. 
There is no known research that focuses on the role of isomorphism in the religious sector (a cursory analysis is provided by Nelson (1993), but they did not focus on isomorphism), which this dissertation addresses, although more information would be helpful about non-profit and religious organizational connections to add to the impact of normative isomorphism. This would benefit from an analysis using network theory (Burt 2005) to examine how the network connections impact policies in both sectors. Most of the current normative isomorphism literature analyzes organizational collaborations that are focused around money. This is useful in the for-profit and public sectors, but also leaves a gap in the literature about how organizations interact to address a need in the community as this is mainly a goal for non-profit and religious organizations. In this dissertation, I show that other organizations impact the accommodations that parishes use for people with disabilities, but the specifics are unclear since the goal of the collaboration is to benefit the public good rather than financial gain. Further research would provide insight into how the two organizations impact each other and provide further evidence for the different types of impacts for normative isomorphism.

Another area of study could be additional isomorphism and niche studies that analyze the religious or nonprofit sectors. This dissertation mentions how isomorphism and niche theory do not explain the findings of the dissertation well because both focus on the for-profit and public sectors almost exclusively. However, other organizational theories explain the results better, which suggests these theories are better suited to analyze the non-profit and public sectors. Further isomorphism and niche research may provide added insights into the theories which would greatly increase the ability of the theories to explain different types of organizations. 
The final area of study that I mention in this dissertation that would mainly benefit the religious organizational research, is how parishioners view accommodations for people with disabilities or lack thereof. As shown in the literature review, the hierarchical power of the Catholic Church can be challenged from parishioners to enact change. This is shown in Gutierrez, Howard-Grenville and Scully (2010) when they analyzed how Voice of the Faithful challenged bishops to include greater representation of laypeople in church decision-making. This type of analysis is missing from the Catholic perspective regarding disability accommodations. The analysis would provide insight into people's perceptions of the quality of accommodations the Church currently provides and to what degree further accommodations are desired. This could provide insight into the degree to which the Church uses sacramental norms as a guideline rather than a rule, if the Church lacks the resources to implement accommodations for people, and how much of a priority the Church regards disabilities accommodations. Analyzing this information would make the degree to which a bishop is able to coerce pastors versus the autonomy of the pastor clearer.

\section{$\underline{\text { Recommendations }}$}

This section includes two recommendations based on the results of the dissertation. The first recommendation is for priests and bishops to prioritize hiring someone with a disability or have them on a committee so that they regularly interact with that person. A bishop/priest's interaction with someone with a disability is one of the strongest factors in all the models and I predict acts as a catalyst for change because they challenge the sensemaking of the bishop/priest. Therefore, if the bishop/priest 
interacts with someone with a disability then they are spurred to start the accommodations process. This point is also supported by Tilly's (1998) research that creating equality within organizations entails listening to people that are being discriminated against in order to create a solution, unless the solution may further the power of the organization. The people in the parish/diocese with disabilities should have a voice in which accommodations are implemented to implement which acknowledges the disablement process and take the whole person into account (Verbrugge and Jette 1994). Additionally, this means the Catholic Church will not waste resources on accommodations that people do not need and implement accommodations that will acknowledge the personhood of people with disabilities.

A second recommendation is to seek out other organizations that provide accommodations for people with disabilities and try to generate ideas for disabilities accommodations the parish/diocese can provide. These do not have to be formal associations but can simply include a call to a parish that is known for disabilities accommodations. This is consistent with the networking literature which articulates how networks are beneficial for novel ideas (Powell 1990). Learning about disability accommodations and implementing an accommodation provides a more welcoming atmosphere for people with disabilities. This can encourage people with disabilities to attend the sacraments and other church events, which increases the likelihood that the bishop/priest interacts with someone with a disability and engages the bishop/priest in the disablement process out of which discussions about accommodations can arise organically while taking the disablement process into consideration. 


\section{REFERENCES}

Americans with Disabilities Act (1990).

1991. Catholic Encyclopedia. Huntington, IN: Our Sunday Visitor.

1994. Catechism of the Catholic Church. New York, NY: Catholic Book Publishing Co.

. 2018. "Faith and Disability Inclusion Survey." Vol. 2020. Rockville, MD: RespectAbility.

2019, "Disability Employment Legislation", Washington, D.C. Retrieved 9/12/2019, 2019.

2020, "21st Century Catholic Evangelization", Washington D.C.: National Conference for Catechetical Leadership. Retrieved 4/18/2020, 2020 (21stcenturycatholicevangelization.org ).

adainfo.org. 2017, "Religious Organizations and Private Clubs under the Ada", Rockville, MD: Mid-Atlantic ADA Center. Retrieved 7/6/2020, 2020.

Akaliyski, Plamen. 2019. "United in Diversity? The Convergence of Cultural Values among Eu Member States and Candidates." European Journal of Political Research 58(2):388-411. doi: 10.1111/1475-6765.12285.

Ali, Waris and Jedrzej George Frynas. 2018. "The Role of Normative Csr-Promoting Institutions in Stimulating Csr Disclosures in Developing Countries." Corporate Social Responsibility and Environmental Management 25(4):373-90. doi: 10.1002/csr.1466.

Amor-Esteban, Víctor, Isabel-María García-Sánchez and Mª-Purificación GalindoVillardón. 2018. "Analysing the Effect of Legal System on Corporate Social Responsibility (Csr) at the Country Level, from a Multivariate Perspective." Social Indicators Research : An International and Interdisciplinary Journal for Quality-of-Life Measurement 140(1):435-52. doi: 10.1007/s11205-017-1782-2.

Arvidson, Malin. 2018. "Change and Tensions in Non-Profit Organizations: Beyond the Isomorphism Trajectory." VOLUNTAS: International Journal of Voluntary and Nonprofit Organizations : Official journal of the International Society for ThirdSector Research 29(5):898-910. doi: 10.1007/s11266-018-0021-z. 
Aurini, Janice. 2006. "Crafting Legitimation Projects: An Institutional Analysis of Private Education Businesses." Sociological Forum 21(1):83-111. doi: 10.1007/s11206006-9004-8.

Barroso, Alicia and Marco S. Giarratana. 2013. "Product Proliferation Strategies and Firm Performance: The Moderating Role of Product Space Complexity." Strategic Management Journal 34(12):1435-52.

Bartunek, Jean M. 1984. "Changing Interpretive Schemes and Organizational Restructuring: The Example of a Religious Order." Administrative Science Quarterly 29(3):355-72. doi: 10.2307/2393029.

Beckert, Jens. 2010. "Institional Isomorphism Revisited: Convergence and Divergence in Institutional Change." Sogiological Theory 28(2):150-66.

Bishops, United States Conference of Catholic. 2019, "Bishops and Dioceses", Washington, D.C. Retrieved 7/18/19.

Brannen, Julia. 1992. "Combining Qualitative and Quantitative Approaches: An Overview." Pp. 3-38 in Mixing Methods: Qualitative and Quantitative Research, edited by J. Brannen. Brookfield, VT: Ashgate Publishing Company.

Bureau, U.S. Census. 2017, "How Disability Data Are Collected from the American Community Survey". Retrieved 1/15/2020, 2020 (https://www.census.gov/topics/health/disability/guidance/data-collectionacs.html).

Bureau, United States Census. 2014. "American Community Survey Design and Methodology (January 2014) Chapter 4: Sample Design and Selection." Vol. Washington, D.C.: United States Census Bureau.

Bureau, United States Census. 2019, "American Community Survey (Acs)", Washington, DC. Retrieved 7/16/19.

Burnham, Kenneth P., David R. Anderson and Kathryn P. Huyvaert. 2011. "Aic Model Selection and Multimodel Inference in Behavioral Ecology: Some Background, Observations, and Comparisons." Behavioral Ecology and Sociobiology 65(1):2335 .

Burruss, George W. and Matthew J. Giblin. 2014. "Modeling Isomorphism on Policing Innovation: The Role of Institutional Pressures in Adopting Community-Oriented Policing." Crime and Delinquency 60(3):331-55.

Burt, Ronald S. 2005. Brokerage and Closure: An Introduction to Social Capital. New York, NY: Oxford University Press. 
Campbell-Reed, Eileen. 2017, "State of Clergywomen in the U.S.: A Statistical Update", Nashville, TN. Retrieved 9/19/2019, 2019 (https://eileencampbellreed.org/stateof-clergy/).

Carey, Raymond C. 1972. "Correlates of Satisfaction in the Priesthood." Administrative Science Quarterly 17(2):185-95. doi: 10.2307/2393953.

Carroll, Glenn R. 1985. "Concentration and Specialization- Dynamics of Niche Width Populations of Organizations." American Journal of Sociology 90(6):1262-83.

Carroll, Glenn R. and Michael T. Hannan. 1989. "Density Dependence in the Evolution of Populations of Newspaper Organizations." American Sociological Review 54(4):524-41.

Chancellor. 2019. "Interviewer." Louisville, KY, edited by J. Holland.

Clarke, Lee Ben. 1999. Mission Improbable : Using Fantasy Documents to Tame Disaster. Chicago: University of Chicago Press.

Covey, Herbert C. 2005. "Western Christianity's Two Historical Treatments of People with Disabilities or Mental Illness." The Social Science Journal 42(1):107-14. doi: http://dx.doi.org/10.1016/j.soscij.2004.11.009.

Croucher, Gwilym and Peter Woelert. 2016. "Institutional Isomorphism and the Creation of the Unified National System of Higher Education in Australia: An Empirical Analysis." Higher Education (00181560) 71(4):439-53. doi: 10.1007/s10734-0159914-6.

CRUX. 2018. "German Bishops Turn Down Pope's Translation Change to Lord's Prayer." CRUX. Retrieved 27 January, 2018.

Dalton, Melville. 1959. Men Who Manage: Fusions of Feeling and Theory in Administration. New York, NY: John Wiley \& Sons.

Darko, Nicholas. 2013. "Change in the Context of Church Culture: Towards a Conceptual Framework in Africa." Organization Development Journal 31(4):47-61.

Data, Homeland Infrastructure Foundation-Level. 2018, "About Hifld", Reston, VA: Department of Homeland Security. Retrieved 8/7/2019.

Davis, Gerald F. 1991. "Agents without Principles? The Spread of the Poison Pill through the Intercorporate Network." Administrative Science Quarterly 36(4):583.

De Freitas, Carlos Alberto Sampaio and Tomás de Aquino Guimarães. 2007.

"Isomorphism, Institutionalization and Legitimacy: Operational Auditing at the Court of Auditors." RAC - Revista de Administração Contemporânea 11:151-73. 
Dengah, H. J. François. 2017. "Religion as Cultural Models: Developing an Emic Measure of Religiosity." Journal for the Scientific Study of Religion 56(1):104-25. doi: doi:10.1111/jssr.12313.

Dicen, Karl Basil, Chachaya Yodsuwan, Ken Butcher and Nantaporn Mingkwan. 2019. "The Institutional Context for Experiential Learning Investment in Hospitality Education: A Case Study from Thailand." Pp. 143-60 in Tourism Education and Asia, Perspectives on Asian Tourism 2509-4211: Singapore : Springer Singapore : Springer.

Díez-Martín, Emilio, Emilio Díez-de-Castro and Adolfo Vázquez-Sánchez. 2018. "Refocusing Isomorphism to Explain Organizational Legitimacy: A New Approach." Pp. 23-43 in Organizational Legitimacy : Challenges and Opportunities for Businesses and Institutions: Cham : Springer International Publishing : Springer.

DiMaggio, Paul. 1991. "Constructing an Organizational Field as a Professional Project: U.S. Art Museums, 1920-1940." New institutionalism in organizational analysis / edited by Walter W. Powell and Paul J. DiMaggio.

DiMaggio, Paul J. and Walter W. Powell. 1983. "The Iron Cage Revisited: Institutional Isomorphism and Collective Rationality in Organizational Fields." American Sociological Review 48(2):147-60.

Dingle, Shannon. 2018. "Resisting Ableism in the American Church." Sojourners.

Dobbin, Frank and Erin L. Kelly. 2007. "How to Stop Harassment: Professional Construction of Legal Compliance in Organizations." American Journal of Sociology 112(4):1203-43.

Dougherty, Kevin. 2017. "American Values, Mental Health, and Using Technology in the Age of Trump: Findings from the Baylor Religion Survey, Wave 5." Vol. Baylor Religion Survey. Waco, TX: Baylor University.

Dougherty, Kevin D. and Mark T. Mulder. 2009. "Congregational Responses to Growing Urban Diversity in a White Ethnic Denomination." Social Problems 56(2):335-56.

Dutta, Koushik. 2016. "Dynamic Isomorphism and Decision Maker Attributes." Systemic Practice \& Action Research 29(4):355-77. doi: 10.1007/s11213-016-9369-4.

Extension, Catholic. 2019, "Mission Dioceses": Catholic Extension. Retrieved 5/8/2019, 2019 (https://www.catholicextension.org/mission-dioceses).

Fennell, Mary L. and Jeffrey A. Alexander. 1987. "Organizational Boundary Spanning in Institutionalized Environments." ACADEMY OF MANAGEMENT JOURNAL 30(3):456-76. 
Fichter, Stephen J., Thomas P. Gaunt, Catherine Hoegeman and Paul M. Perl. 2019. "Catholic Bishops in the United States : Church Leadership in the Third Millennium." New York, NY: Oxford University Press. Retrieved. (http://search.ebscohost.com/login.aspx?direct=true \&scope=site \&db=nlebk\&db= $\underline{\text { nlabk\&AN }=1968617}$

http://dx.doi.org/10.1093/oso/9780190920289.001.0001

http://proxy.library.carleton.ca/login?url=http://dx.doi.org/10.1093/oso/9780190920289.0 $\underline{01.0001}$

http://www.library.yorku.ca/e/resolver/id/287745842).

Fox, John. 1991. Regression Diagnostics, Edited by M. S. Lewis-Beck. Newbury Park, California: Sage Publications.

Freeman, J. and M. T. Hannan. 1983. "Niche Width and the Dynamics of Organizational Populations." American Journal of Sociology 88(6):1116-45.

Frumkin, Peter and Joseph Galaskiewicz. 2004. "Institutional Isomorphism and Public Sector Organizations." Journal of Public Administration Research and Theory: $J$ PART 14(3):283-307.

Galaskiewicz, Joseph and Stanley Wasserman. 1989. "Mimetic Processes within an Interorganizational Field: An Empirical Test." Administrative Science Quarterly 34(3):454.

Gautier, Mary, Jonathon Holland and Connie Newman, eds. 2017. Catholic Ministry Formation Directory, Edited by M. Gautier. Washington, DC: Center for Applied Research in the Apostolate.

Gilmour, Peter. 1997. "Leadership and Religion in the 21 St Century." Journal of Leadership Studies 4(4):33.

Granovetter, Mark. 1985. "Economic Action and Social Structure: The Problem of Embeddedness." American Journal of Sociology 91(3):481-510.

Gransow, Bettina and Susanna Price. 2019. "Social Risk Management at Aiib - Chinese or International Characteristics?". Journal of Chinese Political Science 24(2):289311. doi: 10.1007/s11366-018-9553-8.

Greve, H. R. 2000. "Market Niche Entry Decisions: Competition, Learning, and Strategy in Tokyo Banking, 1894-1936." ACADEMY OF MANAGEMENT JOURNAL 43(5):816-36.

Greve, Henrich R. 2003. Organizational Learning from Performance Feedback: A Behavioral Perspective on Innovation and Change. Cambridge, UK: Cambridge University Press. 
Gunarathne, Nuwan and Ki-Hoon Lee. 2019. "Institutional Pressures and Corporate Environmental Management Maturity." Management of Environmental Quality: An International Journal 30(1):157-75. doi: 10.1108/MEQ-02-2018-0041.

Gutierrez, Betzaluz, Jennifer Howard-Grenville and Maureen A. Scully. 2010. "The Faithful Rise Up: Split Identification and an Unlikely Change Effort." The Academy of Management Journal 53(4):673-99.

Hannan, Michael T. and John Freeman. 1977. "The Population Ecology of Organizations." American Journal of Sociology 82(5):929-64. doi: $10.1086 / 226424$.

Hannan, Michael T. and John H. Freeman. 1989. Organizational Ecology. Cambridge, MA: Harvard University Press.

Haveman, Heather A. 1993. "Follow the Leader: Mimetic Isomorphism and Entry into New Markets." Administrative Science Quarterly 38(4):593.

Hearn, Adrian H. 2004. "Afro-Cuban Religions and Social Welfare: Consequences of Commercial Development in Havana." Human Organization 63(1):78-87. doi: http://dx.doi.org/10.17730/humo.63.1.glp3t7d3hcf6rbgv.

Holland, Jonathon and Thomas Gaunt. 2016a. "Meeting the Needs of Those with Disabilities in the Church: A Profile of How Parishes in the United States Accommodate People with Disabilities." Vol. Washington, DC: Center for Applied Research in the Apostolate.

Holland, Jonathon and Thomas Gaunt. 2016b. "Meeing the Needs of Those with Disabilities in the Church: A Profile of How Dioceses and Catholic Charities in the United States Accommodate People with Disabilities." Vol. Washington, DC: Center for Applied Research in the Apostolate.

Houbiers, Marianne. 2004. "Towards a Social Statistical Database and Unified Estimates at Statistics Netherlands." Journal of Official Statistics 20(1):55.

Hsu, Greta. 2006. "Jacks of All Trades and Masters of None: Audiences' Reactions to Spanning Genres in Feature Film Production." Administrative Science Quarterly 51(3):420-50.

Kallio, Tomi J. and Päivikki Kuoppakangas. 2013. "Bandwagoning Municipal Enterprises: Institutional Isomorphism and the Search for the Third Way." Policy Studies 34(1):19-35. doi: 10.1080/01442872.2012.731842.

Krause, Neal, Kenneth I. Pargament and Gail Ironson. 2017. "Spiritual Struggles and Health: Assessing the Influence of Socioeconomic Status." Journal for the Scientific Study of Religion 0(0). doi: doi:10.1111/jssr.12364. 
Langley, W. Mary and William M. Kahnweiler. 2003. "The Role of Pastoral Leadership in the Sociopolitically Active African American Church." Organization Development Journal 21(2):43.

Leadership, National Conference for Catechetical. 2020, "Organizations", Washington, DC. Retrieved 2/21/2020, 2020

(https://www.21stcenturycatholicevangelization.org/evangelizationorganizations.html).

Leiter, Jeffrey. 2005. "Structural Isomorphism in Australian Nonprofit Organizations." VOLUNTAS: International Journal of Voluntary and Nonprofit Organizations 16(1):1-32.

Lent, Monica, Alistair Anderson, Mohammad Sohail Yunis and Hina Hashim. 2019. "Understanding How Legitimacy Is Acquired among Informal Home-Based Pakistani Small Businesses." International Entrepreneurship and Management Journal 15(2):341-61. doi: 10.1007/s11365-019-00568-7.

Levitt, Barbara and Clifford Nass. 1989. "The Lid on the Garbage Can: Institutional Constraints on Decision Making in the Technical Core of College-Text Publishers." Administrative Science Quarterly 34(2):190.

Li, David C. 2018. "Do Managerial Ethics and Legal Education Influence Online Privacy Policies in Greater China?". Asian Journal of Business Ethics 7(2):117-36. doi: 10.1007/s13520-017-0080-z.

Lowery, David, Virginia Gray, Justin Kirkland and Jeffrey J. Harden. 2012. "Generalist Interest Organizations and Interest System Density: A Test of the Competitive Exclusion Hypothesis." Social Science Quarterly 93(1):21-41.

March, James G. and Herbert A. Simon. 1958. "Cognitive Limits on Rationality." Pp. 136-71 in Organizations. New York, NY: Wiley.

McCormack, Mark M. 2012. "Consulting Practice in the American Congregation: From Decline to Appreciative Inquiry." Organization Development Journal 30(4):7387.

McPherson, Miller. 1983. "An Ecology of Affiliation." American Sociological Review 48(4):519-32. doi: 10.2307/2117719.

Meyer, John W. and Brian Rowan. 1977. "Institutionalized Organizations: Formal Structure as Myth and Ceremony." American Journal of Sociology 83(2):340-63. doi: $10.1086 / 226550$.

Mizruchi, Mark S. and Lisa C. Fein. 1999. "The Social Construction of Organizational Knowledge: A Study of the Uses of Coercive, Mimetic, and Normative Isomorphism." Administrative Science Quarterly 44(4):653-83. 
Moreira-Almeida, Alexander, Francisco Lotufo Neto and G. Koenig Harold. 2006.

"Religiousness and Mental Health: A Review." Associação Brasileira de

Psiquiatria - ABP.

MUHSEN. 2020, "Volunteer Respite Program", Naperville, IL. Retrieved 2/17/2020, 2020.

Nelson, Reed E. 1993. "Authority, Organization, and Societal Context in Multinational Churches." Administrative Science Quarterly 38(4):653-82. doi:

$10.2307 / 2393340$.

Nie, Fanhao and Daniel V. A. Olson. 2016. "Demonic Influence: The Negative Mental Health Effects of Belief in Demons." Journal for the Scientific Study of Religion 55(3):498-515. doi: doi:10.1111/jssr.12287.

Nielsen, Kim E. 2012. A Disability History of the United States. Boston: Beacon Press.

Noguchi, Chieko and Miguel Guilarte. 2020, "Usccb Statements on Coronavirus (Covid19)", Washington, DC: United States Conference of Catholic Bishops. Retrieved 7/9/2020, 2020 (http://www.usccb.org/news/2020/20-45.cfm).

O'Connell. 2006a. Logistic Regression Models for Ordinal Response Variables, Vol. 146, Edited by T. F. Liao. Thousand Oaks, CA: Sage Publications.

O'Connell, Ann A. 2006b. Logistic Regression Models for Ordinal Response Variables. Thousand Oaks, CA: Sage.

Palmer, Donald. 2012. Normal Organizational Wrongdoing: A Critical Analysis of Theories of Misconduct in and by Organizations. New York, NY: Oxford University Press.

Pampel, Fred C. 2000. Logistic Regression: A Primer. Thousand Oaks, CA: Sage Publications.

Park, Susan. 2014. "Institutional Isomorphism and the Asian Development Bank's Accountability Mechanism: Something Old, Something New; Something Borrowed, Something Blue?". Pacific Review 27(2):217-39. doi: 10.1080/09512748.2014.882394.

Piazza, Alessandro and Julien Jourdan. 2018. "When the Dust Settles: The Consequences of Scandals for Organizational Competition." ACADEMY OF MANAGEMENT JOURNAL 61(1):165-90. doi: 10.5465/amj.2015.1325.

Podolny, Joel M., Toby E. Stuart and Michael T. Hannan. 1996. "Networks, Knowledge, and Niches: Competition in the Worldwide Semiconductor Industry, 1984-1991." American Journal of Sociology 102(3):659-89. 
Powell, Walter W. 1990. "Neither Market nor Hierarchy." Pp. 295-336 in Research in Organizational Behavior, Vol. 12, edited by B. Staw and L. L. Cummings. Greenwich, CT: JAI Press.

Priest, Diocesan. 2020. "Interview with a Diocesan Priest." in Diocese, edited by J. Holland.

Proeschold-Bell, Rae Jean, Ashley Eisenberg, Christopher Adams, Bruce Smith, Sara Legrand and Amber Wilk. 2015. "The Glory of God Is a Human Being Fully Alive: Predictors of Positive Versus Negative Mental Health among Clergy." Journal for the Scientific Study of Religion 54(4):702-21. doi: doi:10.1111/jssr.12234.

Puttick, Steven. 2017. "'You'll See That Everywhere: Institutional Isomorphism in Secondary School Subject Departments." School Leadership \& Management 37(1/2):61-79. doi: 10.1080/13632434.2017.1293633.

Radaelli, Claudio M. 2000. "Policy Transfer in a European Union: Institutional Isomorphism as a Source of Legitimacy." Governance 13(1):25.

Reimer, Sam. 2011. "Orthodoxy Niches: Diversity in Congregational Orthodoxy among Three Protestant Denominations in the United States." Journal for the Scientific Study of Religion 50(4):763-79.

RespectAbility. 2019, "Respectability: About Us", Rockville, MD. Retrieved February 17, 2020, 2020 (https://www.respectability.org/about-us/).

Roberts, Karlene H. 1990. "Some Characteristics of One Type of High Reliability Organization." Organization Science 1(2):160-76.

Rothstein, Laura and Julia Irzyk. 2017. Disabilities and the Law, Edited by L. Rothstein. Danvers, MA: Thomson Reuters.

Rothstein, Laura. 2018. "Interview." edited by J. Holland.

Scheid, Teresa L. and Mark C. Suchman. 2001. "Ritual Conformity to the Americans with Disabilities Act: Coercive and Normative Isomorphism." Pp. 105-40 in The Organizational Response to Social Problems.

Schneider, Benjamin. 1972. "Toward Specifying the Concept of Work Climate: A Study of Roman Catholic Diocesan Priests." Journal of Applied Psychology 56(6):44755.

Schroeder, Larry D., David L. Sjoquist and Paula E. Stephan. 2017. Understanding Regression Analysis: An Introductory Guide. Thousand Oaks, CA: Sage Publications. 
Silverman, Wiliam H. 1983. "Measuring Member Satisfaction with the Church." Journal of Applied Psychology 68(4):664-77.

Smith, Tom W. 1983. "The Hidden 25 Percent: An Analysis of Nonresponse on the 1980 General Social Survey." The Public Opinion Quarterly 47(3):386-404.

Sohn, Min-Woong. 2001. "Distance and Cosine Measures of Niche Overlap." Social Networks 23(2):141-65.

Stewart-Thomas, Michelle. 2010. "Gendered Congregations, Gendered Service: The Impact of Clergy Gender on Congregational Social Service Participation." Gender, Work \& Organization 17(4):406-32. doi: 10.1111/j.14680432.2009.00484.x.

Stokes, Maura E., Charles S. Davis, Gary G. Koch and Institute Statistical Analysis System. 2012. Categorical Data Analysis Using the Sas System. Cary, NC: SAS Inst.

Stone, Deborah. 2012. Policy Paradox: The Art of Political Decision Making. New York, NY: W. W. Norton \& Company, Inc. .

Sturges, Jane, Michael Clinton, Neil Conway and Alexandra Budjanovcanin. 2019. "I Know Where I'm Going: Sensemaking and the Emergence of Calling." Journal of Vocational Behavior. doi: https://doi.org/10.1016/j.jvb.2019.02.006.

Switzer, Jacqueline Vaughn. 2003. Disabled Rights : American Disability Policy and the Fight for Equality. Washington, D.C.: Georgetown University Press.

Szafran, Robert F. 1980. "The Effect of Executive and Professional Membership Values on the Timing and Influence of Structural Innovation in Religious Organizations." Sociology of Work and Occupations 7(2):188-209. doi: 10.1177/073088848000700203.

Szafran, Robert F. 1981. "Control Structures in Religious Organizations:Accounting for Organizational Patterns and Individual Perceptions." Sociology of Work and Occupations 8(3):327-52. doi: 10.1177/073088848100800303.

Taylor, Dennis and Latif Oylan. 2008. "Environmental Reporting by City Governments in Australia: Influences of Isomorphism, Decoupling and Management Dominant Logic." World of Accounting Science 10(3):7-21.

Tilly, Charles. 1998. Durable Inequality. Berkeley, CA: University of California Press.

Townsend, Stephanie M. and Rebecca Campbell. 2007. "Homogeneity in CommunityBased Rape Prevention Programs: Empirical Evidence of Institutional Isomorphism." Journal of Community Psychology 35(3):367-82. 
Usher, J. M. 1999. "Specialists, Generalists, and Polymorphs: Spatial Advantages of Multiunit Organization in a Single Industry." Academy of Management Review 24(1):143-50.

Vallier, Ivan. 1971. "The Roman Catholic Church: A Transnational Actor." International Organization 25(3):479. doi: 10.1017/S0020818300026278.

Verbrugge, Lois M. and Allen M. Jette. 1994. "The Disablement Process." Social science \& medicine (1982) 38(1):1-14.

Weber, Max. 1978. Economy and Society. Berkeley, CA: University of California Press.

Weick, Karl, Kathlene M. Sutcliffe and David Obstfeld. 2005. "Organizing and the Process of Sensemaking." Organization Science 16(4):409-21.

Weick, Karl E. 1976. "Educational Organizations as Loosely Coupled Systems." Administrative Science Quarterly 21(1):1-19.

Woelert, Peter and Gwilym Croucher. 2018. "The Multiple Dynamics of Isomorphic Change: Australian Law Schools 1987-1996." Minerva : A Review of Science, Learning and Policy 56(4):479-503. doi: 10.1007/s11024-018-9350-8.

Wooden, Cindy. 2016. "Disabled People Must Not Be Hidden Away, Says Pope Francis." in Catholic Herald. London, England: Catholic Herald.

Yang, Yefei, Antonio K. W. Lau, Peter K. C. Lee, Andy C. L. Yeung and T. C. Edwin Cheng. 2019. "Efficacy of China's Strategic Environmental Management in Its Institutional Environment." International Journal of Operations \& Production Management 39(1):138-63. doi: 10.1108/IJOPM-11-2017-0695.

Yorozu, Chie. 2017. "New Institutional Entrepreneurship and a Celebrity Ceo: The Role of Institutional Actors in Japan." Journal of Organisational Transformation \& Social Change 14(2):165-85. doi: 10.1080/14779633.2017.1341763.

Zech, Charles E., Mary L. Gautier, Mark M. Gray, Jonathon L. Wiggins and Thomas P. Gaunt. 2017. Catholic Parishes of the 21st Century. New York, NY: Oxford University Press.

Zou, Hailiang, Xuemei Xie, Guoyou Qi and Mengyu Yang. 2019. "The Heterogeneous Rrelationship between Board Social Ties and Corporate Environmental Responsibility in an Emerging Economy." Business Strategy and the Environment 28(1):40-52. doi: 10.1002/bse.2180.

Zucker, Lynne G. 1977. "The Role of Institutionalization in Cultural Persistence." American Sociological Review 42(5):726-43. 


\section{APPENDIX I: SUMMARY TABLES}

The numbers in parentheses refers to which data source the variable is obtained from.

\begin{tabular}{|l|l|l|}
\hline \multicolumn{2}{|c|}{ Table 6.1: Methods Summary Table: Isomorphism } \\
\hline & \multicolumn{1}{|c|}{ Question 1 } & \multicolumn{1}{c|}{ Question 2 } \\
\hline Data sources: & $\begin{array}{l}\text { CARA Diocesan Survey-1 } \\
\text { Bishops Survey-2 } \\
\text { ACS-3 }\end{array}$ & $\begin{array}{l}\text { CARA Diocesan Survey-1 } \\
\text { CARA Parish Survey-4 } \\
\text { Internet Search-5 }\end{array}$ \\
\hline Dependent Variable(s): & Sacramental Norms (1) & $\begin{array}{l}\text { Sacramental Prep (4) } \\
\text { Marriage Prep (4) }\end{array}$ \\
\hline Independent Variables: & $\begin{array}{l}\text { Mimetic } \\
\text { Region (1) } \\
\text { Neighbor (1) } \\
\text { Normative } \\
\text { Catholic University (2) } \\
\text { Gregorian University (2) } \\
\text { Disability Organization (1) } \\
\text { Catholic Organization (1) } \\
\text { Non-Catholic Organization (1) } \\
\text { Personnel (1) }\end{array}$ & $\begin{array}{l}\text { Mimetic } \\
\text { City (5) } \\
\text { Diocese (5) } \\
\text { Normative } \\
\text { Catholic Organization (4) } \\
\text { Non-Catholic Organization (4) } \\
\text { Council (4) } \\
\text { Coercive } \\
\text { Diocese Policy (1) }\end{array}$ \\
\hline Control Variables: & $\begin{array}{l}\text { Population (1) } \\
\text { Staff (1) } \\
\text { Elderly (3) } \\
\text { School (1) } \\
\text { Mission (1) }\end{array}$ & $\begin{array}{l}\text { Household (4) } \\
\text { Staff (4) } \\
\text { Location (4) } \\
\text { Elderly (4) } \\
\text { School (4) }\end{array}$ \\
\hline Diocese & Parish \\
\hline Level of Measurement: & Ordered Logistic Regression \\
\hline Statistical Method: & Binary Logistic Regression &
\end{tabular}




\begin{tabular}{|c|c|c|}
\hline \multicolumn{3}{|c|}{ Table 6.2: Methods Summary Table: Isomorphism and Ecology } \\
\hline & Question 3- Part 1 & Question 3- Part 2 \\
\hline Data sources: & $\begin{array}{l}\text { CARA Diocesan Survey-1 } \\
\text { Bishops Survey-2 } \\
\text { ACS-3 } \\
\text { Internet Search-5 } \\
\text { NCSL.org-6 } \\
\text { Census Bureau- } 7\end{array}$ & $\begin{array}{l}\text { CARA Diocesan Survey-1 } \\
\text { ACS-3 } \\
\text { CARA Parish Survey-4 } \\
\text { Internet Search-5 } \\
\text { Census Bureau- } 7 \\
\text { https://hifld-geoplatform.com- } 8\end{array}$ \\
\hline Dependent Variable(s): & Sacramental Norms (1) & $\begin{array}{l}\text { Sacramental Prep (4) } \\
\text { Marriage Prep (4) }\end{array}$ \\
\hline Independent Variables: & $\begin{array}{l}\text { Mimetic } \\
\text { Diocese (1) } \\
\text { Neighbor (1) } \\
\text { Normative } \\
\text { Disability Organization (1) } \\
\text { Catholic Organization (1) } \\
\text { Personnel (1) } \\
\text { Catholic University (2) } \\
\text { Gregorian University (2) } \\
\text { Niche } \\
\text { DCompetition (6) } \\
\text { Community (7) }\end{array}$ & $\begin{array}{l}\text { Mimetic } \\
\text { Diocese (4) } \\
\text { Neighbor (4) } \\
\text { Normative } \\
\text { Catholic Organization (4) } \\
\text { Non-Catholic Organization (4) } \\
\text { Personnel (4) } \\
\text { Coercive } \\
\text { Diocese Policy (1) } \\
\text { Niche } \\
\text { PCompetition (8) } \\
\text { Community (7) } \\
\text { Foundation (1) } \\
\end{array}$ \\
\hline Control Variables: & $\begin{array}{l}\text { Staff (1) } \\
\text { Elderly (3) } \\
\text { School (1) } \\
\text { Mission (1) }\end{array}$ & $\begin{array}{l}\text { Staff (4) } \\
\text { Location (4) } \\
\text { Elderly (4) } \\
\text { School (4) } \\
\end{array}$ \\
\hline Level of Measurement: & Diocese & Parish \\
\hline Statistical Method: & Binary Logistic Regression & Ordered Logistic Regression \\
\hline
\end{tabular}


APPENDIX II: DIAGNOSTICS

\section{Models 1.1 \& 1.2}

Table 7.1: Variance Intolerance Factors for Models 1.1 and 1.2

\begin{tabular}{|l|c|}
\hline Variable & Variance Inflation Factors \\
\hline Number of parishes in diocese & 2.97 \\
\hline Number of parishes in diocese, squared & 2.21 \\
\hline Number of elderly in diocese & 2.01 \\
\hline Regional dioceses with disability sacramental norm & 1.88 \\
\hline Mission diocese & 1.67 \\
\hline Neighboring diocese with disability sacramental norm & 1.62 \\
\hline Disability Partner Organization- Catholic organization & 1.39 \\
\hline Bishop's Seminary Background- Catholic University & 1.36 \\
\hline Has personnel with disability & 1.34 \\
\hline Bishop's Seminary Background- Gregorian University & 1.26 \\
\hline Diocese runs a school & 1.26 \\
\hline $\begin{array}{l}\text { Disability Partner Organization- Non-Catholic } \\
\text { organization }\end{array}$ & 1.20 \\
\hline
\end{tabular}

\section{Table 7.2: Box-Tidwell Test for Models 1.1 and 1.2}

\begin{tabular}{|l|c|c|}
\hline Variable & $\begin{array}{c}\text { Nonlinearity } \\
\text { Statistic }\end{array}$ & P-value \\
\hline Number of parishes in diocese & 2.467 & 0.116 \\
\hline $\begin{array}{l}\text { Neighboring diocese with disability sacramental } \\
\text { norm }\end{array}$ & 2.009 & 0.156 \\
\hline Number of parishes in diocese squared & 0.988 & 0.320 \\
\hline $\begin{array}{l}\text { Regional dioceses with disability sacramental } \\
\text { norm }\end{array}$ & 0.213 & 0.644 \\
\hline Number of elderly people in diocese & 0.005 & 0.942 \\
\hline
\end{tabular}




\section{Models 1.3 \& 1.4}

Table 7.3: Variance Intolerance Factors for Models 1.3 and 1.4

\begin{tabular}{|l|c|}
\hline Variable & Variance Inflation Factors \\
\hline Number of elderly in diocese & 4.12 \\
\hline Number of parishes in diocese & 3.09 \\
\hline Number in diocese with a disability & 2.70 \\
\hline Number of parishes in diocese squared & 2.25 \\
\hline Regional dioceses with disability sacramental norm & 1.95 \\
\hline Mission diocese & 1.73 \\
\hline Neighboring diocese with disability sacramental norm & 1.66 \\
\hline Disability Partner Organization- Catholic organization & 1.39 \\
\hline Bishop's Seminary Background- Catholic University & 1.37 \\
\hline Has personnel with disability & 1.34 \\
\hline Diocese runs a school & 1.28 \\
\hline Bishop's Seminary Background- Gregorian University & 1.26 \\
\hline $\begin{array}{l}\text { Disability Partner Organization- Non-Catholic } \\
\text { organization }\end{array}$ & 1.23 \\
\hline State disability law & 1.13 \\
\hline
\end{tabular}

Table 7.4: Box-Tidwell Test for Models 1.3 and 1.4

\begin{tabular}{|l|c|c|}
\hline Variable & $\begin{array}{c}\text { Nonlinearity } \\
\text { Statistic }\end{array}$ & P-value \\
\hline Number of parishes in diocese & 6.571 & $0.010^{*}$ \\
\hline Number in diocese with a disability & 5.969 & $0.015^{*}$ \\
\hline $\begin{array}{l}\text { Regional dioceses with disability sacramental } \\
\text { norm }\end{array}$ & 1.583 & 0.208 \\
\hline Number of parishes in diocese squared & 1.405 & 0.236 \\
\hline Number of elderly in diocese & 1.080 & 0.299 \\
\hline $\begin{array}{l}\text { Neighboring diocese with disability sacramental } \\
\text { norms }\end{array}$ & 0.057 & 0.811 \\
\hline
\end{tabular}

* Both of these values are below the 0.05 threshold, so the researcher added a squared variables to the equation to fix the issues, but the variables created problems in the model. The AIC was also worse, therefore the squared and cubed variables were left out of the model. 
Models 2.1 \& 2.2

Table 7.5: Variance Intolerance Factors for Models 2.1 and 2.2

\begin{tabular}{|l|c|}
\hline Variable & $\begin{array}{c}\text { Variance Inflation } \\
\text { Factors }\end{array}$ \\
\hline Parish Location- Rural & 1.94 \\
\hline Number of households in parish & 1.86 \\
\hline Parish Location- Suburban & 1.71 \\
\hline Parish runs a school & 1.32 \\
\hline Number of parish staff & 1.27 \\
\hline Disability Partner Organization- Catholic organization & 1.26 \\
\hline Disability Partner Organization- Non-Catholic organization & 1.18 \\
\hline Disability position & 1.14 \\
\hline $\begin{array}{l}\text { Other parish in same city known for disability } \\
\text { accommodations }\end{array}$ & 1.08 \\
\hline Parish committee member with a disability & 1.07 \\
\hline Parish's diocese has disability accommodation policy & 1.07 \\
\hline $\begin{array}{l}\text { Other parish in diocese known for disability } \\
\text { accommodation }\end{array}$ & 1.05 \\
\hline
\end{tabular}

Table 7.6: Box-Tidwell Test for Models 2.1 and 2.2

\begin{tabular}{|l|c|c|}
\hline Variable & Nonlinearity Statistic & P-value \\
\hline Number of households in parish & 2.765 & 0.096 \\
\hline Number of parish staff & 0.546 & 0.460 \\
\hline
\end{tabular}

Table 7.7: Studentized Pearson Residuals for Models 2.1 and 2.2

\begin{tabular}{|l|c|c|}
\hline Cut & \multicolumn{2}{|c|}{ Studentized Pearson Residual } \\
\hline Cut 1 between "Not at All"/ "Only a little" and "Somewhat" & Minimum & Maximum \\
\hline Cut 2 between "Somewhat" and "Very Much" & -9.92 & 0.94 \\
\hline
\end{tabular}


Table 7.8: Brant Test for Models 2.1 and 2.2

\begin{tabular}{|l|c|}
\hline Variable & P-value* \\
\hline Disability Partner Organization- Catholic organization & 0.03 \\
\hline $\begin{array}{l}\text { Other parish in diocese known for disability } \\
\text { accommodation }\end{array}$ & 0.06 \\
\hline Disability Partner Organization- Non-Catholic organization & 0.10 \\
\hline Parish location- Suburban & 0.23 \\
\hline Parish committee member with a disability & 0.34 \\
\hline Parish Location- Rural & 0.35 \\
\hline Parish's diocese has disability accommodation policy & 0.36 \\
\hline Number of households in parish & 0.67 \\
\hline Disability position & 0.77 \\
\hline $\begin{array}{l}\text { Other parish in same city known for disability } \\
\text { accommodations }\end{array}$ & 0.88 \\
\hline Number of parish staff & 0.89 \\
\hline Parish runs a school & 0.91 \\
\hline
\end{tabular}

*A significant p-value is evidence that the variable violates the parallel lines test.

\section{Models 2.3 and 2.4}

Table 7.9: Variance Intolerance Factors for Models 2.3 and 2.4

\begin{tabular}{|l|c|}
\hline Variable & $\begin{array}{c}\text { Variance Inflation } \\
\text { Factors }\end{array}$ \\
\hline Parish Location- Rural & 2.41 \\
\hline Number of Christian churches in six-mile radius & 2.13 \\
\hline Parish Location- Suburban & 1.99 \\
\hline Number of households in parish & 1.88 \\
\hline Number in city with a disability & 1.67 \\
\hline Parish runs a school & 1.32 \\
\hline Number of parish staff & 1.28 \\
\hline Disability Partner Organization- Catholic organization & 1.27 \\
\hline Disability Partner Organization- Non-Catholic organization & 1.18 \\
\hline Disability position & 1.14 \\
\hline $\begin{array}{l}\text { Other parish in same city known for disability } \\
\text { accommodations }\end{array}$ & 1.11 \\
\hline Parish founded with disability accommodation & 1.09 \\
\hline Parish committee members with a disability & 1.08 \\
\hline Parish's diocese has disability accommodation policy & 1.08 \\
\hline $\begin{array}{l}\text { Other parish in diocese known for disability } \\
\text { accommodations }\end{array}$ & 1.06 \\
\hline
\end{tabular}


Table 7.10: Box-Tidwell Test for Models 2.3 and 2.4

\begin{tabular}{|l|c|c|}
\hline Variable & Nonlinearity Statistic & P-value \\
\hline Number of households in parish & 2.755 & 0.097 \\
\hline Number of parish staff & 0.937 & 0.333 \\
\hline $\begin{array}{l}\text { Number of Christian churches in six-mile } \\
\text { radius }\end{array}$ & 0.415 & 0.519 \\
\hline Number in city with a disability & 0.417 & 0.519 \\
\hline
\end{tabular}

Table 7.11: Studentized Pearson Residuals for Models 2.3 and 2.4

\section{Cut}

Studentized Pearson Residual

Cut 1 between "Not at All"/ "Only a little" and "Somewhat"

Cut 2 between "Somewhat" and "Very Much"

Table 7.12: Brant Test for Models 2.3 and 2.4

\begin{tabular}{|l|c|}
\hline Variable & P-value* \\
\hline Disability Partner Organization- Catholic organization & 0.03 \\
\hline $\begin{array}{l}\text { Other parish in diocese known for disability } \\
\text { accommodation }\end{array}$ & 0.06 \\
\hline Disability Partner Organization- Non-Catholic organization & 0.09 \\
\hline Parish Location- Rural & 0.27 \\
\hline Number of Christian churches in six-mile radius & 0.37 \\
\hline Number in city with a disability & 0.44 \\
\hline Parish committee member with a disability & 0.51 \\
\hline Parish's diocese has disability accommodation policy & 0.56 \\
\hline Number of households in parish & 0.57 \\
\hline Parish Location- Suburban & 0.62 \\
\hline Disability position & 0.72 \\
\hline Parish founded with disability accommodation & 0.76 \\
\hline Parish runs a school & 0.82 \\
\hline $\begin{array}{l}\text { Other parish in same city known for disability } \\
\text { accommodations }\end{array}$ & 0.84 \\
\hline Number of parish staff & 0.99 \\
\hline
\end{tabular}

*A significant p-value is evidence that the variable violates the parallel lines test. 
Table 7.13: Generalized Estimation Equation Predicting the Initiation Sacramental Policies Cut between "Not at All"/"Only a Little" and "Somewhat"/"Very Much" with a Catholic $\underline{\text { Parish }}$

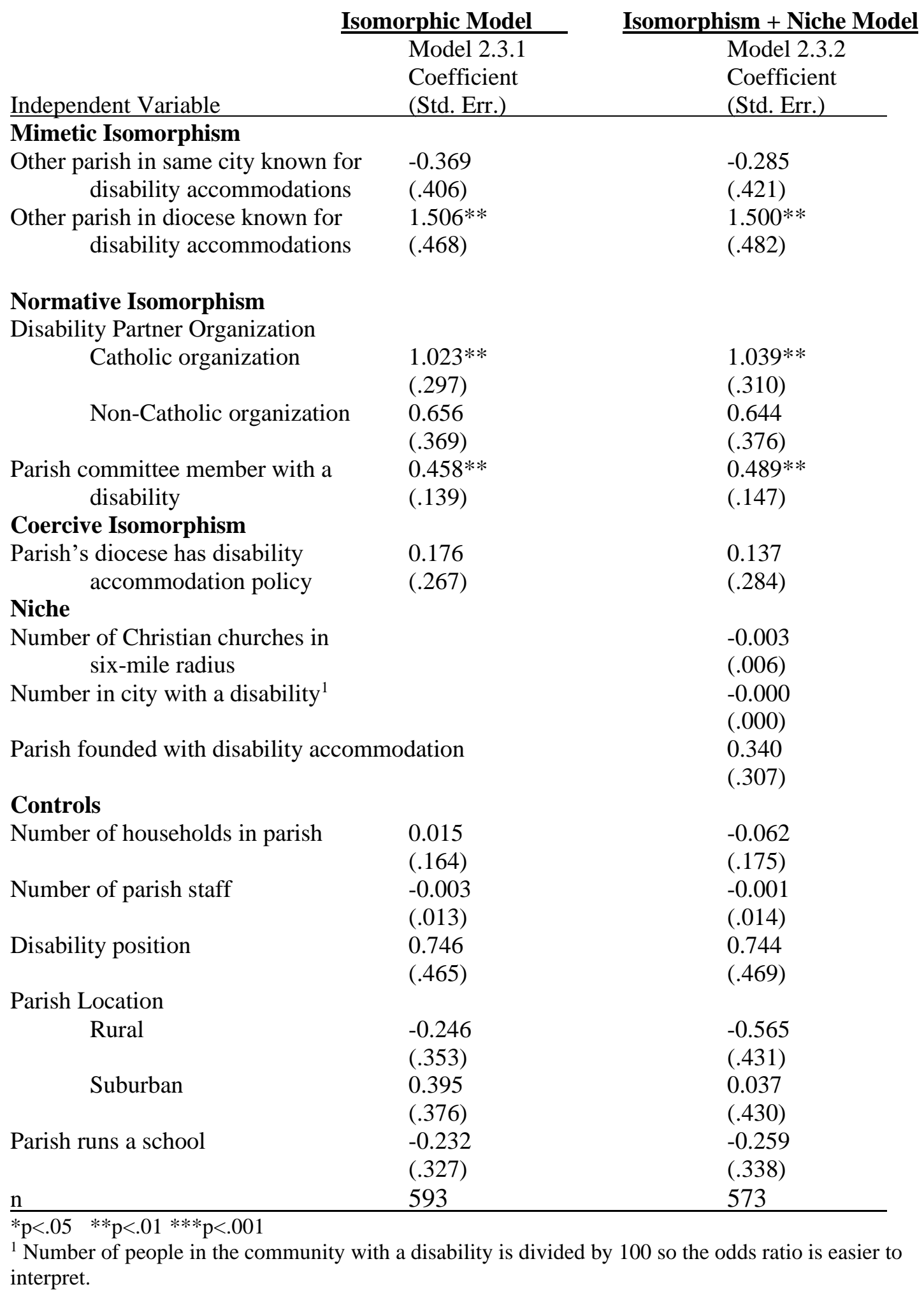


Table 7.14: Generalized Estimation Equation Predicting the Initiation Sacramental Policies Cut between "Not at All"/"Only a Little"/"Somewhat" and "Very Much" with a Catholic $\underline{\text { Parish }}$

\begin{tabular}{|c|c|c|}
\hline Independent Variable & $\begin{array}{l}\text { Isomorphic Model } \\
\text { Model } 2.3 .2 \\
\text { Coefficient } \\
\text { (Std. Err.) }\end{array}$ & $\begin{array}{c}\text { Isomorphism + Niche Models } \\
\text { Model } 2.4 \\
\text { Odds Ratio } \\
\text { (Std. Err.) }\end{array}$ \\
\hline \multicolumn{3}{|l|}{ Mimetic Isomorphism } \\
\hline $\begin{array}{l}\text { Other parish in same city known for } \\
\text { disability accommodations }\end{array}$ & $\begin{array}{l}-0.363 \\
(.272)\end{array}$ & $\begin{array}{l}-0.319 \\
(.281)\end{array}$ \\
\hline $\begin{array}{l}\text { Other parish in diocese known for } \\
\text { disability accommodations }\end{array}$ & $\begin{array}{l}0.613^{* *} \\
(.233)\end{array}$ & $\begin{array}{l}0.624^{*} \\
(.246)\end{array}$ \\
\hline \multicolumn{3}{|l|}{ Normative Isomorphism } \\
\hline \multicolumn{3}{|l|}{ Disability Partner Organization } \\
\hline Catholic organization & $\begin{array}{l}0.406^{*} \\
(.203)\end{array}$ & $\begin{array}{l}0.408 \\
(.209)\end{array}$ \\
\hline Non-Catholic organization & $\begin{array}{l}0.059 \\
(.207)\end{array}$ & $\begin{array}{l}0.023 \\
(.211)\end{array}$ \\
\hline $\begin{array}{l}\text { Parish committee member with a } \\
\text { disability }\end{array}$ & $\begin{array}{l}0.593 * * * \\
(.093)\end{array}$ & $\begin{array}{l}0.583 * * * \\
(.097)\end{array}$ \\
\hline \multicolumn{3}{|l|}{ Coercive Isomorphism } \\
\hline $\begin{array}{l}\text { Parish's diocese has disability } \\
\text { accommodation policy }\end{array}$ & $\begin{array}{l}-0.057 \\
(.195)\end{array}$ & $\begin{array}{l}-0.028 \\
(.208)\end{array}$ \\
\hline \multicolumn{3}{|l|}{ Niche } \\
\hline $\begin{array}{l}\text { Number of Christian churches in } \\
\text { six-mile radius }\end{array}$ & & $\begin{array}{l}-0.003 \\
(.004)\end{array}$ \\
\hline Number in city with a disability ${ }^{1}$ & & $\begin{array}{l}-0.000 \\
(.000)\end{array}$ \\
\hline $\begin{array}{l}\text { Parish founded with disability } \\
\text { accommodation }\end{array}$ & & $\begin{array}{l}0.448^{*} \\
(.196)\end{array}$ \\
\hline \multicolumn{3}{|l|}{ Controls } \\
\hline Number of households in parish & $\begin{array}{l}0.072 \\
(.111)\end{array}$ & $\begin{array}{l}0.011 \\
(.116)\end{array}$ \\
\hline Number of parish staff & $\begin{array}{l}-0.000 \\
(.008)\end{array}$ & $\begin{array}{l}-0.001 \\
(.008)\end{array}$ \\
\hline Disability position & $\begin{array}{l}0.593^{*} \\
(.238)\end{array}$ & $\begin{array}{l}0.585^{*} \\
(.240)\end{array}$ \\
\hline \multicolumn{3}{|l|}{ Parish Location } \\
\hline Rural & $\begin{array}{l}-0.057 \\
(.255)\end{array}$ & $\begin{array}{l}-0.103 \\
(.297)\end{array}$ \\
\hline Suburban & $\begin{array}{l}-0.007 \\
(.243)\end{array}$ & $\begin{array}{l}-0.142 \\
(.272)\end{array}$ \\
\hline Parish runs a school & $\begin{array}{l}-0.208 \\
(.213)\end{array}$ & $\begin{array}{l}-0.196 \\
(.219)\end{array}$ \\
\hline$\underline{\mathrm{n}}$ & 593 & 573 \\
\hline
\end{tabular}




\section{Models 3.1 \& 3.2}

Table 7.15: Variance Intolerance Factors for Models 3.1 and 3.2

\begin{tabular}{|l|c|}
\hline Variable & $\begin{array}{c}\text { Variance Inflation } \\
\text { Factors }\end{array}$ \\
\hline Parish Location- Rural & 1.93 \\
\hline Number of households in parish & 1.86 \\
\hline Parish Location- Suburban & 1.70 \\
\hline Parish runs a school & 1.33 \\
\hline Number of parish staff & 1.27 \\
\hline Disability Partner Organization- Catholic organization & 1.25 \\
\hline $\begin{array}{l}\text { Disability Partner Organization- Non-Catholic } \\
\text { organization }\end{array}$ & 1.18 \\
\hline Disability Position & 1.14 \\
\hline $\begin{array}{l}\text { Other parish in same city known for disability } \\
\text { accommodations }\end{array}$ & 1.09 \\
\hline Parish committee member with a disability & 1.08 \\
\hline Parish's diocese has disability accommodation policy & 1.08 \\
\hline $\begin{array}{l}\text { Other parish in diocese known for disability } \\
\text { accommodations }\end{array}$ & 1.06 \\
\hline
\end{tabular}

Table 7.16: Box-Tidwell Test for Models 3.1 and 3.2

\begin{tabular}{|l|c|c|}
\hline Variable & Nonlinearity Statistic & P-value \\
\hline Number of households in parish & 2.905 & 0.088 \\
\hline Number of parish staff & 0.486 & 0.486 \\
\hline
\end{tabular}

Table 7.17: Studentized Pearson Residuals for Models 3.1 and 3.2

\begin{tabular}{|l|c|c|}
\hline Cut & \multicolumn{2}{|c|}{ Studentized Pearson Residual } \\
\hline & Minimum & Maximum \\
\hline Cut 1 between "Not at All" and "Only a little" & -4.37 & 1.01 \\
\hline Cut 2 between "Only a little" and "Somewhat" & -2.75 & 1.83 \\
\hline Cut 3 between "Somewhat" and "Very Much" & -1.77 & 2.63 \\
\hline
\end{tabular}


Table 7.18: Brant Test for Models 3.1 and 3.2

\begin{tabular}{|l|c|}
\hline Variable & P-value* \\
\hline Number of parish staff & 0.11 \\
\hline Parish's diocese has disability accommodation policy & 0.23 \\
\hline Parish Location- Rural & 0.26 \\
\hline Number of households in parish & 0.26 \\
\hline Parish committee member with a disability & 0.29 \\
\hline Disability position & 0.33 \\
\hline Parish runs a school & 0.36 \\
\hline Disability Partner Organization- Non-Catholic organization & 0.75 \\
\hline Parish location- Suburban & 0.76 \\
\hline $\begin{array}{l}\text { Other parish in same city known for disability } \\
\text { accommodations }\end{array}$ & 0.85 \\
\hline Disability Partner Organization- Catholic organization & 0.95 \\
\hline $\begin{array}{l}\text { Other parish in diocese known for disability } \\
\text { accommodation }\end{array}$ & 0.96 \\
\hline
\end{tabular}

*A significant p-value is evidence that the variable violates the parallel lines test.

Models 3.3 and 3.4

Table 7.19: Variance Intolerance Factors for Models 3.3 and 3.4

\begin{tabular}{|l|c|}
\hline Variable & $\begin{array}{c}\text { Variance Inflation } \\
\text { Factors }\end{array}$ \\
\hline Parish Location- Rural & 2.36 \\
\hline Number of Christian churches in six-mile radius & 2.12 \\
\hline Parish Location- Suburban & 1.97 \\
\hline Number of households in parish & 1.88 \\
\hline Number in city with a disability & 1.69 \\
\hline Parish runs a school & 1.33 \\
\hline Number of parish staff & 1.28 \\
\hline Disability Partner Organization- Catholic organization & 1.26 \\
\hline $\begin{array}{l}\text { Disability Partner Organization- Non-Catholic } \\
\text { organization }\end{array}$ & 1.17 \\
\hline Disability Position & 1.14 \\
\hline $\begin{array}{l}\text { Other parish in same city known for disability } \\
\text { accommodations }\end{array}$ & 1.13 \\
\hline Parish founded with disability accommodation & 1.09 \\
\hline Parish committee member with a disability & 1.09 \\
\hline Parish's diocese has disability accommodation policy & 1.09 \\
\hline $\begin{array}{l}\text { Other parish in diocese known for disability } \\
\text { accommodations }\end{array}$ & 1.07 \\
\hline
\end{tabular}




\begin{tabular}{|l|c|c|}
\hline \multicolumn{3}{|c|}{ Table 7.20: Box-Tidwell Test for Models 3.3 and 3.4 } \\
\hline Variable & Nonlinearity Statistic & P-value \\
\hline Number of households in parish & 0.178 & 0.673 \\
\hline Number of parish staff & 0.063 & 0.802 \\
\hline $\begin{array}{l}\text { Number of Christian churches in six-mile } \\
\text { radius }\end{array}$ & 0.442 & 0.506 \\
\hline Number in city with a disability & 0.882 & 0.364 \\
\hline
\end{tabular}

\begin{tabular}{|l|c|c|}
\hline \multicolumn{3}{|c|}{ Table 7.21: Studentized Pearson Residuals for Models 3.3 and 3.4 } \\
\hline Cut & Studentized Pearson Residual \\
\hline & Minimum & Maximum \\
\hline Cut 1 between "Not at all" and "Only a little" & -5.29 & 1.37 \\
\hline Cut 2 between "Only a little" and "Somewhat" & -3.28 & 1.89 \\
\hline Cut 3 between "Somewhat" and "Very Much" & -2.05 & 2.93 \\
\hline
\end{tabular}

Table 7.22: Brant Test for Models 3.3 and 3.4

\begin{tabular}{|l|c|}
\hline Variable & P-value* \\
\hline Parish Location- Rural & 0.17 \\
\hline Number of parish staff & 0.17 \\
\hline Number of households in parish & 0.21 \\
\hline Parish committee member with a disability & 0.28 \\
\hline Disability position & 0.29 \\
\hline Parish runs a school & 0.32 \\
\hline Parish's diocese has disability accommodation policy & 0.39 \\
\hline Disability Partner Organization- Non-Catholic organization & 0.64 \\
\hline Parish founded with disability accommodation & 0.67 \\
\hline Number of Christian churches in six-mile radius & 0.73 \\
\hline Other parish in same city known for disability & 0.78 \\
accommodations & 0.83 \\
\hline Number in city with a disability & 0.84 \\
\hline Parish Location- Suburban & 0.85 \\
\hline Disability Partner Organization- Catholic organization & 0.98 \\
\hline $\begin{array}{l}\text { Other parish in diocese known for disability } \\
\text { accommodation }\end{array}$ & \\
\hline
\end{tabular}

*A significant $\mathrm{p}$-value is evidence that the variable violates the parallel lines test. 
Table 7.23: Generalized Estimation Equation Predicting Marriage Preparation Policies Cut between "Not at All" and "Only a Little"/"Somewhat"/"Very Much" with a Catholic Parish

\begin{tabular}{|c|c|c|}
\hline Independent Variable & $\begin{array}{l}\text { norphic Model } \\
\text { Model } 3.5 .1 \\
\text { Coefficient } \\
\text { (Std. Err.) }\end{array}$ & $\begin{array}{c}\text { Isomorphism + Niche Models } \\
\text { Model 3.5.2 } \\
\text { Coefficient } \\
\text { (Std. Err.) } \\
\end{array}$ \\
\hline \multicolumn{3}{|l|}{ Mimetic Isomorphism } \\
\hline $\begin{array}{l}\text { Other parish in same city known for } \\
\text { disability accommodations }\end{array}$ & $\begin{array}{l}-0.264 \\
(.355)\end{array}$ & $\begin{array}{l}-0.252 \\
(.363)\end{array}$ \\
\hline $\begin{array}{l}\text { Other parish in diocese known for } \\
\text { disability accommodations }\end{array}$ & $\begin{array}{l}0.226 \\
(.281)\end{array}$ & $\begin{array}{l}0.216 \\
(.279)\end{array}$ \\
\hline \multicolumn{3}{|l|}{ Normative Isomorphism } \\
\hline \multicolumn{3}{|l|}{ Disability Partner Organization } \\
\hline Catholic organization & $\begin{array}{l}0.514^{*} \\
(.261)\end{array}$ & $\begin{array}{l}0.396 \\
(.273)\end{array}$ \\
\hline Non-Catholic organizations & $\begin{array}{l}0.206 \\
(.286)\end{array}$ & $\begin{array}{l}0.210 \\
(.292)\end{array}$ \\
\hline $\begin{array}{l}\text { Parish committee member with a } \\
\text { disability }\end{array}$ & $\begin{array}{l}0.642 * * * \\
(.128)\end{array}$ & $\begin{array}{l}0.679 * * * \\
(.135)\end{array}$ \\
\hline \multicolumn{3}{|l|}{ Coercive Isomorphism } \\
\hline $\begin{array}{l}\text { Parish's diocese has disability } \\
\text { accommodation policy }\end{array}$ & $\begin{array}{l}0.166 \\
(.267)\end{array}$ & $\begin{array}{l}0.152 \\
(.241)\end{array}$ \\
\hline \multicolumn{3}{|l|}{ Niche } \\
\hline \multicolumn{2}{|l|}{$\begin{array}{l}\text { Number of Christian churches in } \\
\text { six-mile radius }\end{array}$} & $\begin{array}{l}-0.002 \\
(.000)\end{array}$ \\
\hline \multicolumn{2}{|l|}{ Number in city with a disability ${ }^{1}$} & $\begin{array}{l}-0.000 \\
(.000)\end{array}$ \\
\hline \multicolumn{2}{|l|}{$\begin{array}{l}\text { Parish founded with a disability } \\
\text { accommodation }\end{array}$} & $\begin{array}{l}0.604 * \\
(.277)\end{array}$ \\
\hline \multicolumn{3}{|l|}{ Controls } \\
\hline Number of households in parish & $\begin{array}{l}-0.212 \\
(.148)\end{array}$ & $\begin{array}{l}-0.333^{*} \\
(.156)\end{array}$ \\
\hline Number of parish staff & $\begin{array}{l}0.011 \\
(.014)\end{array}$ & $\begin{array}{l}0.011 \\
(.014)\end{array}$ \\
\hline Disability Position & $\begin{array}{l}0.575 \\
(.355)\end{array}$ & $\begin{array}{l}0.558 \\
(.359)\end{array}$ \\
\hline \multicolumn{3}{|l|}{ Parish Location } \\
\hline Rural & $\begin{array}{l}-0.036 \\
(.327)\end{array}$ & $\begin{array}{l}-0.472 \\
(.394)\end{array}$ \\
\hline Suburban & $\begin{array}{l}-0.038 \\
(.311)\end{array}$ & $\begin{array}{l}-0.435 \\
(.362)\end{array}$ \\
\hline Parish runs a school & $\begin{array}{l}-0.119 \\
(.280)\end{array}$ & $\begin{array}{l}-0.062 \\
(.289)\end{array}$ \\
\hline$\underline{\mathrm{n}}$ & 558 & 573 \\
\hline
\end{tabular}


Table 7.24: Generalized Estimation Equation Predicting the Initiation Sacramental Policies Cut between "Not at All"/"Only a Little" and "Somewhat"/"Very Much" with a Catholic $\underline{\text { Parish }}$

\begin{tabular}{|c|c|c|}
\hline Independent Variable & $\begin{array}{l}\text { lorphic Model } \\
\text { Model } 3.6 .1 \\
\text { Coefficient } \\
\text { (Std. Err.) }\end{array}$ & $\begin{array}{c}\text { Isomorphism + Niche Models } \\
\text { Model 3.6.2 } \\
\text { Coefficient } \\
\text { (Std. Err.) } \\
\end{array}$ \\
\hline \multicolumn{3}{|l|}{ Mimetic Isomorphism } \\
\hline $\begin{array}{c}\text { Other parish in same city known for } \\
\text { disability accommodations }\end{array}$ & $\begin{array}{l}-0.106 \\
(.280)\end{array}$ & $\begin{array}{l}-0.059 \\
(.289)\end{array}$ \\
\hline $\begin{array}{l}\text { Other parish in diocese known for } \\
\text { disability accommodations }\end{array}$ & $\begin{array}{l}0.131 \\
(.220)\end{array}$ & $\begin{array}{l}0.148 \\
(.222)\end{array}$ \\
\hline \multicolumn{3}{|l|}{ Normative Isomorphism } \\
\hline \multicolumn{3}{|l|}{ Disability Partner Organization } \\
\hline Catholic organization & $\begin{array}{l}0.492^{*} \\
(.213)\end{array}$ & $\begin{array}{l}0.478^{*} \\
(.221)\end{array}$ \\
\hline Non-Catholic organization & $\begin{array}{l}0.048 \\
(.215)\end{array}$ & $\begin{array}{l}0.016 \\
(.211)\end{array}$ \\
\hline $\begin{array}{l}\text { Parish committee member with a } \\
\text { disability }\end{array}$ & $\begin{array}{l}0.598 * * * \\
(.099)\end{array}$ & $\begin{array}{l}0.625 * * * \\
(.104)\end{array}$ \\
\hline \multicolumn{3}{|l|}{ Coercive Isomorphism } \\
\hline $\begin{array}{l}\text { Parish's diocese has disability } \\
\text { accommodation policy }\end{array}$ & $\begin{array}{l}0.056 \\
(.192)\end{array}$ & $\begin{array}{l}0.044 \\
(.197)\end{array}$ \\
\hline \multicolumn{3}{|l|}{ Niche } \\
\hline \multicolumn{2}{|l|}{$\begin{array}{l}\text { Number of Christian churches in } \\
\text { six-mile radius }\end{array}$} & $\begin{array}{l}0.001 \\
(.004)\end{array}$ \\
\hline \multicolumn{2}{|l|}{ Number in city with a disability ${ }^{1}$} & $\begin{array}{l}-0.000 \\
(.000)\end{array}$ \\
\hline \multicolumn{2}{|l|}{$\begin{array}{l}\text { Parish founded with a disability } \\
\text { accommodation }\end{array}$} & $\begin{array}{l}0.384 \\
(.207)\end{array}$ \\
\hline \multicolumn{3}{|l|}{ Controls } \\
\hline Number of households in parish & $\begin{array}{l}-0.119 \\
(.115)\end{array}$ & $\begin{array}{l}-0.178 \\
(.120)\end{array}$ \\
\hline Number of parish staff & $\begin{array}{l}0.001 \\
(.008)\end{array}$ & $\begin{array}{l}0.000 \\
(.008)\end{array}$ \\
\hline Disability Position & $\begin{array}{l}0.446 \\
(.244)\end{array}$ & $\begin{array}{l}0.440 \\
(.248)\end{array}$ \\
\hline \multicolumn{3}{|l|}{ Parish location } \\
\hline Rural & $\begin{array}{l}0.425 \\
(.266)\end{array}$ & $\begin{array}{l}0.243 \\
(.307)\end{array}$ \\
\hline Suburban & $\begin{array}{l}-0.142 \\
(.247)\end{array}$ & $\begin{array}{l}-0.348 \\
(.276)\end{array}$ \\
\hline Parish runs a school & $\begin{array}{l}-0.287 \\
(.220)\end{array}$ & $\begin{array}{l}-0.294 \\
(.225)\end{array}$ \\
\hline$\underline{\mathrm{n}}$ & 558 & 573 \\
\hline
\end{tabular}


Table 7.25: Generalized Estimation Equation Predicting the Initiation Sacramental Policies Cut between "Not at All"/"Only a Little"/"Somewhat" and "Very Much" with a Catholic $\underline{\text { Parish }}$

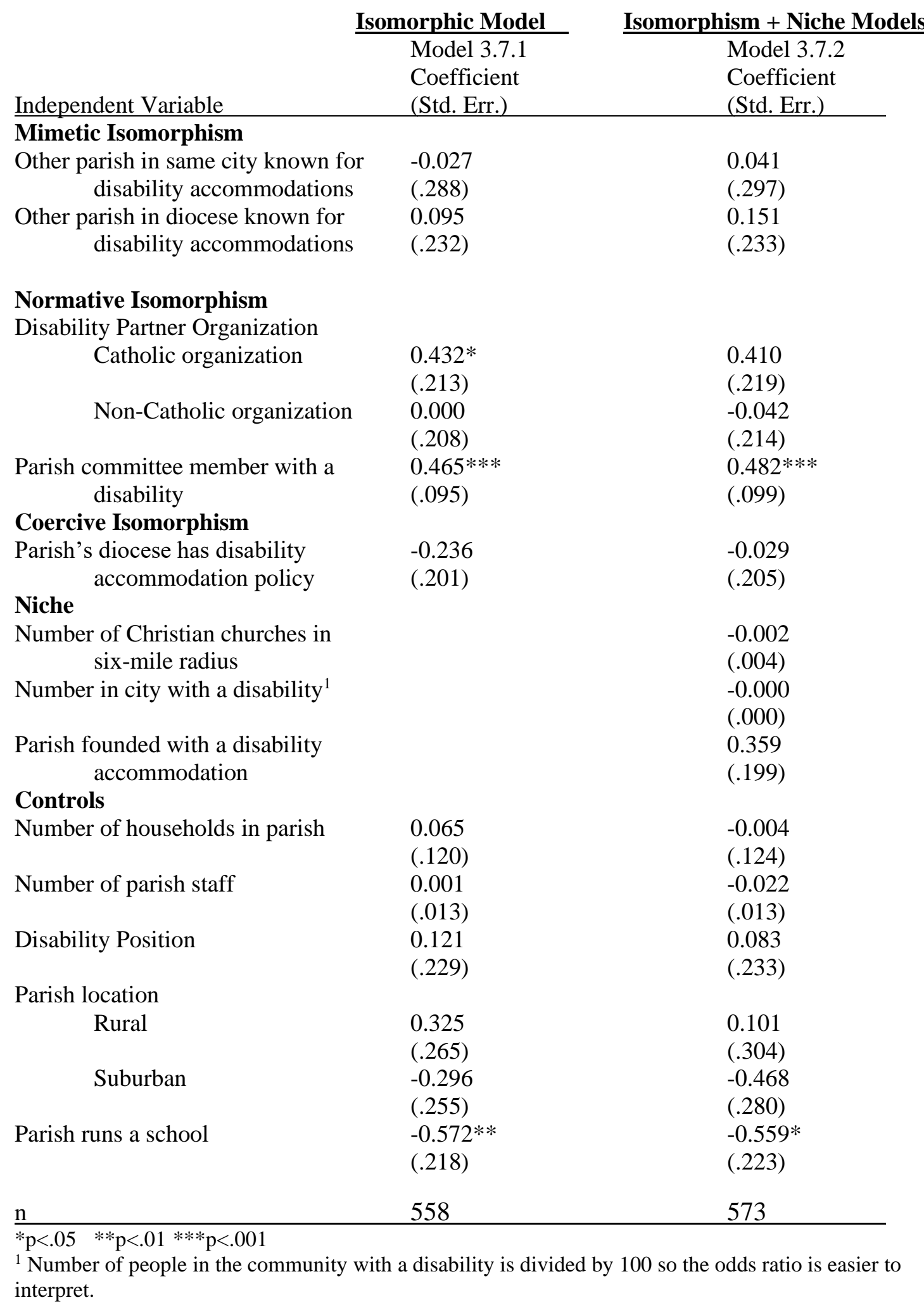




\title{
CURRICULUM VITAE
}

\author{
Jonathon Holland \\ Lutz Hall 103 \\ University of Louisville \\ Louisville, KY 40292 \\ 217-714-7659 (Cell) \\ jonathon.holland@louisville.edu
}

\section{EDUCATION}

Ph.D. University of Louisville, Applied Sociology, Anticipated August 2020 Areas of Specialization: Quantitative Methodology and Organizational Sociology Dissertation Chair: Dr. David Roelfs

M.A. University of Kentucky, Sociology, 2014

Thesis title: Explaining Public Opinion towards a Federal Education Reform: The Impact of Accountability, Symbolism, Group Interest, and Authoritarianism on Support for the No Child Left Behind Law

Thesis Chairs: Dr. Thomas Janoski and Dr. Janet Stamatel

B.S. Bradley University, Double major in Sociology and Philosophy, 2011 Minors in Psychology and Religious Studies

\section{ACADEMIC EMPLOYMENT EXPERIENCE}

2017-Present Graduate Teaching Assistant for Department of Sociology at the University of Louisville, Louisville, KY

2015-2017 Research Associate at the Center for Applied Research in the Apostolate (CARA) at Georgetown University, Washington, D.C.

2014-2015 Research Assistant at the Center for Applied Research in the Apostolate (CARA) at Georgetown University, Washington, D.C.

2011-2013 Teaching Assistant for Department of Sociology at the University of Kentucky, Lexington, KY 


\section{PUBLICATIONS}

\section{Journal Articles:}

Walker, Alicia, Amy Bush, Ken Sanchagrin, Jonathon Holland. 2017 "We've got to keep meeting like this: A pilot study comparing academic performance in shiftingmembership cooperative groups versus stable-membership cooperative groups in an introductory-level lab." College Teaching. 65(1): 9-16. doi:10.1080/87567555.2016.1222574

\section{Book Chapters:}

Holland, Jonathon, Mary Johnson, Patricia Wittberg. 2018. "Associates and Religious Institutes" in Pathways to Religious Life, edited by Thomas Gaunt. New York, NY: Oxford University Press.

\section{Edited Volumes:}

Gautier, Mary L., Jonathon Holland, and Connie Neuman. 2015-2017. Catholic Ministry Formation Directory. Washington, D.C.: CARA at Georgetown University.

\section{Research Reports:}

Jonathon Holland. March 2020. Measuring the Psychological Needs of Catholics in Louisville and the Surrounding Counties. Louisville, KY.

Wiggins, Jonathon L. and Jonathon Holland. October 2016. Statistical Profile of the Parishes of the Carmelite Province of the Most Pure Heart of Mary. Washington, D.C.: CARA at Georgetown University.

Wiggins, Jonathon L. and Jonathon Holland. October 2016. Evaluation and Impact of the Summer 2016 Catholic Ministry Leadership Institute. Washington, D.C.:

CARA at Georgetown University.

Holland, Jonathon and Thomas Gaunt. September 2016. Meeting the Needs of Those with Disabilities in the Church: A Profile of How Dioceses and Catholic Charities in the United States Accommodate People with Disabilities. Washington, D.C.: CARA at Georgetown University.

Holland, Jonathon and Jonathon L. Wiggins. July 2016. Assessing Men of Saint Joseph Chapters. Washington, D.C.: CARA at Georgetown University. 
Holland, Jonathon and Thomas Gaunt. June 2016. Meeting the Needs of Those with Disabilities in the Church: A Profile of How Parishes in the United States Accommodate People with Disabilities. Washington, D.C.: CARA at Georgetown University.

Gautier, Mary L. and Jonathon Holland. May 2016. Partners in Mission: An Updated Profile of Associates and Religious in the United States and Canada Part II. Washington, D.C.: CARA at Georgetown University.

Gautier, Mary L. and Jonathon Holland. April 2016. Partners in Mission: An Updated Profile of Associates and Religious in the United States and Canada. Washington, D.C.: CARA at Georgetown University.

Holland, Jonathon and Jonathon L. Wiggins. March 2016. Schools, Educational Centers, Youth and Family Services, and the District Office: 2015-2016 Statistical District Reports. (2 reports) Washington, D.C.: CARA at Georgetown University.

Wiggins, Jonathon L. and Jonathon Holland. March 2016. Schools, Educational Centers, Support Ministries and the District Office: 2015-2016 District Statistical Reports. (2 reports) Washington, D.C.: CARA at Georgetown University.

Wiggins, Jonathon L. and Jonathon Holland. August 2015. Parish Life Survey. Washington, D.C.: CARA at Georgetown University.

Gautier, Mary L., Jonathon L. Wiggins, and Jonathon Holland. August 2015. The Role of the Family in Nurturing Vocations to Religious Life and Priesthood: A Report for the National Religious Vocation Conference. Washington, D.C.: CARA at Georgetown University.

Gautier, Mary L. and Jonathon Holland. August 2015. Catholic Legal Immigration Network, Inc. 2014 Annual Survey of Affiliates. Washington, D.C.: CARA at Georgetown University.

Wiggins, Jonathon L., Thomas Gaunt, and Jonathon Holland. February 2016. Schools, Educational Centers, Youth and Family Services, and Support Ministries: A Report for the Brothers of the Christian Schools Lasallian Region of North America (RELAN) 2014-2015 Statistical Report. Washington, D.C.: CARA at Georgetown University.

Wiggins, Jonathon L. and Jonathon Holland. February 2015. Schools, Educational Centers, Youth and Family Services, and District Offices: A Report for the Brothers of the Christian Schools in DENA 2014-2015 Statistical Report. Washington, D.C.: CARA at Georgetown University. 
Wiggins, Jonathon L., Thomas Gaunt, and Jonathon Holland. February 2015. Schools, Educational Centers, Youth and Family Services, and Support Ministries: A Report for the Brothers of the Christian Schools Lasallian Region of North America (RELAN) 2014-2015 Statistical Report. Washington, D.C.: CARA at Georgetown University.

Gray, Mark M. and Jonathon Holland. December 2014. Global Catholicism. Washington, D.C.: CARA at Georgetown University.

Holland, Jonathon and Jonathon L. Wiggins. November 2014. Cultural Diversity InPew Survey Individual Parish Reports. (8 reports) Washington, D.C.: CARA at Georgetown University.

Wiggins, L. Jonathon and Jonathon Holland. November 2014. Cultural Diversity InPew Survey Individual Parish Reports. (24 reports) Washington, D.C.: CARA at Georgetown University.

Gautier, Mary L. and Jonathon Holland. October 2014. Pastoral Practice in Light of the National Statutes on the Catechumenate: A Report for the United States Conference of Catholic Bishops. Washington, D.C.: CARA at Georgetown University.

\section{Articles in Progress:}

Holland, Jonathon. “Cultural Factors Affecting How Catholic Dioceses Accommodate People with Disabilities"

Holland, Jonathon. "Defining and Implementing Cultural Isomorphism: How Isomorphism affects Catholic Parishes"

Holland, Jonathon and Audrey Seah. "Isomorphism in Guidelines for Accommodations for People with Disabilities in the Catholic Church"

Seah, Audrey and Jonathon Holland. "What are We Counting Again? A Conversation about Theologically Informed Sociology"

\section{AWARDS}

2019 Outstanding Research Award from the Sociology Department at the University of Louisville for the 2018-2019 academic year.

2018 Outstanding Research Award from the Sociology Department at the University of Louisville for the 2017-2018 academic year. 
2016 Invitation by the Assistant Director for Higher Education at the United States Conference of Catholic Bishops to work on a research initiative of campus ministers and students in the United States.

2011 Received Provosts Award ( ${ }^{\text {nd }}$ place) for Academic Research at the Bradley University Undergraduate Scholarship Exposition

2011 Dean's List last four consecutive semesters at Bradley University

\section{PRESENTATIONS}

\section{Invited Conference Presentations:}

"Author Meets Critics: Pathways to Religious Life." Presented at the Society for the Scientific Study of Religion (Las Vegas, NV, October 27, 2018).

\section{Conference Presentations:}

Holland, Jonathon. "What are We Counting Again? A Conversation about Theologically Informed Sociology" Presented at the Society for the Scientific Study of Religion (St. Louis, MO, October 25, 2019).

Holland, Jonathon. "The State of Campus Ministry in the Catholic Church for U.S. Colleges and Universities" Presented at the Society for the Scientific Study of Religion (Las Vegas, NV, October 27, 2018).

Holland, Jonathon. "Effects of State Laws on Diocesan Policies Concerning People with Disabilities" Presented at the Society for the Scientific Study of Religion (Las Vegas, NV, October 26, 2018).

Holland, Jonathon. "The Role of Isomorphism in Ways that the Catholic Church Accommodates People with Disabilities" Presented at the American Sociological Association. (Philadelphia, PA, August 11, 2018).

Holland, Jonathon. "How the Catholic Church in the United States Accommodates People with Disabilities: A Focus on Diocesan Strategies" Presented at the annual meeting of the Mid-South Sociological Association. (Chattanooga, TN, October 21, 2017).

Holland, Jonathon. "Evangelization and Growth Among Catholic Lay Associates in the United States and Canada" Presented at the annual meeting of the Society for the Scientific Study of Religion (Washington, DC, October 15, 2017).

Holland, Jonathon and Eva Coll. "The Impact of Socioeconomic Class Towards Views on Online College Education" Presented for roundtable at the annual meeting of the Southern Sociological Society (Greenville, SC, April 17, 2017). 
Holland, Jonathon. "Evangelization to People with Disabilities in Catholic Parishes" Presented at the annual meeting of the Society for the Scientific Study of Religion (Atlanta, GA, October 28, 2016).

Holland, Jonathon. "The Impact of Politics on Views toward Education" Presented at the Annual Meeting of the Southern Sociological Society (Atlanta, GA, April 15, 2016).

Holland, Jonathon. "Is there an A in team? Comparing Team-Based Learning and Cooperative Group Learning in Sociology 101 Recitation Sections" Presented at the Annual Meeting of the North Central Sociological Association (Indianapolis, IN, April 5, 2013).

Crawford, Lizabeth A. and Jonathon Holland. "Expansion of a Measure of Beliefs about Alcohol and the College Experience." Presented for roundtable presentation at the Annual Meeting of the Midwest Sociological Society (St. Louis, MO, March, 2011).

Holland, Jonathon. "Predictors of College Students' Attitudes Toward Socialism." Presented at Bradley University's Undergraduate Scholarship Exposition (Peoria, IL, March 18, 2011).

\section{TEACHING EXPERIENCE}

\section{Courses Taught:}

2019-2020 Introduction to Sociology SOC 201 (enrollment of 55 and 41)

Fall 2018 Introduction to Statistics SOC 301 (enrollment of 24)

\section{$\underline{\text { Recitation Sections Taught: }}$}

2017-2018 Race in the U.S. SOC 210 with Dr. Melanie Gast, instructor

2011-2013 Introduction to Sociology SOC 101 with Dr. Christopher Oliver, instructor

\section{Courses Prepared to Teach:}

Social Research Methods; Introduction to Statistics; Organizational Sociology; Introduction to Sociology

\section{Special Training:}

2017 Blackboard techniques (seminar that articulated techniques used in Blackboard for teaching undergraduate students) 
2017 GTA Academy (9 seminars discussing techniques used to improve pedagogy at the collegiate level)

2012 Team-Based Learning (A semester of observing, practicing, and grading the method in Introduction to Criminology)

\section{SERVICE}

\section{Department:}

2018 - 2020 Speaker Series Representative for Sociology Graduate Student Association at the University of Louisville

2017 - 2018 Secretary for Sociology Graduate Student Association at the University of Louisville

\section{Conference:}

2019 Session Convener for "Religion and Identity" at the Society for the Scientific Study of Religion Annual Meeting. (St. Louis, MO, October 25-27, 2019)

\section{PROFESSIONALASSOCIATIONS}

2019-Present

2018-Present

2016-Present

2015-2017

2017
Alpha Kappa Delta Sociology Honor Society

American Sociological Association

Society for the Scientific Study of Religion

Southern Sociological Society

Mid-South Sociological Society 